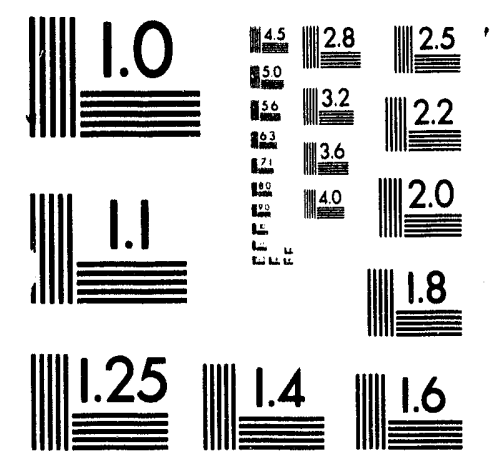



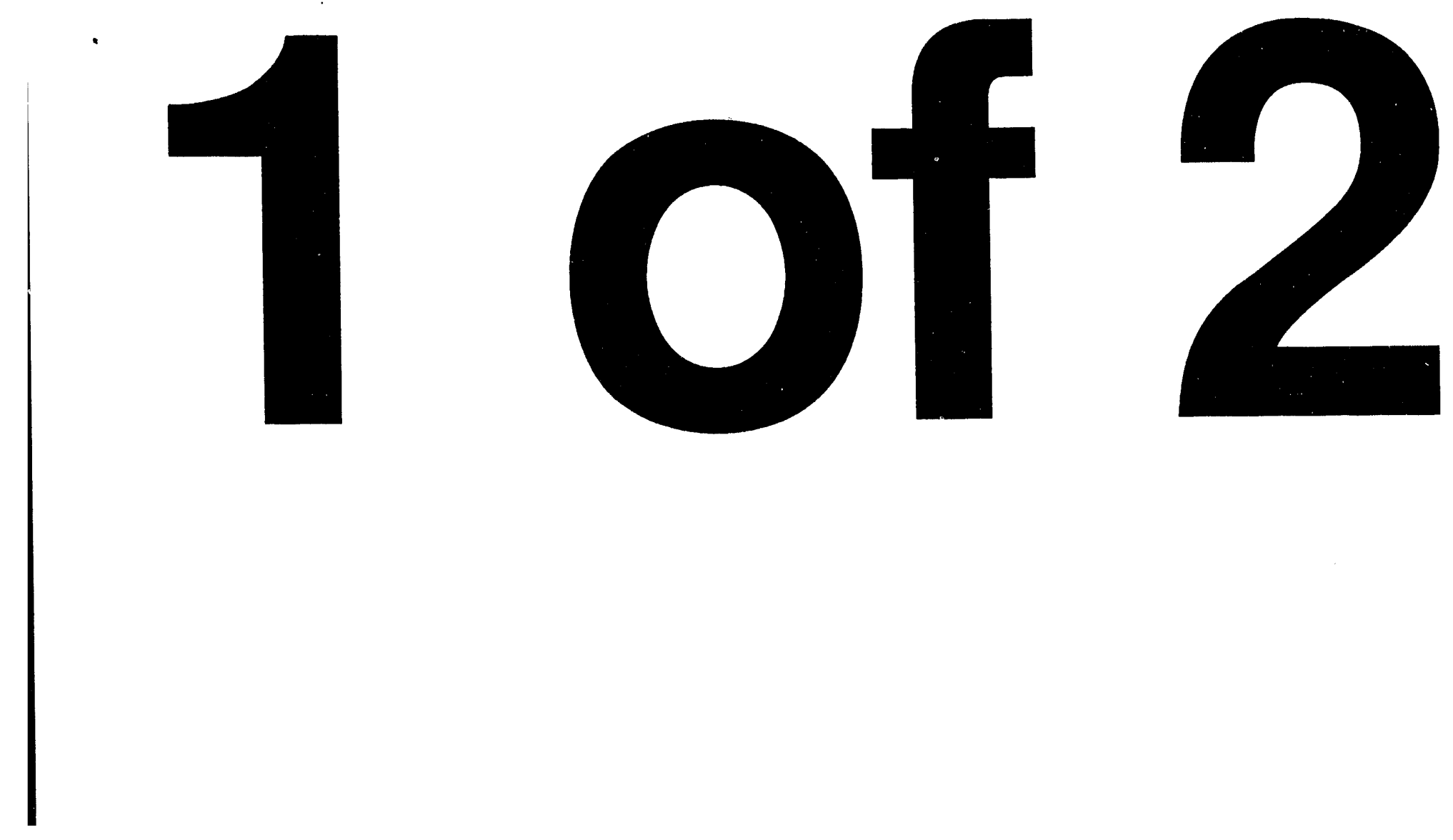


\title{
Measurement of Elemental Speciation by Iiquid Chromatography - Inductively Coupled Plasma Mass Spectrometry (IC-ICP-MS) with the Direct Injection Nebulizer (DIN)
}

\author{
by Sam Shum
}

\author{
thesis submitted to Iowa State University \\ Ames Laboratory, U. S. DOE \\ Iowa State University \\ Ames, Iowa 50011
}

Date Transmitted: May 1993

\author{
Prepared for the U. S. Department of Energy \\ Under contract no. $\mathrm{W}-7405$-eng-82.
}

\section{DISCLAIMER}

This report was prepared as an account of work sponsored by an agency of the United States Government. Neither the United States Government nor any agency thereof, nor any of their employees, makes any warranty, express or implied, or assumes any legal liability or responsibility for the accuracy, completeness, or usefulness of any information, apparatus, product, or process disclosed, or represents that its use would not infringe privately owned rights. Reference herein to any specific commercial product, process, or service by trade name, trademark, manufacturer, or otherwise does not necessarily constitute or imply its endorsement, recommendation, or favoring by the United States Government or any agency thereof. The views and opinions of authors expressed herein do not necessarily state or reflect those of the United States Government or any agency thereof. 
Measurement of elemental speciation by liquid chromatography - inductively coupled plasma mass spectrometry (LC-ICP-MS) with the direct injection nebulizer (DIN)

\section{Sam Chiu-Kin Shum}

In charge of major work: R. S. Houk

From the Department of Chemistry

Iowa State University

A new version of the direct injection nebulizer (DIN) is used to interface liquid chromatographic (LC) separations with element - selective detection by inductively coupled plasma - mass spectrometry (ICP-MS). The advantages of using LC-DIN-ICP-MS include little dead volume, low sample and solvent consumption, excellent plasma stability when nebulizing samples containing concentrated organic solvent, excellent absolute detection limits, excellent precision, superior chromatographic resolution, and reduced memory effects from memory-prone elements (e.g., $\mathrm{Hg})$.

Various compounds containing arsenic $\left(\mathrm{AsO}_{2}{ }^{-}, \mathrm{HAsO}_{4}{ }^{2-}, \mathrm{CH}_{3} \mathrm{AsO}_{3}{ }^{2-}\right.$ and $\left.\left(\mathrm{CH}_{3}\right)_{2} \mathrm{AsO}_{2}^{-}\right)$, tin $\left(\mathrm{CH}_{3} \mathrm{Sn}^{3+},\left(\mathrm{CH}_{3}\right)_{2} \mathrm{Sn}^{2+},\left(\mathrm{C}_{2} \mathrm{H}_{5}\right)_{2} \mathrm{Sn}^{2+}\right.$ and $\left.\left(\mathrm{CH}_{3}\right)_{3} \mathrm{Sn}^{+}\right)$, mercury $\left(\mathrm{Hg}^{+2}\right.$, $\mathrm{CH}_{3} \mathrm{Hg}^{+}, \mathrm{C}_{2} \mathrm{H}_{5} \mathrm{Hg}^{+}$and $\left.\mathrm{C}_{6} \mathrm{H}_{5} \mathrm{Hg}^{+}\right)$and lead $\left(\mathrm{Pb}^{+2},\left(\mathrm{CH}_{3}\right)_{3} \mathrm{~Pb}^{+}\right.$and $\left.\left(\mathrm{C}_{2} \mathrm{H}_{5}\right)_{3} \mathrm{~Pb}^{+}\right)$are separated by reversed-phase ion-pairing LC. Selenium species $\left(\mathrm{SeO}_{3}{ }^{2-}\right.$ and $\left.\mathrm{SeO}_{4}{ }^{2-}\right)$ are separated by ion chromatography (IC). Several metalloproteins containing $\mathrm{Na}, \mathrm{Fe}$, $\mathrm{Cu}, \mathrm{Zn}, \mathrm{Cd}, \mathrm{Ba}$, and $\mathrm{Pb}$ are separated by size-exclusion chromatography (SEC). 
Some of these compounds are separated and measured in biological and environmental samples such as human urine and human serum. Detection limits are $\approx 3,0.7,1$, $0.5,5,0.5,15,7$, and $0.2 \mathrm{pg}$ for $\mathrm{Fe}, \mathrm{Cu}, \mathrm{Zn}, \mathrm{As}, \mathrm{Se}, \mathrm{Cd}, \mathrm{Sn}, \mathrm{Hg}$, and $\mathrm{Pb}$, respectively. Microbore ( $1-2 \mathrm{~mm}$ i.d.) packed columns are employed because the liquid flow rates used $\left(30-100 \mu \mathrm{L} \mathrm{min}{ }^{-1}\right)$ are compatible with the DIN.

Aerosol droplet sizes and velocities from a DIN are measured with radial and axial spatial resolution by phase doppler particle analysis (PDPA). The droplets on the central axis of the spray become finer and their size becomes more uniform when $\approx 20 \%$ methanol is added to the usual aqueous solvent. This could explain why the analyte signal is a maximum at this solvent composition when the DIN is used for ICP-MS. Mean droplet velocities are 12 to $22 \mathrm{~m} \mathrm{~s}^{-1}$ with standard deviations of \pm 4 to $\pm 7 \mathrm{~m} \mathrm{~s}^{-1}$. The outer fringes of the aerosol plume tend to be enriched in large droplets. The Sauter mean diameter $\left(D_{3,2}\right)$ and velocity of the droplets also vary substantially with axial position in the aerosol plume. These findings are valuable for improving the analytical performance of the DIN. 
Measurement of elemental speciation by liquid chromatography - inductively coupled plasma mass spectrometry (LC-ICP-MS) with the direct injection nebulizer (DIN)

\title{
Sam Chiu-Kin Shum
}

\author{
A Dissertation Submitted to the \\ Graduate Faculty in Partial Fulfillment of the \\ Requirements for the Degree of \\ DOCTOR OF PHILOSOPHY \\ Department: Chemistry \\ Major: Analytical Chemistry
}

Approved:

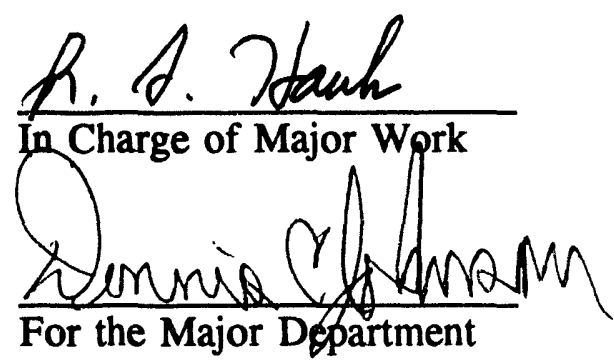

For the Graduate College

Iowa State University

Ames, Iowa 
ii

TABLE OF CONTENTS

GENERAL INTRODUCTION

PAPER I. ELEMENTAL SPECIATION BY LIQUID CHROMATOGRAPHY - INDUCTIVELY COUPLED PLASMA MASS SPECTROMETRY WITH DIRECT INJECTION NEBULIZATION

INTRODUCTION

EXPERIMENTAL SECTION

RESULTS AND DISCUSSION

CONCLUSION

LITERATURE CITED

PAPER II. SPECIATION OF MERCURY AND LEAD COMPOUNDS BY MICROBORE COLUMN LIQUID CHROMATOGRAPHY - INDUCTIVELY COUPLED PLASMA MASS SPECTORMETRY WITH DIRECT INJECTION NEBULIZATION

INTRODUCTION

EXPERIMENTAL SECTION

RESULTS AND DISCUSSION

LITERATURE CITED 
iii

PAPER III. SPATIALLY RESOLVED MEASUREMENTS OF

SIZE AND VELOCITY DISTRIBUTIONS OF

AEROSOL DROPLETS FROM A DIRECT INJECTION NEBULIZER

$\begin{array}{ll}\text { INTRODUCTION } & 84\end{array}$

$\begin{array}{lr}\text { EXPERIMENTAL SECTION } & 86\end{array}$

$\begin{array}{lr}\text { RESULTS AND DISCUSSION } & 89\end{array}$

$\begin{array}{ll}\text { CONCLUSION } & 101\end{array}$

$\begin{array}{lc}\text { LITERATURE CITED } & 102\end{array}$

PAPER IV. ELEMENTAL SPECIATION BY ANION EXCHANGE AND SIZE EXCLUSION CHROMATOGRAPHY WITH DETECTION BY INDUCTIVELY COUPLED PLASMA MASS SPECTROMETRY WITH DIRECT INJECTION NEBULIZATION

INTRODUCTION

$\begin{array}{ll}\text { EXPERIMENTAL SECTION } & 126\end{array}$

$\begin{array}{ll}\text { RESULTS AND DISCUSSION } & 130\end{array}$

$\begin{array}{ll}\text { CONCLUSION } & 135\end{array}$

LITERATURE CITED 136

$\begin{array}{ll}\text { SUMMARY } & 151\end{array}$

ADDITIONAL LITERATURE CITED 155

$\begin{array}{ll}\text { ACKNOWLEDGEMENTS } & 161\end{array}$ 
GENERAL INTRODUCTION

Since its introduction in 1980 (1), inductively coupled plasma mass spectrometry (ICP-MS) has become a widely used analytical technique for elemental analysis (2-14). Furthermore, ICP-MS has been used as an element-selective detector for chromatography to provide elemental speciation information (15-46). In elemental speciation, one wants to identify and quantify various chemical species that together comprise the total element concentration in a sample. This is important because the toxicity and biological importance of many trace elements depend greatly on their chemical forms and/or oxidation states. A good example is arsenic. Figure 1 shows six common arsenic species. $\mathrm{As}(\mathrm{III})$ and $\mathrm{As}(\mathrm{V})$ are the most toxic; administration of $21 \mu \mathrm{g}$ of As in the form of As(III) and $41 \mu \mathrm{g}$ of As in the form of As(V) causes $50 \%$ mortality in rats within 96 hours (47). Monomethylarsonic acid and dimethylarsinic acid are only moderately toxic (48), while arsenobetaine and arsenocholine are relatively nontoxic $(49,50)$. In fact, biotransformation of inorganic arsenic to DMA and finally to arsenobetaine is the detoxification mechanism for many marine animals such as fish, shrimp and lobster (51-56). The end product is either excreted or stored.

Atomic spectroscopic detection methods such as atomic mass spectrometry, atomic emission spectrometry, atomic absorption spectrometry and atomic fluorescence generally measure only the total concentration or amount for the 


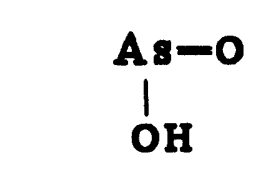

As(III)<smiles>C[As](O)(O)O</smiles>

Monomethylarsonic acid (MMA)

$\left(\mathrm{CH}_{3}\right)_{3} \mathrm{As}^{+}\left(\mathrm{CH}_{2}\right) \mathrm{CO}_{2}^{-}$

Arsenobetaine

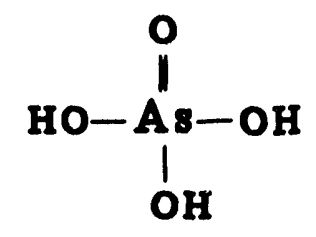

As (V)

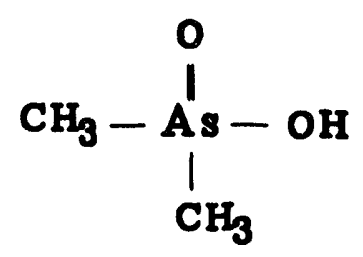

Dimethylarsinic acid (DMA)

$\left(\mathrm{CH}_{3}\right)_{3} \mathrm{As}^{+}\left(\mathrm{CH}_{2}\right)_{2} \mathrm{OH}$

Arsenocholine

Figure 1. Six common arsenic compounds. 
elements of interest. However, by coupling with chromatographic separations, atomic spectroscopic detection methods become species selective detection methods, i.e., speciation information can be obtained (15). Here various elemental species will first be separated by chromatographic methods and then observed one at a time by the detection system.

Inductively coupled plasma mass spectrometry (ICP-MS) is one of the most attractive detection systems for elemental speciation because of its extremely high sensitivity and low detection limits. So far, various separation schemes, including reversed-phase (RP) (16-20), reversed-phase ion-pairing (RP-IP) (21-29), ion chromatography (IC) $(16,23,25,30-35)$, size exclusion chromatography (SEC) $(16,36-$ 43), supercritical fluid chromatography (SFC) (44) and gas chromatography (GC) $(45,46)$ have been coupled with ICP-MS. Nevertheless, there is still substantial room for improvement including better chromatographic separations and lower detection limits.

\section{An Overview of ICP-MS}

The ICP is an atmospheric pressure discharge in a flowing gas stream (usually argon). Electrical power is added inductively to the plasma from a radio-frequency generator (57). The temperature of an ICP is in the range of 6000 to $8000 \mathrm{~K}(58,59)$. Due to the high temperature of the plasma, sample constituents travelling through the axial channel of the ICP will be vaporized, atomized and ionized. For most elements, 
the degree of ionization in the plasma is almost $100 \%$ (14). Exceptions are those elements with high ionization energies (IE), such as $\mathrm{Hg}$ (IE $=10.5 \mathrm{eV}$, only $38 \%$ ionized).

Since the ICP operates at atmospheric pressure, ions formed in the plasma must be extracted into a vacuum system before they can be mass analyzed. Figure 2 shows the schematic diagram of an ICP and a typical ion extraction interface (14). Sample in the form of aerosol is injected into the plasma (Figure 2, B) through the axial channel of the torch (Figure 2, C). A metal cone, the sampler, with a circular orifice of about $1 \mathrm{~mm}$ diameter is immersed into the normal analytical zone where ions are located (Figure 2, E). Ions and neutral gas flow from the ICP through the sampling orifice into the first stage of the vacuum chamber, which is evacuated by a mechanical pump to a pressure of about 1 torr. Due to the reduction in pressure, a supersonic jet forms behind the sampler. The central section of the jet flows through a second orifice called the skimmer. Behind the skimmer, several ion lenses are used to focus and direct ions into a quadrupole mass analyzer $(3,60)$.

For most ICP-MS experiments, a pneumatic nebulizer is used to introduce liquid sample to the plasma. Figure 3 shows a schematic diagram of a concentric pneumatic nebulizer with a spray chamber (61). Liquid sample is introduced through a narrow tube, and at the exit end, the liquid is shattered into aerosol droplets by a stream of Ar gas. The spray chamber prevents large droplets from reaching the plasma and removes as much solvent as possible when cooled $(62,63)$. However, 


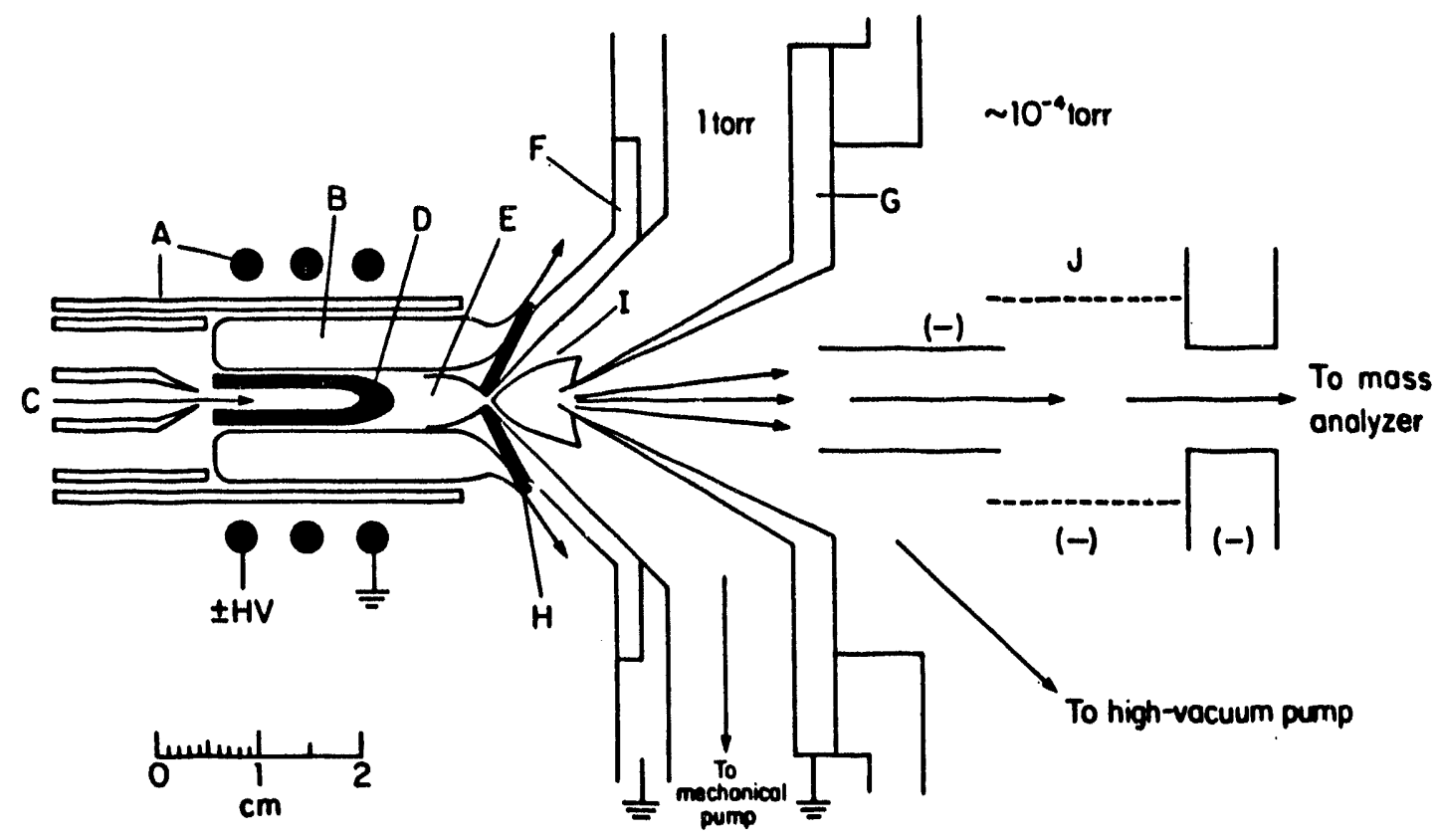

Figure 2. ICP and ion sampling interface. $A=$ torch and load coil $(\mathrm{HV}=$ high voltage), $\mathrm{B}=$ induction region of $\mathrm{ICP}, \mathrm{C}=\mathrm{a}$ solution aerosol being injected into axial channel, $\mathrm{D}=$ initial radiation zone, $\mathrm{E}=$ normal analytical zone, $F=$ nickel cone with sampling orifice in tip, $G=$ skimmer cone, $\mathrm{H}=$ boundary layer of ICP gas deflected outside sampling orifice, $\mathrm{I}=$ expanding jet of $\mathrm{C}$ gas sampled from ICP, and $\mathrm{J}=$ ion lens elements. Reproduced from reference (14) with permission. 


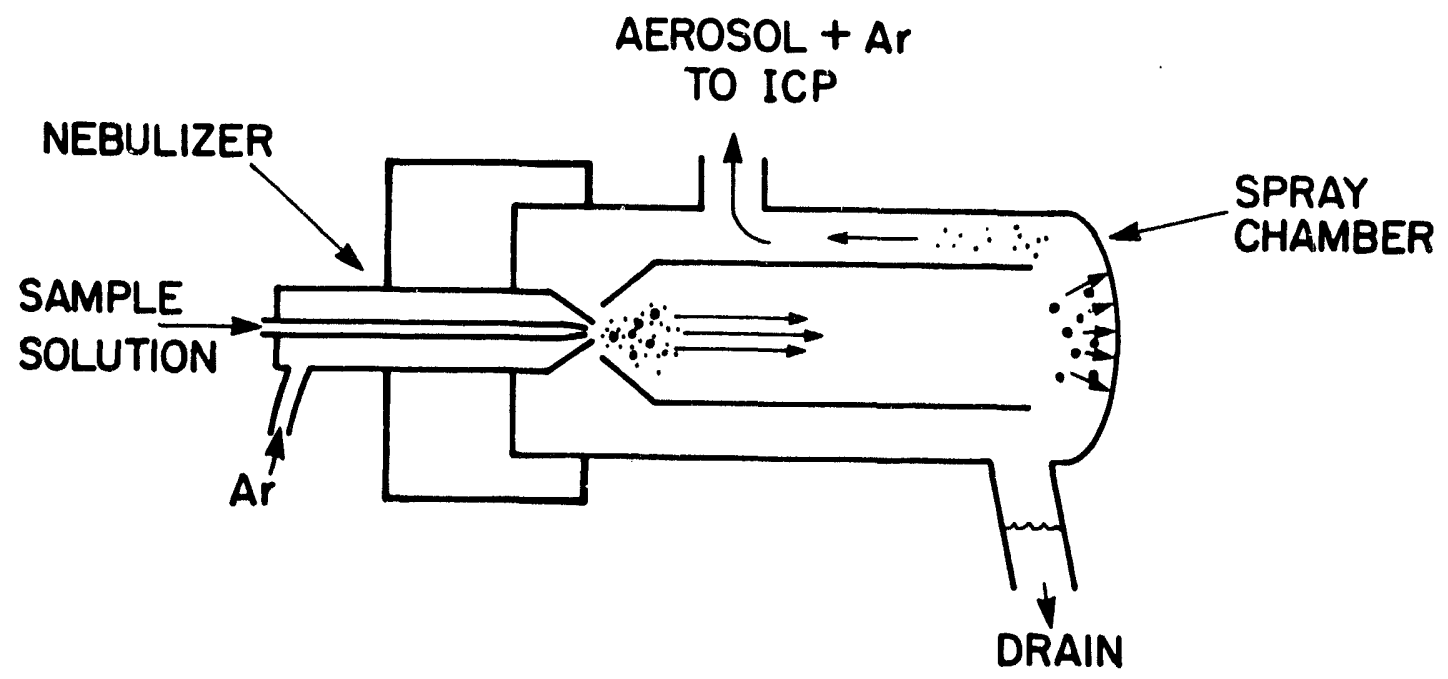

Figure 3. Concentric pneumatic nebulizer and spray chamber for introducing solution into an ICP. Reproduced from reference (61) with permission. 
there are shortcomings of this type of nebulizer. First, only $1-3 \%$ of the sample reaches the plasma while most of the sample goes down to the drain. Second, the spray chamber has a large dead volume that can cause substantial chromatographic band broadening when used to couple LC to ICP-MS.

\section{Direct Injection Nebulization}

For the present work, a new version of the direct injection nebulizer (DIN) was used to coupled LC to ICP-MS $(27,29,64)$. Figure 4 shows the schematic diagram of a DIN and a regular DIN torch. The design and construction of the DIN have been discussed elsewhere $(27,65)$. In brief, a DIN is composed of a nebulizer tip, a ceramic support tube, some swagelok fittings and a capillary sample transfer line. Typically, a $50 \mu \mathrm{m}$ internal diameter $\mathrm{x} 40 \mathrm{~cm}$ long capillary is used. A stream of pressurized Ar gas passes through the swagelok tee (Figure 4, C) and exits with high linear velocity at the end of the nebulizer tip. Aerosol is produced pneumatically at the tip of the nebulizer. When fully assembled, the direct injection nebulizer is placed inside a DIN torch. The nebulizer tip is positioned even with the inner tube of the torch and only $2-3 \mathrm{~mm}$ from the base of the plasma. With the DIN, $100 \%$ of the sample is introduced into the plasma and the use of a spray chamber is unnecessary.

In this dissertation results for the elemental speciation of more than 20 compounds of arsenic, tin, mercury, lead, selenium and metalloproteins are presented. 
Figure 4. DIN and DIN torch. $A=$ stainless steel nebulizer tip, $B=$ ceramic support tube, $C=$ swagelok tee and fittings, $D=$ fused silica capillary for introducing liquid sample, $\mathrm{E}=$ entrance for the DIN, $\mathrm{F}$ = make-up gas inlet, $\mathbf{G}=$ auxilliary gas inlet, $\mathrm{H}=$ plasma gas inlet. 


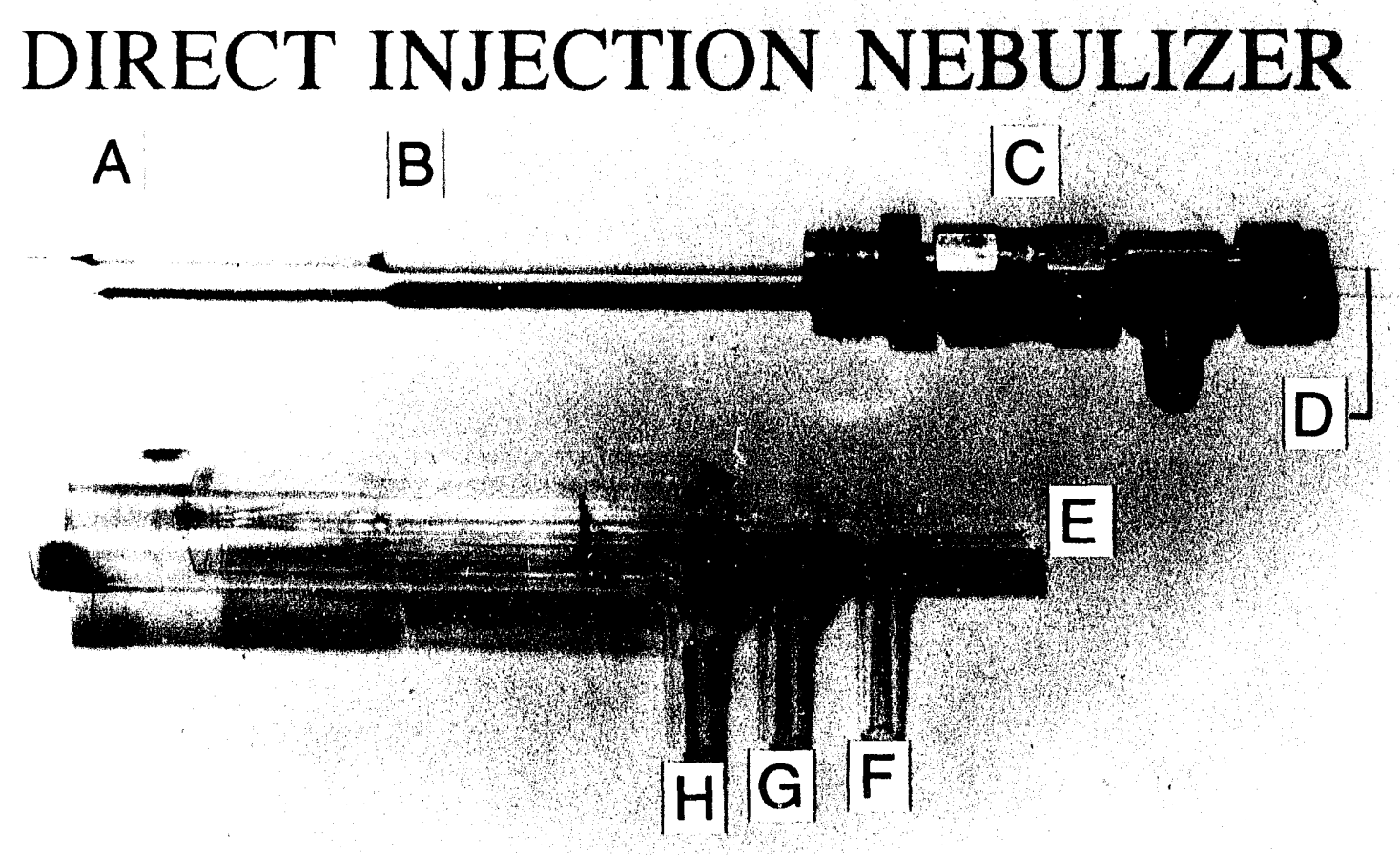


The development of the direct injection nebulizer, a new device used to couple microbore LC to ICP-MS, is emphasized.

\section{Explanation of Dissertation Format}

This dissertation is composed of four papers formatted for publication in four different journals. Each paper stands independent of the others as a complete scientific manuscript with accompanying tables, figures and literature cited. References cited in this general introduction and the summary are given after the summary.

In the first paper, a new version of the direct injection nebulizer (DIN) is used to interface liquid chromatographic (LC) separations with element - selective detection by inductively coupled plasma - mass spectrometry (ICP-MS). The DIN injects all the sample into the ICP and has a dead volume of less than $1 \mu \mathrm{L}$. Charged species of As and $\mathrm{Sn}$ are separated as ion pairs on a micro-scale $(1 \mathrm{~mm}$ i.d.), packed, reversed phase column. Detection limits are $0.2-0.6 \mathrm{pg}$ As and $8-10 \mathrm{pg} \mathrm{Sn}$. For methanol/water eluents, signal is highest at $25 \%$ methanol and stays within $25 \%$ of this maximum as the methanol fraction is varied from $20 \%$ to $80 \%$. Compared to LCICP-MS with conventional nebulizers, the absolute detection limits and chromatographic resolution are substantially superior, and the dependence of analyte signal on solvent composition is somewhat less severe with the DIN.

In the second paper, various cationic species of $\mathrm{Hg}\left(\mathrm{Hg}^{+2}, \mathrm{MeHg}^{+}, \mathrm{EtHg}^{+}\right.$, 
and $\left.\mathrm{PhHg}^{+}\right)$and $\mathrm{Pb}\left(\mathrm{Pb}^{+2},(\mathrm{Me})_{3} \mathrm{~Pb}^{+}\right.$, and $\left(\mathrm{Et}_{3} \mathrm{~Pb}^{+}\right)$are separated as ion pairs by reversed-phase liquid chromatography. Lead is detected at $\approx 0.2 \mathrm{pg}$ and $\mathrm{Hg}$ at $\approx 7$ pg by inductively coupled plasma - mass spectrometry (ICP-MS). A direct injection nebulizer (DIN) minimizes band broadening and yields good sensitivity by injecting all the sample into the plasma. Chromatographic conditions such as mobile phase composition and the compound used for ion pairing are selected based on the mutual requirements of chromatographic performance and detection sensitivity. The inorganic ions $\mathrm{Pb}^{+2}$ and $\mathrm{Hg}^{+2}$ can be monitored directly in human urine by simply diluting and injecting the liquid sample. The organolead and organomercury ions were not concentrated enough to be seen directly in urine, but good separations were obtained when these compounds were spiked into the sample.

In the third paper, aerosol droplet sizes and velocities from a direct injection nebulizer (DIN) are measured with radial and axial spatial resolution by phase doppler particle analysis (PDPA). The droplets on the central axis of the spray become finer and their size becomes more uniform when $\approx 20 \%$ methanol is added to the usual aqueous solvent. This could explain why the analyte signal is a maximum at this solvent composition when the DIN is used for inductively coupled plasma - mass spectrometry (ICP-MS). Mean droplet velocities are 12 to $22 \mathrm{~m} \mathrm{~s}^{-1}$ with standard deviations of \pm 4 to $\pm 7 \mathrm{~m} \mathrm{~s}^{-1}$. The outer fringes of the aerosol plume tend to be enriched in large droplets. The Sauter mean diameter $\left(D_{3.2}\right)$ and velocity of the droplets also vary substantially with axial position in the aerosol plume. 
In the last paper, a direct injection nebulizer (DIN) is used with packed microbore columns for anion chromatography (AC) and size exclusion chromatography (SEC). Two Se species $\left(\mathrm{SeO}_{3}{ }^{2-}\right.$ and $\left.\mathrm{SeO}_{4}{ }^{2-}\right)$ are separated by $\mathrm{AC}$ with detection limits of $15 \mathrm{pg}$ Se. The isotope ratio ${ }^{74} \mathrm{Se} /{ }^{78} \mathrm{Se}$ can be measured with a relative standard deviation of $0.5 \%$ on $25 \mathrm{ng}$ of each Se species during the actual chromatographic separation. Proteins in human serum are separated by SEC without sample pretreatment. The metals present in each molecular weight fraction are determined by ICP-MS with detection limits of $0.5-3 \mathrm{pg}$ metal. These absolute detection limits are $1-2$ orders of magnitude better than those obtained with conventional nebulizers. 
PAPER I

ELEMENTAL SPECIATION BY LIQUID CHROMATOGRAPHY INDUCTIVELY COUPLED PLASMA MASS SPECTROMETRY WITH DIRECT INJECTION NEBULIZATION 


\section{INTRODUCTION}

Atomic spectroscopic methods generally measure only the total concentration or amount of the element(s) of interest. However, these methods can provide speciation information when cumbined with chromatographic separations. Inductively coupled plasma mass spectrometry (ICP-MS) has demonstrated excellent sensitivity and selectivity as a chromatographic detector both in initial demonstration studies (1-

7) and in several real applications. Examples of the latter include the measurement of (a) As species in fish tissue (7-9) and urine $(10,11)$, (b) various elements in polychaetes (12), (c) Cd species in foods (13), and (d) species of $\mathrm{Pb}$ (14) and $\mathrm{Au}(15)$ in blood.

Although some speciation applications can be addressed by chromatographic separations with ICP-MS detection in its present state, there is still substantial room for improvement. Most liquid chromatography-ICP-MS (LC-ICP-MS) studies have employed conventional nebulizers, which introduce only $1-3 \%$ of the sample into the plasma and have large dead volumes that can cause band broadening. In fact, the nebulizer is generally recognized to be one of the weakest components of the entire ICP-MS apparatus.

Fassel and co-workers $(16,17)$ addressed these problems for ICP emission spectrometry by using a direct injection nebulizer (DIN). A microconcentric pneumatic nebulizer is positioned inside the torch with its tip only $3-4 \mathrm{~mm}$ from the 
base of the plasma. Virtually all of the sample is injected into the plasma, and the dead volume is only $2 \mu \mathrm{l}$ or less. A new version of the DIN that is simpler to construct and more rugged was described recently by Wiederin et al. (18), as were some initial results pertaining to the use of the new DIN for LC separations (19). The work described in this paper represents a more thorough evaluation of the DIN as an interface between an LC column and an ICP-MS detector. Micro-scale LC separations in small, packed columns are studied because the liquid flow rates used $\left(\approx 30 \mu 1 \mathrm{~min}^{-1}\right)$ are compatible with the DIN and the dead volume is low enough to prevent excessive band broadening. Conventional nebulizers would have problems in both these areas if used with such columns. 


\section{EXPERIMENTAL SECTION}

\section{ICP-MS Device and Conditions}

The inductively coupled plasma mass spectrometer used was the Elan Model 250 (Perkin-Elmer Sciex, Thornhill, Ontario, Canada). Detailed descriptions of the instrumental system and conditions are given in Table 1. Various plasma and sampling conditions were optimized daily to maximize the signal from the analyte of interest.

\section{DIN Construction and Characteristics}

The DIN used in this work was modified somewhat from the one described previously (Fig. 1 of ref. 18). These modifications are summarized in Table 2. The fused silica capillary was narrower (30 compared with $50 \mu \mathrm{m}$ i.d. for the previous DIN), which minimized dead volume and post-column band broadening. The outer tube of the nebulizer tip (i.e., the tube that surrounded the open end of the sample capillary) was ceramic and the support tube was stainless steel. The width of the annular gap between the inner capillary and the nebulizer tip was approximately 25 $\mu \mathrm{m}$, as for the previous work (18).

Some operating characteristics of the $30 \mu \mathrm{m}$ DIN were very different from those of the previous DIN (18). In the present work, the nebulizer gas flow rate that produced maximum ion signal was only $0.121 \mathrm{~min}^{-1}$. The total gas flow rate (i.e., 
nebulizer flow + make up flow $=0.421 \mathrm{~min}^{-1}$ ) was also much lower than that obtained with the previous DIN $\left(1.301 \mathrm{~min}^{-1}\right)$. Finally, the finer $30 \mu \mathrm{m}$ capillary became plugged more readily. For example, nebulization of a $5 \mathrm{mmol} \mathrm{dm}^{-3}$ solution of sodium dodecylsulfate for only 15 min completely plugged the $30 \mu \mathrm{m}$ capillary. Plugging was not a serious problem during the chromatography work; eluents containing metal salts were avoided because they also suppressed analyte signals by the usual matrix effects (20-26).

\section{Arsenic and Alkyltin Separations}

A schematic diagram of the separation system is given in Fig. 1. A digital high-performance liquid chromatography (HPLC) pump (SSI Model 222D) with a bioclean micro-flow pump head (Scientific Systems, State College, PA, USA) was employed. The solvent switching valve (Fig. 1, C) was a Rheodyne 9010 metal- free injector with a $3 \mathrm{ml}$ PEEK injection loop. Solvents of different composition were loaded onto the $3 \mathrm{ml}$ loop and then connected to the main stream. The solvent in a 3 $\mathrm{ml}$ loop lasted approximately $100 \mathrm{~min}$. Samples were injected using a Rheodyne 7410 micro-injector with a $0.5 \mu l$ internal sample loop disc. The analytical column (Fig. 1, F) used in all studies was a $10 \mathrm{~cm}$ long, $1 \mathrm{~mm}$ i.d. metal-free GLT column packed with $5 \mu \mathrm{m}$ diameter Inertsil ODS-2 material (Scientific Glass Engineering, Austin, TX, USA). A silica pre-column was placed between the pump and the analytical column to saturate the mobile phase with silica. The connections (Fig. 1, $\mathrm{H}_{1}$ and $\mathrm{H}_{2}$ ) 
from the column inlet to the sample injector and the column outlet to the switching valve were $5 \mathrm{~cm}$ long, $50 \mu \mathrm{m}$ i.d. polysil tubes (Scientific Glass Enginerring). The switching valve was another Rheodyne 9010 injector with a $1 \mathrm{ml}$ PEEK injection loop. Standard solutions for optimizing ICP-MS conditions were loaded onto the $1 \mathrm{ml}$ loop and then injected into the nebulizer. The fused silica capillary of the DIN was connected to the switching valve. The outlet of the analytical column was directed into the DIN at all times except during optimization. Mobile phase flow rate was maintained at $30 \mu 1 \mathrm{~min}^{-1}$. The dead volume of the system was $<1 \mu 1$.

The separation conditions for both arsenic and alkyltin speciation are summarized in Table 3. The analytical column was equilibrated with the ion pairing reagent and mobile phase prior to use. Several different combinations of organic modifier concentration, type and concentration of counter ion, $\mathrm{pH}$, etc. were evaluated to optimize chromatographic performance. The conditions listed in Table 3 are those that yielded the best chromatographic resolution of the various sets tested.

The ICP-MS device was operated in multi-element monitoring mode (Table 4). Plasma and sampling conditions were optimized by introducing a solution composed of As and $\mathrm{Sn}$ at $250 \mu \mathrm{g} \mathrm{l}^{-1}$ each. Backgrounds were determined by a biank injection. The count rates were smoothed with a ten-point Savitzky - Golay routine (27). Peak area was determined by summing all the counts under a peak. For this work, the detection limit is defined as the amount of the element necessary to give a peak area equal to three times the standard deviation of the background count rate at each mass. 
The detection limits for each species were estimated from their calibration curves (log - log plot).

\section{Effect of Solvent Composition on Ion Signal}

Flow injection techniques were employed. The inlet of the fused silica capillary was connected to the first injector (Fig. 1, C); i.e., the analytical column was bypassed. Stock solutions of three easily ionized elements ( $\mathrm{Ga}, \mathrm{Nd}$ and $\mathrm{Tl})$ and four moderately ionized elements (As, Se, $\mathrm{Sn}$ and $\mathrm{Hg}$ ) at $200 \mu \mathrm{g} \mathrm{l}^{-1}$ each in various solvents were prepared. These solutions were then loaded onto the injection loop and nebulized. The pump and transfer line leading to the injector were flushed with the appropriate solvent blank after each change of solvent composition. A solution of Rh (i.e. an element in the middle of the mass range) at $200 \mu \mathrm{g}^{-1}$ was introduced to the plasma for optimization. The solution flow rate was maintained at $50 \mu \mathrm{l} \mathrm{min}{ }^{-1}$.

Ion count rates for all seven elements were measured in multi-element monitoring mode (Table 4). Backgrounds were determined using approximately 30 points prior to injection of the sample solution. Count rates were determined by averaging about 30 points of steady-state signal, followed by background subtraction.

\section{Effect of Liquid Flow Rate on Ion Signal}

Instrumentation, experimental conditions and data acquisition were the same as those for the experiments carried out to determine the effect of solvent composition. 
A solution of six elements $\left(\mathrm{Be}, \mathrm{As}, \mathrm{Se}, \mathrm{Sn}, \mathrm{Nd}\right.$ and $\mathrm{Hg}$ ) at $300 \mu \mathrm{g} \mathrm{t}^{-1}$ each in distilled, de-ionized water (DDW) was introduced into the plasma. The plasma and sampling conditions were readjusted at each flow rate being studied to obtained the maximum response for $\mathrm{Rh}$.

\section{Reagents and Samples}

The mobile phases were prepared as follows. Ion pairing reagents Q7 $(0.5$ mol dm${ }^{-3}$ heptatriethylammonium phosphate) and $\mathrm{S} 7\left(0.5 \mathrm{~mol} \mathrm{dm}^{-3}\right.$ sodium heptanesulfonate) were purchased from Regis Chemical Company (Morton Grove, IL, USA). For As speciation, mobile phases of Q7 were prepared by adding appropriate organic modifier (HPLC grade) to the ion-pairing reagent and then diluting with DDW. For alkyltin speciation, ammonium heptanesulfonate was prepared by passing S7 through a column filled with cation-exchange resin Dowex 50W - X8 in the ammonium form. The resulting stock solution of ammonium heptanesulfonate was then diluted with organic modifier (HPLC grade) and DDW. Nitric acid (5\%) and ammonium hydroxide $\left(1 \mathrm{~mol} \mathrm{dm}^{-3}\right)$ were added to adjust the $\mathrm{pH}$. All mobile phases were filtered through a $0.45-\mu \mathrm{m}$ pore nylon filter and de-gassed under light vaccum from an aspirator for $20 \mathrm{~min}$. After use, the column was flushed overnight with a solution of $50 \%$ methanol in water at a flow rate of $50 \mu 1 \mathrm{~min}^{-1}$.

Sodium arsenate $\left(A s^{v}\right)$, sodium arsenite $\left(A s^{\mathrm{III}}\right)$, dimethylarsinic acid (DMAA), monomethyltin trichloride (MMT-TCl), dimethyltin dichloride (DMT-DCl), 
trimethyltin chloride (TMT-Cl), and diethyltin dichloride (DET-DCl) were obtained from Alfa Products (Danvers, MA, USA) and were used without further purification. Stock solutions of arsenic and alkyltin species were prepared from the above analytical-reagent grade compounds in DDW. A previously made stock solution of monomethylarsonic acid (MMAA) containing $100 \mu \mathrm{g} \mathrm{l}^{-1}$ As was used.

Stock solutions of seven elements ( $\mathrm{Ga}, \mathrm{As}, \mathrm{Se}, \mathrm{Sn}, \mathrm{Nd}, \mathrm{Hg}$ and $\mathrm{Tl}$ ) and six elements (Be, As, $\mathrm{Se}, \mathrm{Sn}, \mathrm{Nd}$ and $\mathrm{Hg}$ ) were prepared by diluting $1000 \mathrm{ppm}$ standards (PLASMACHEM Associates, Bradley Beach, NJ, USA) in solvents with the appropriate organic modifier. All other chemicals used were of analytical-reagent grade. 


\section{RESULTS AND DISCUSSION}

\section{Effect of Liquid Flow Rate on Ion Signal}

Fig. 2 shows the effect of liquid flow rate on analyte signal with the present $30 \mu \mathrm{m}$ DIN at very low flow rates. After each change of liquid flow rate, the plasma and sampling conditions (Table 1) were readjusted to yield maximum analyte signal. The ion signals of all six elements studied varied linearly with liquid flow rate if the ICP conditions were readjusted to compensate for the change in solvent load. For each element, the correlation coefficient for a plot of ion signal versus liquid flow rate was $0.994-0.999$. The sensitivity that could be obtained after readjustment dropped with flow rate because the ICP-MS is, of course, a mass flow sensitive detector. Most of the present work was performed at a liquid flow rate of $30 \mu \mathrm{lmin}$. Previous work has shown that a $30 \mu \mathrm{m}$ DIN provides useful analyte signals even at flow rates as low as $4 \mu 1 \mathrm{~min}^{-1}$. Hence, ICP-MS detection could conceivably be used with very low flow rate separation methods such as open tubular LC or capillary zone electrophoresis (CZE). However, operation at such low liquid flow rates would require one of the new generation ICP-MS devices (28) with 100 times better sensitivity than that of the veteran instrument used in this work.

\section{Effect of Solvent Composition on Ion Signal}

In LC-ICP-MS, increasing the organic content of the mobile phase generally 
causes problems such as a decrease in analyte sensitivity $(29,30)$, an increase in the abundance of polyatomic ions containing carbon $(29,31,32)$, and deposition of solid carbon on the sampling orifice $(29,30)$. Nebulization of volatile solvents such as methanol can extinguish the plasma or make it unstable (33-37). For these reasons, most LC experiments with ICP detection have been isocratic with aqueous eluents containing only modest amounts of organic modifiers (e.g., $30 \%$ methanol or less). In this section, the effects of changing solvent composition on analyte signal with the DIN are described.

With the DIN, the plasma tolerated $\mathrm{MeOH}$ or acetonitrile $(\mathrm{ACN})$ very well. No green $\mathrm{C}_{2}$ emission was observed visually from the plasma unless the solvent contained at least $60 \% \mathrm{MeOH}$. The analyte signal did not drift perceptibly when $85 \%$ $\mathrm{MeOH}$ was nebulized for at least one hour. Presumably, oxygen from the $\mathrm{H}_{2} \mathrm{O}$ and $\mathrm{MeOH}$ helped prevent deposition of carbon on the sampling cone $(29,30,38)$. The plasma did not go out and remained stable when either $100 \% \mathrm{MeOH}$ or $70 \% \mathrm{ACN}$ were nebulized; however, carbon deposition on the sampling cone from these latter solvents caused substantial signal drift.

Fig. 3 shows the effect of solvent composition on ion signal for three easily ionized elements $(\mathrm{Ga}, \mathrm{Nd}$ and $\mathrm{Tl})$. The ion signal increased sharply for mixtures containing up to $25 \% \mathrm{MeOH}$ and then decreased very gradually at $\mathrm{MeOH}$ fractions above $25 \%$. Results from replicate experiments showed that the maximum analyte signal was in the range of $20-30 \% \mathrm{MeOH}$ in water, and $15-25 \% \mathrm{ACN}$ in water. 
Normalized curves for the same elements in ACN were almost identical with those in Fig. 3 except that the decrease in the ion signal for ACN was more marked. Presumably, the plasma was cooled more extensively by $\mathrm{ACN}$ than $\mathrm{MeOH}$. For these easily ionized elements, the analyte signal varied only by $\pm 15 \%$ as the solvent composition changed from $20 \%$ to $80 \% \mathrm{MeOH}$ (Fig. 3). A reasonable plateau was found between 15 and $60 \% \mathrm{ACN}$.

Fig. 4 shows the effect of solvent composition on ion signal for four moderately ionized elements ( $\mathrm{As}, \mathrm{Se}, \mathrm{Sn}$ and $\mathrm{Hg}$ ). The general shape of the curves was similar to those in Fig. 3 except that the decreases at higher methanol concentrations were steeper in Fig. 4. The signals for these moderately ionized elements were more dependent on solvent composition than the signals for the easily ionized elements. Presumably this is because plasma cooling had more of an effect on the ionization efficiency for elements with high ionization energies. Nevertheless, analyte signal varied only by $\pm 25 \%$ as the solvent composition changed from 20 to $80 \% \mathrm{MeOH}$ (Fig. 4). For ACN, a reasonable plateau was found between $15 \%$ and $60 \%$ ACN. Thus mild solvent gradients (in HPLC) in this range should not induce extreme changes in analyte sensitivity with the DIN. This capability is an attractive feature because the species selectivity in LC-ICP-MS is based solely on retention, thus good chromatographic separations are necessary. Use of the DIN outside the torch in a spray chamber with desolvation may remove enough solvent to facilitate the use of solvent gradients, although band broadening may be substantial in the aerosol 
transfer line between the nebulizer and the plasma.

\section{Arsenic Separation}

A typical chromatogram of a solution containing As ${ }^{\mathrm{III}}$, DMAA, MMAA, and $\mathrm{As}^{\mathrm{v}}$ is shown in Fig. 5. Separation conditions are given in Table 3. The analytical figures of merit under these separation conditions are shown in Table 5. The peaks for both inorganic and organic As species were baseline resolved, compared with previous work $(1,19)$ where either As ${ }^{\mathrm{III}}$ and MMAA, or DMAA and MMAA could not be resolved. The $\mathrm{pH}$ was held at 6.0 to keep all arsenic species in their ionic forms. At a higher $\mathrm{pH}(\approx 7.0)$, the retention time for MMAA increased from 7.6 $\min$ to $9.6 \mathrm{~min}$, while the retention time for $\mathrm{As}^{\mathrm{v}}$ increased to $>30 \mathrm{~min}$. Peak-area measurements indicated that the sensitivity (count rate per ng of As) was similar for the various forms of As (Table 5). The precision based on five replicate injections of approximately $0.5 \mathrm{ng}$ (as As) of each species and measurement of peak areas was better than 4\% RSD for all four species (Table 5). Calibration curves for each species based on injections of $0.05,0.5,1,5$ and $10 \mathrm{ng}$ (as As) and peak areas were all linear with correlation coefficients of 0.9994 or better. Absolute detection limits were approximately $0.6 \mathrm{pg}$ of As for all four forms (Table 5). These absolute detection limits are superior by factors of 50 to 500 over those obtained previously by LC-ICP-MS with conventional nebulizers (1,6-11). The improvement in absolute detection limits is expected because all of the sample reaches the plasma with the 
DIN. Relative detection limits for As species are about $1 \mathrm{ppb}$. As the injected volume in the present work is very low $(0.5 \mu \mathrm{l})$, these relative detection limits are comparable to or slightly worse than those obtained with conventional nebulizers and much larger injections.

A step gradient can be used to elute the last As peak more rapidly (Fig. 6). The first three peaks were eluted with $5 \%$ methanol in water for $11 \mathrm{~min}$. The As ${ }^{v}$ peak was then eluted by stepping the eluent up to $25 \%$ methanol in water. The step gradient was performed by storing the second eluent ( $25 \%$ methanol in water) in the 3 $\mathrm{ml}$ loop (Fig. 1, C) in front of the column and then injecting this loop $11 \mathrm{~min}$ after sample injection. Note that both the baseline and sensitivity of the fourth peak increased. The reproducibility of this separation is still approximately $4 \%$ RSD (five replicate injections) for all four species. The absolute detection limit for the fourth peak $\left(\mathrm{As}^{\mathrm{v}}\right)$ is $\approx 0.2 \mathrm{pg}$. The improved detection limit is due to a great extent to the enhancement in sensitivity when the eluent is $25 \% \mathrm{MeOH}$ (Fig. 4).

\section{Alkyltin Separation}

A typical chromatogram of a standard mixture of MMT-TCl, DMT-DCl, DET-DCl, and TMT-Cl is shown in Fig. 7. Pertinent conditions are given in Table 3. The analytical figures of merit for this separation method are given in Table $6 . \quad A$ reversed-phase cation pairing separation mode was used here. The cation pairing reagent was in the ammonium form rather than the common sodium form to avoid 
matrix effects and clogging of the DIN. Ammonium heptanesulfonate yielded a better separation than ammonium dodecylsulfate. The $\mathrm{pH}$ was maintained at 3.1 to ensure that the alkyltins were present as ions in the mobile phase. A higher percentage of organic modifier ( $25 \%$ methanol) was used in this separation than for the As separations. All four alkyltins were separated, although previous work (39) reported difficulties in resolving MMT and DMT. MMT-TCl gives a broad and split peak, presumably because of an equilibrium among different forms of monomethyltin compound (5). For example, the ion pair species for MMT could be a mixture of $\mathrm{CH}_{3} \mathrm{SnCl}_{2} \mathrm{R}, \mathrm{CH}_{3} \mathrm{SnClR}_{2}$ and $\mathrm{CH}_{3} \mathrm{SnR}_{3}$, where $\mathrm{R}=$ heptanesulfonate. Peak-area measurements indicated that /he sensitivity was similar for the various alkyltins, including MMT-TCl (Table 6). Absolute detection limits are approximately $10 \mathrm{pg}$ for all forms of alkyltin (Table 6,. These absolute detection limits are superior by factors of 5 - 150 over those obtained previously by LC-ICP-MS $(4,5,39-41)$, but are inferior to recent $\mathrm{Sn}$ values obtained by supercritical fluid chromatography with ICP-MS detection (42). The relative detection limits of $16-20 \mathrm{ppb}$ of $\mathrm{Sn}$ in Table 6 are poorer than the values of $0.2-0.4 \mathrm{ppb} \mathrm{Sn}$ in butyltin compounds reported by McLaren et al. (41). The elevated baseline in Fig. 7, which has also been observed previously $(4,39,41)$, is probably due to $\mathrm{Sn}^{+}$although the precise source of this $\mathrm{Sn}$ contamination is uncertain. 


\section{CONCLUSION}

The analytical merits of coupling micro-scale HPLC with ICP-MS with the 30 $\mu \mathrm{m}$ DIN for elemental speciation are demonstrated. Detection limits for As and Sn are improved by $1-2$ orders of magnitude. The low dead volume $(<1 \mu \mathrm{l})$ associated with the DIN resulted in low extracolumn broadening, a vital factor for good resolution in micro-scale LC. In addition, the DIN allows the direct injection of HPLC eluents containing large amounts of organic modifier (up to $85 \% \mathrm{MeOH}$ ) into the ICP, which remains stable over a long period of time. With the DIN, the analyte signal varies only by $\pm 20 \%$ as the eluent is changed from 20 to $80 \% \mathrm{MeOH}$ in $\mathrm{H}_{2} \mathrm{O}$. Thus, mild solvent gradients within this range should not induce extreme changes in analyte sensitivity with the DIN. As the toxicological and biological importance of trace elements depends mainly on their chemical forms, more research efforts in developing methods to identify and quantify chemical species are expected. The excellent detection limits, low dead volume and potential for use with gradient elution make the DIN a significant improvement in LC-ICP-MS for elemental speciation. 


\section{LITERATURE CITED}

(1) Thompson, J. J., and Houk, R. S., Anal. Chem., 1986, 58, 2541.

(2) Dean, J. R., Munro, S., Ebdon, L., Crews, H. M., and Massey, R. C., J. Anal. At. Spectrom., 1987, 2, 607.

(3) Jiang, S. J., and Houk, R. S., Spectrochim. Acta, Part B, 1988, 43, 405.

(4) Suyani, H., Creed, J., Davidson, T., and Caruso, J., J. Chromatogr. Sci., $1989,27,139$.

(5) Suyani, H., Heitkemper, D., Creed, J., Caruso, J., J. Appl. Spectrosc., 1989, 43, 962 .

(6) Shibata, Y., and Morita, M., Anal. Sci., 1989, 5, 107.

(7) Beauchemin, D., Siu, K. W. M., McLaren, J. W., and Berman, S. S., J. Anal. At. Spectrom., 1989, 4, 285.

(8) Beauchemin, D., Bednas, M. E., Berman, S. S., McLaren, J. W., Siu, K. W. M., and Sturgeon, R. E., Anal. Chem., 1988, 60, 2209.

(9) Shibata, Y., and Morita, M., Anal. Chem., 1989, 61, 2118.

(10) Heitkemper, D., Creed, J., Caruso, J., and Fricke, F. L., J. Anal. At. Spectrom., 1989, 4, 279.

(11) Sheppard, B. S., Shen, W.-L., Caruso, J. A., Heitkemper, D. T., and Fricke, F. L., J. Anal. At. Spectrom., 1990, 5, 431. 
(12) Mason, A. Z., Storms, S. D., and Jenkins, K. D., Anal. Biochem., 1990, 186, 187.

(13) Crews, H. M., Dean, J. R., Ebdon, L., and Massey, R. C., Analyst, 1989, 114, 895.

(14) Gercken, B., and Barnes, R. M., Anal. Chem., 1991, 63, 283.

(15) Matz, S. G., Elder, R. C., and Tepperman, K., J. Anal. At. Spectrom., 1989, 4, 767.

(16) Lawrence, K. E., Rice, G. W., and Fassel, V. A., Anal. Chem., 1984, 56, 289.

(17) LaFreniere, K. E., Fassel, V. A., and Eckels, D. E., Anal. Chem., 1987, 59, 879.

(18) Wiederin, D. R., Smith, F. G., and Houk, R. S., Anal. Chem., 1991, 63, 219.

(19) Houk, R. S., Shum, S. C. K., and Wiederin, D. R., Anal. Chim. Acta, 1991, 250,61 .

(20) Olivares, J. A., and Houk, R. S., Anal. Chem., 1986, 58, 20.

(21) Ross, B.S., and Hieftje, G. M., Spectrochim. Acta, Part B, 1991, 46, 1263.

(22) Tan, S. H., and Horlick, G., J. Anal. At. Spectrom., 1987, 2, 745.

(23) Beauchemin, D., McLaren, J. W., and Berman, S. S., Spectrochim. Acta, Part B, 1987, 42, 467.

(24) Gregoire, D. C., Spectrochim. Acta, Part B, 1987, 42, 895. 
(25) Vandecasteele, C., Nagels, M., Vanhoe, H., and Dams, R., Anal. Chim. Acta, 1988, 211, 91.

(26) Crain, J. S., Houk, R. S., and Smith, F. G., Spectrochim. Acta, Part B, 1988, 43, 1355.

(27) Savitzky, A., and Golay, M. J. E., Anal. Chem., 1964, 36, 1627.

(28) PMS 2000, Yokogawa Electric Co., or TS Sola, Turner Scientific.

(29) Hutton, R. C., J. Anal. At. Spectrom., 1986, 1, 259.

(30) Hausler, D., Spectrochim. Acta, Part B, 1987, 42, 63.

(31) Long, S. E., and Martin, T. D., ICP Information Newsletter, 1991, 16, 460.

(32) Wiederin, D. R., Houk, R. S., Winge, R. K., and D'Silva, A. P., Anal. Chem., 1990, 62, 1155.

(33) Boorn, A. W., and Browner, R. F., Anal. Chem., 1982, 54, 1402.

(34) Maessen, F. J. M., Seeverens, P. J. H., and Kreuning, G., Spectrochim. Acta, Part B, 1984, 39, 1171.

(35) Blades, M. W., and Caughlin, B. L., Spectrochim. Acta, Part B, 1985, 40, 579.

(36) Trussel, F. C., Anal. Chem., 1985, 57, 191 R.

(37) Kreuning, G., and Massen, F. J. M. J., Spectrochim. Acta, Part B, 1989, 44, 367.

(38) Browner, R. F., and Boorn, A. W., Anal. Chem. 1984, 56, 786A. 
(39) Houk, R. S., and Jiang, S. J. in Trace Metal Analysis and Speciation, ed. Krull, I. S., Elsevier, Amsterdam, 1991, ch. 5.

(40) Branch, S., Ebdon, L., Hill, S., and O'Neill, P., Anal. Proc., 1989, 26, 401.

(41) McLaren, J. W., Siu, K. W. M., Lam, J. W., Willie, S. N., Maxwell, P. S., Palepu, A., Koether, M., and Berman, S. S., Fresenius J. Anal. Chem., 1990, 337, 721.

(42) Shen, W.-L., Vela, N. P., Sheppard, B. S., and Caruso, J. A., Anal. Chem., 1991, 63, 1491. 
Table 1. Instrument conditions and operating procedures

ICP-MS

ICP torch
Sciex Elan Model 250

Modified Sciex short torch : injector tube orifice diameter $=1 \mathrm{~mm}$; $6 \mathrm{~mm}$ o.d. $\times 4 \mathrm{~mm}$ i.d. quartz $\mathrm{T}$ attached at torch base

Argon flow rates $/ 1 \mathrm{~min}^{-1}$ -

Plasma

Auxiliary

Make-up

Nebulizer gas

Sample flow rate

Forward power

Sampling position

Sampler

Skimmer

Detector voltage

Ion lens setting -

Bessel

Plate

Barrel

Photon stop

Operating pressures -

Interface

Quadrupole chamber $12^{\circ}$

$1^{\circ}$

$0.30^{\circ}$ Regulated by mass flow controller $0.1^{\circ}$

$30 \mu 1 \mathrm{~min}^{-1}$ typical

$1.3 \mathrm{~kW}$

$20 \mathrm{~mm}$ above load coil, on centre

Copper, $1.0 \mathrm{~mm}$ diameter orifice

Nickel, $0.9 \mathrm{~mm}$ diameter orifice

$-4000 \mathrm{~V}$

$-19.80 \mathrm{~V}$

$-11.00 \mathrm{~V}$

$+5.42 \mathrm{~V}$

$-4.16 \mathrm{~V}$

1 Torr

$3 \times 10^{-5}$ Torr

- Typical values cited. These parameters were adjusted daily to optimize ion signal (see text). 
Table 2. DIN modifications

$\begin{array}{lc}\text { Support tube } & \text { Stainless steel (Alltech) } \\ & 1.6 \mathrm{~mm} \mathrm{o.d.} \times 0.76 \mathrm{~mm} \text { i.d. } \times 150 \mathrm{~mm} \text { long } \\ \text { Nebulizer tip } & \text { Ceramic tube (Scientific Instrument Services, Inc.) } \\ & 0.51 \mathrm{~mm} \mathrm{o.d.} \times 200 \mu \mathrm{m} \text { i.d. } \times 15 \mathrm{~mm} \text { long } \\ \text { Capillary } & \text { Fused silica (Polymicro Technologies Inc.) } \\ & 150 \mu \mathrm{m} \text { o.d. } \times 30 \mu \mathrm{m} \text { i.d. } \times 450 \mathrm{~mm} \text { long }\end{array}$

- See Fig. 1 of ref. 18 for diagram identifying support tube, nebulizer tip and capillary. 
Table 3. Chromatographic conditions

\begin{tabular}{|c|c|c|}
\hline & Arsenic Species & Alkyltin Species \\
\hline Column & $\begin{array}{l}\text { Scientific Glass Engineering } \\
\text { Metal free GLT microcolumn } \\
1 \mathrm{~mm} \text { i.d. } \times 100 \mathrm{~mm} \text { long }\end{array}$ & Same \\
\hline Stationary phase & Inertsil ODS-2 & Same \\
\hline Mobile phase & $\begin{array}{l}5 \% \text { methanol in water } \\
5 \mathrm{mmol} \mathrm{dm}^{-3} \text { heptyltriethylammonium } \\
\text { phosphate } \\
\text { pH }=6.0\end{array}$ & $\begin{array}{l}25 \% \text { methanol in water } \\
5 \mathrm{mmol} \mathrm{dm}^{-3} \text { ammonium } \\
\text { heptanesulfonate } \\
\mathrm{pH}=3.1\end{array}$ \\
\hline Sample flow rate & $30 \mu \mathrm{l} \min ^{-1}$ & Same \\
\hline Injection volume & $0.5 \mu 1$ & Same \\
\hline Compounds & $\begin{array}{l}\text { Arsenite }\left(\mathrm{As}^{\mathrm{mI}}\right) \\
\text { Arsenate }\left(\mathrm{As}^{\mathrm{v}}\right) \\
\text { Monomethylarsonic acid (MMAA) } \\
\text { Dimethylarsinic acid (DMAA) }\end{array}$ & $\begin{array}{l}\text { Monomethyltin trichloride (MMT-TCl) } \\
\text { Dimethyltin dichloride (DMT-DCl) } \\
\text { Diethyltin dichloride (DET-DCl) } \\
\text { Trimethyltin chloride (TMT-Cl) }\end{array}$ \\
\hline Isotopes monitored & $\mathrm{m} / \mathrm{z}=75$ & $\mathrm{~m} / \mathrm{z}=120$ \\
\hline
\end{tabular}


Table 4. Data acquisition

Data acquisition -

Ion signal versus flow rate and ion signal versus eluent composition
Arsenic and tin separations
Multi-element monitoring mode, low resolution setting; three measurements per peak spaced $\mathrm{m} / \mathrm{z}=0.1$ about peak top; dwell time at each position $20 \mathrm{~ms}$, with total measurement time of $0.3 \mathrm{~s}$

$\begin{array}{lc}\text { Elements } & \mathrm{m} / \mathrm{z} \\ \mathrm{Be} & 9 \\ \mathrm{Ga} & 69 \\ \mathrm{As} & 75 \\ \mathrm{Se} & 78 \\ \mathrm{Sn} & 120 \\ \mathrm{Nd} & 144 \\ \mathrm{Hg} & 202 \\ \mathrm{Tl} & 205\end{array}$

Multi-element monitoring mode, low resolution setting; one measurement per peak; dwell time $20 \mathrm{~ms}$, with total measurement time of $1 \mathrm{~s}$ 
Table 5. Analytical figures of merit for separation of arsenic species (Fig. 5)

\begin{tabular}{|c|c|c|c|c|}
\hline Compounds & $A s^{I I I}$ & DMAA & MMAA & $A s^{v}$ \\
\hline Retention time $/ \mathrm{min}$ & 2.0 & 5.0 & 7.6 & 29.7 \\
\hline $\begin{array}{l}\text { Sensitivity/counts } \mathrm{ng}^{-1} \\
\quad\left(\begin{array}{ll}\mathrm{x} & 10^{5}\end{array}\right)\end{array}$ & 2.4 & 2.2 & 2.6 & 2.3 \\
\hline $\operatorname{RSD}^{*}(\%)$ & 3.5 & 3.8 & 3.0 & 3.2 \\
\hline $\begin{array}{l}\text { Detection limits }^{\dagger}- \\
\text { (a) Amount of As/pg } \\
\text { (b) Amount of As/ } / \mathrm{g} \mathrm{l}^{-1}\end{array}$ & $\begin{array}{l}0.6 \\
1.2\end{array}$ & $\begin{array}{l}0.6 \\
1.2\end{array}$ & $\begin{array}{l}0.5 \\
1.0\end{array}$ & $\begin{array}{l}0.6 \\
1.2\end{array}$ \\
\hline
\end{tabular}

- Relative standard deviation of peak area for 5 replicate injections of $0.5 \mathrm{ng}$ (as As) of each species. See Table 3 for HPLC conditions.

+ Detection limit defined as amount of As required to yield a net peak that was $3 x$ the standard deviation of the background. Calibration curves and peak areas were used in these calculations. 
Table 6. Analytical figures of merit for alkyltin separation (Fig. 7)

\begin{tabular}{lcccc}
\hline Compounds & MMT-TCl & DMT-DCl & DET-DCl & TMT-Cl \\
Retention time/min & 4.6 & 7.4 & 10.5 & 14.1 \\
$\begin{array}{l}\text { Sensitivity/counts } \mathrm{ng}^{-1} \text { of } \mathrm{Sn} \\
\quad\left(\mathrm{x} 10^{4}\right)\end{array}$ & 4.7 & 5.5 & 4.8 & 5.0 \\
$\begin{array}{l}\text { Detection limits - } \\
\text { (a) Amount of } \mathrm{Sn} / \mathrm{pg}\end{array}$ & 10 & 8 & 10 & \\
(b) amount of $\mathrm{Sn} / \mu \mathrm{g} \mathrm{I}^{-1}$ & 20 & 16 & 20 & 18 \\
\hline
\end{tabular}

- Detection limit defined as amount of $\mathrm{Sn}$ required to yield a net peak that was $3 x$ the standard deviation of the background. Peak areas were used in these calculations. 


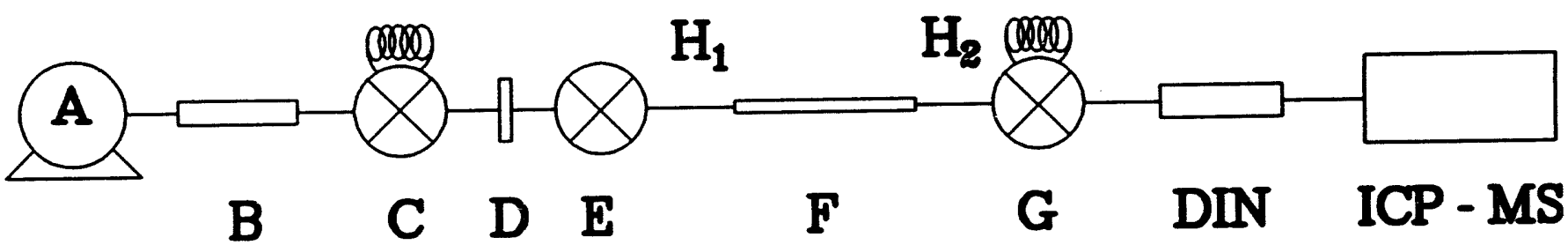

Fig. 1. Schematic diagram of the separation system: (A) HPLC pump; (B) pre-column; (C) solvent switching valve; (D) inlet filter; (E) micro-injector; (F) analytical column; (G) switching valve; and $\left(\mathrm{H}_{1}\right)$ and $\left(\mathrm{H}_{2}\right)$ polysil tubes 


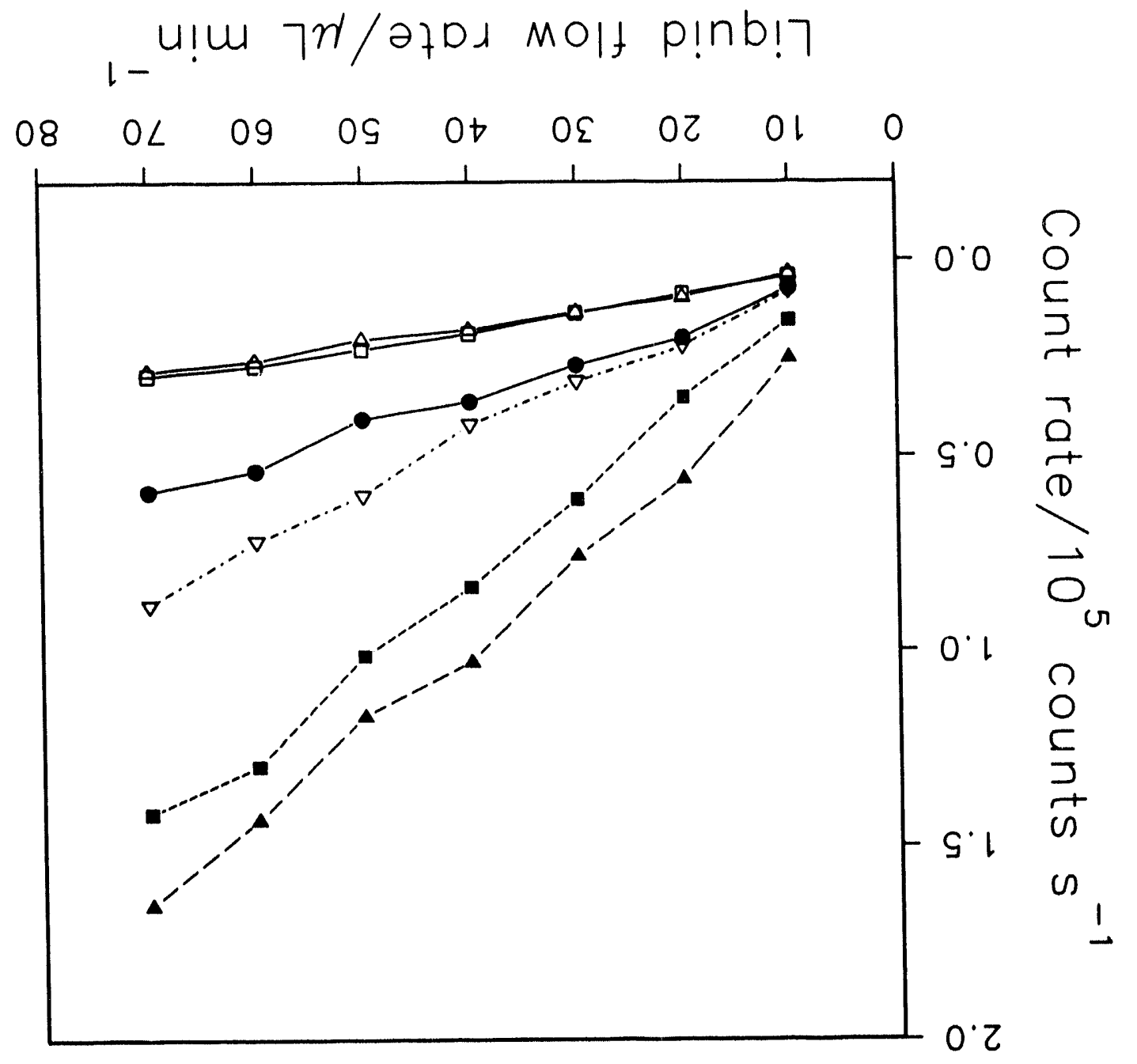




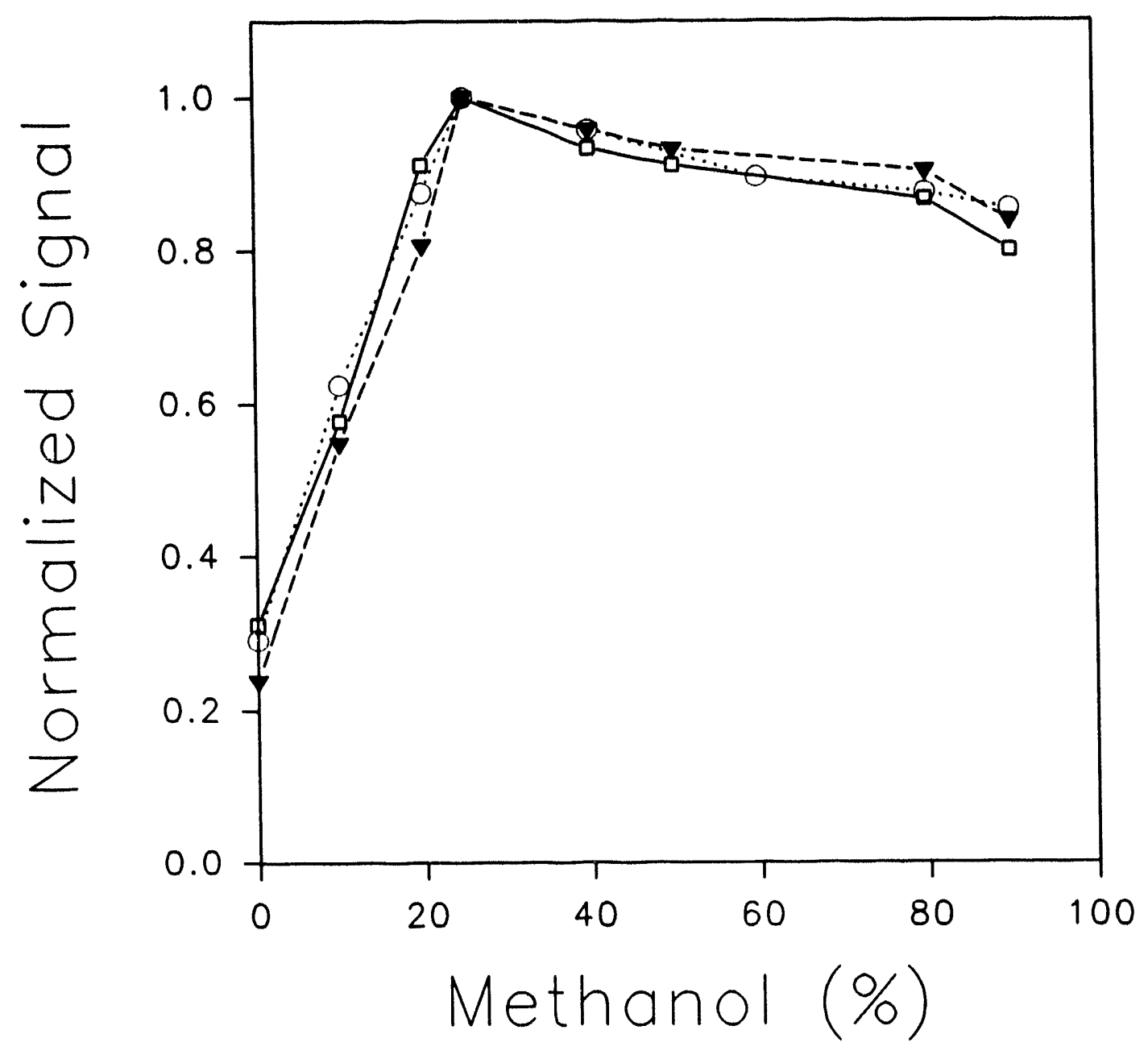

Fig. 3. Effect of solvent composition on ion signal for $\mathrm{Ga}(\square), \mathrm{Nd}(\boldsymbol{\nabla})$, and $\mathrm{Tl}$ (O) 


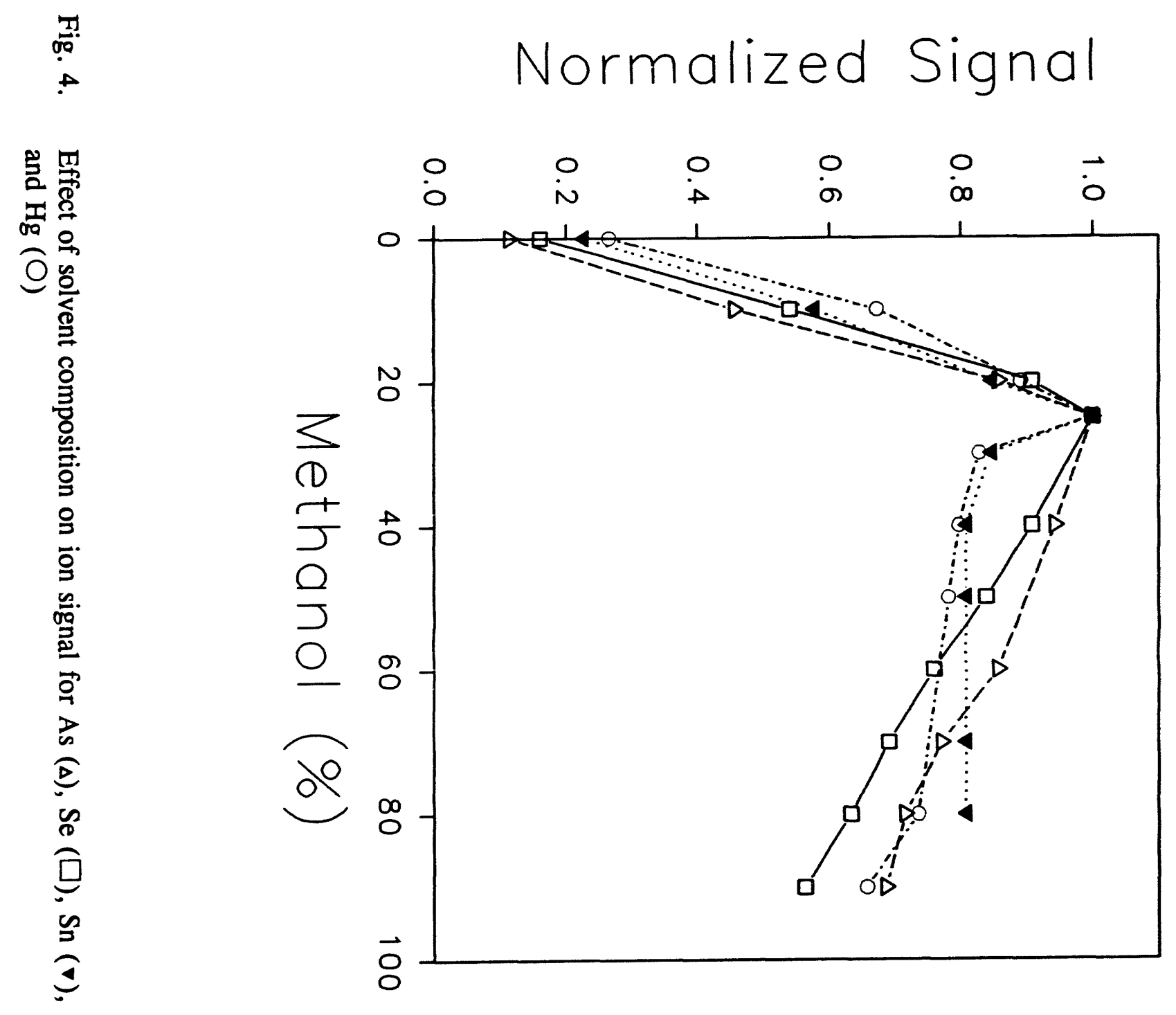




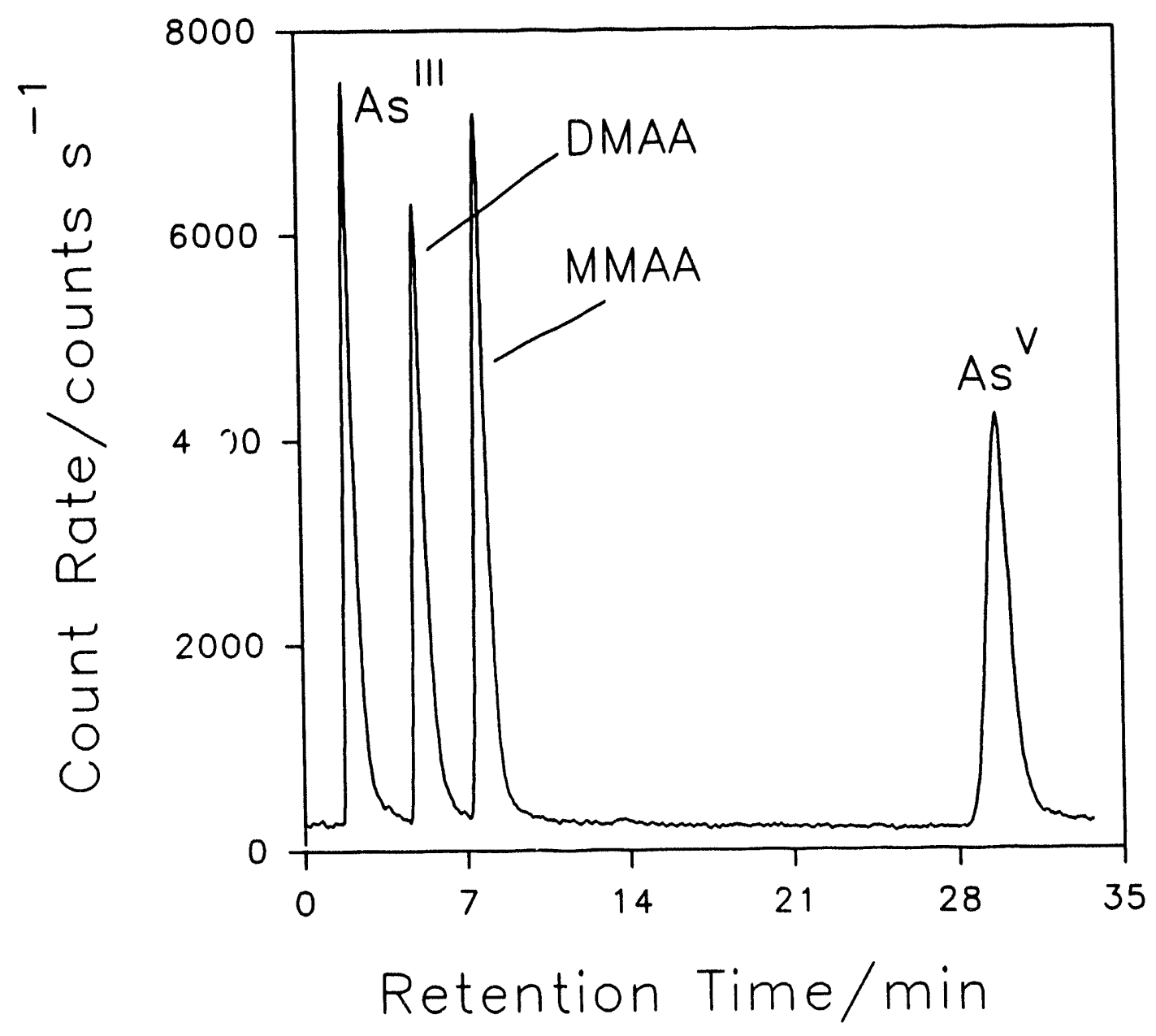

Fig. 5. Separation of four arsenic compounds, $0.5 \mathrm{ng}$ of As for each species. HPLC conditions as in Table 3. Background, $\approx 200$ counts $\mathrm{s}^{-1}$ 

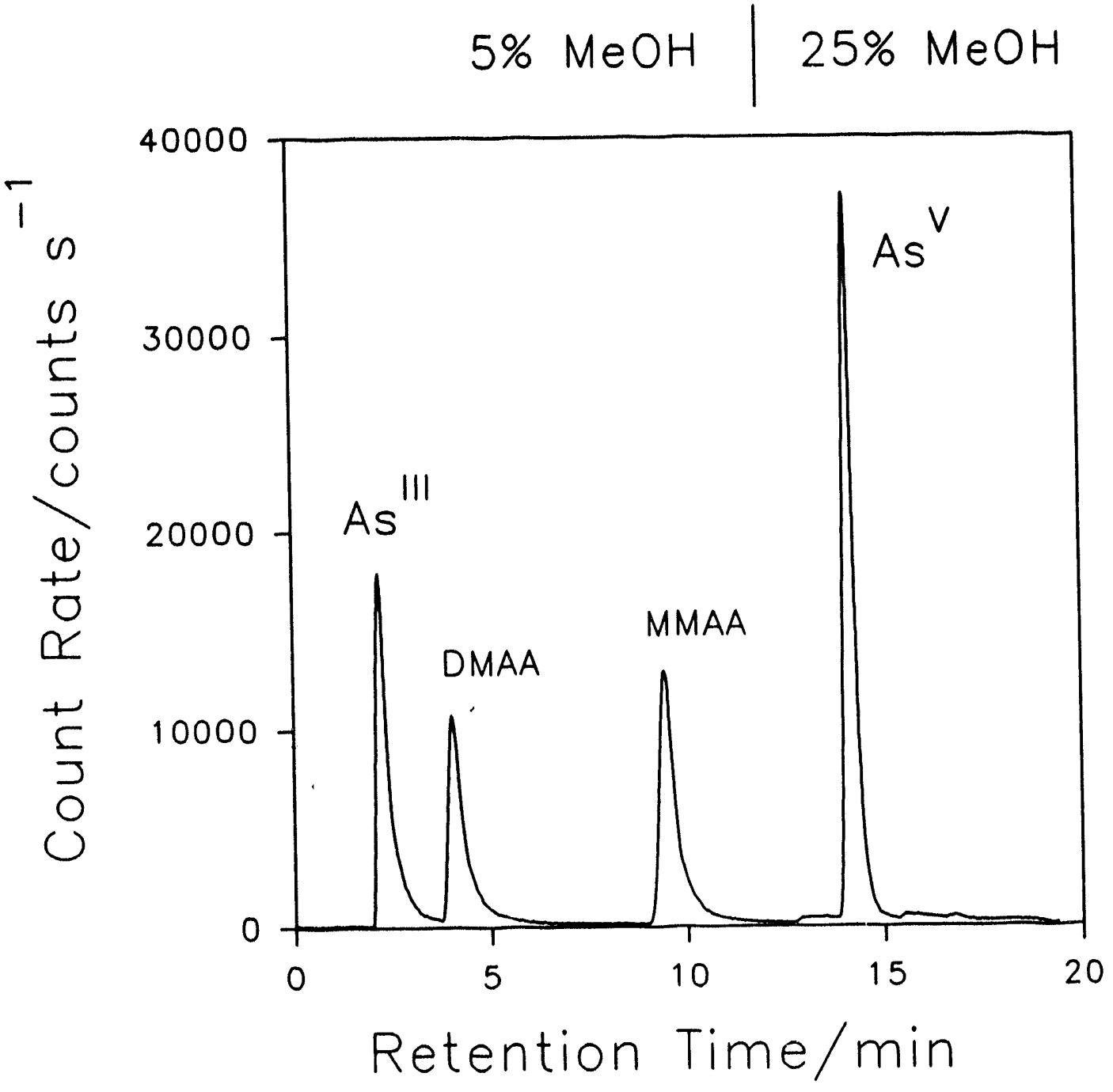

Fig. 6. Separation of four arsenic compounds with step gradient, $0.8 \mathrm{ng}$ of As for each species. Eluent composition was $5 \mathrm{mmol} \mathrm{dm}^{-3}$ heptyltriethylammonium phosphate (Q7) in $\mathrm{MeOH}-\mathrm{H} 2 \mathrm{O}(5+95)$ for the first $11 \mathrm{~min}$, and then stepped to $5 \mathrm{mmol} \mathrm{dm}-3$ Q7 in MeOH-H2O $(25+$ 75). The $\mathrm{pH}$ was adjusted to 7 for both eluents. Background for first 11 $\min , \approx 200$ counts $\mathrm{s}-1$, and then increased to $\approx 400$ counts $\mathrm{s}^{-1}$ after 13 $\min$ 


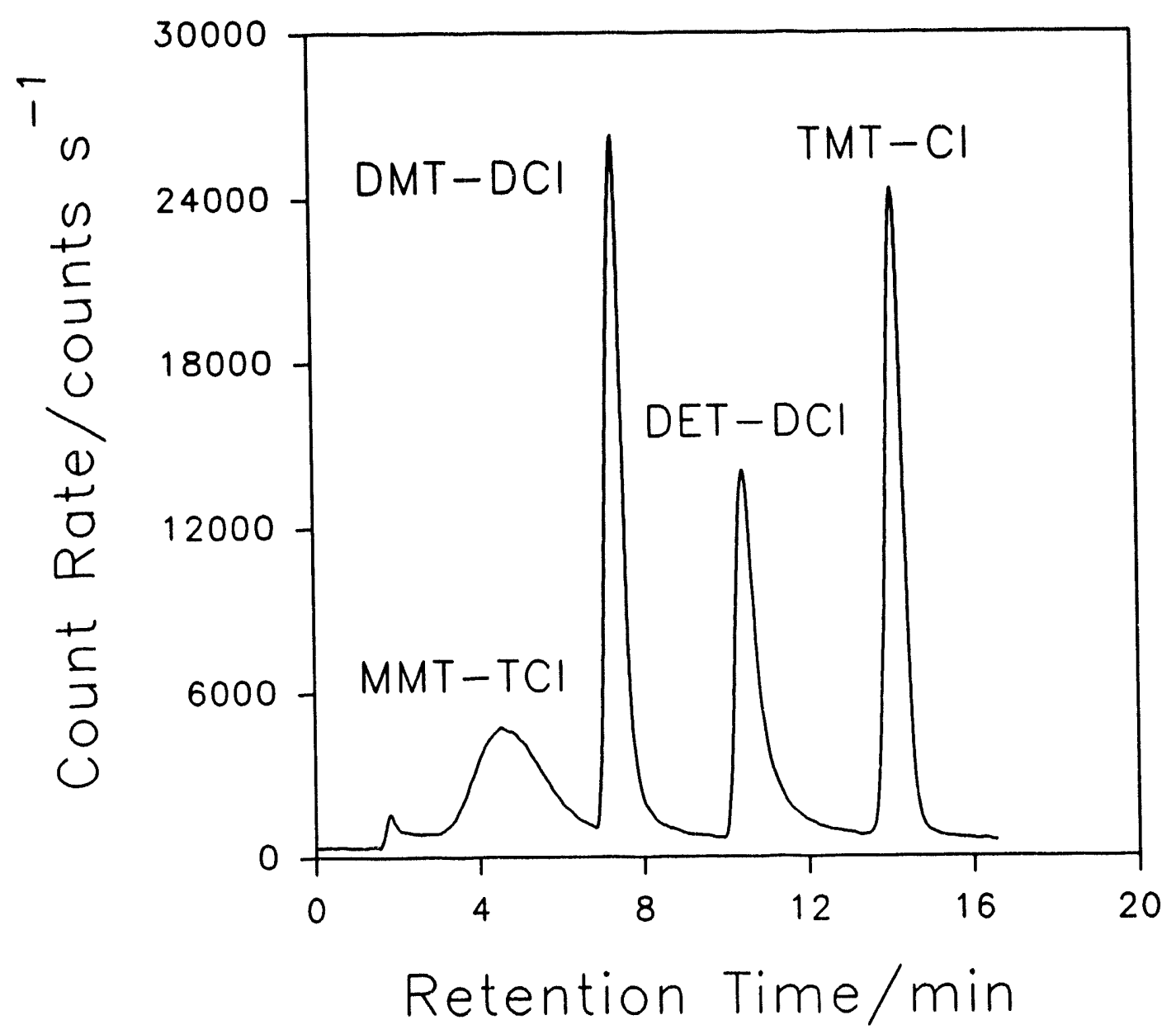

Fig. 7. Separation of four alkyltin compounds, $6 \mathrm{ng}$ of $\mathrm{Sn}$ for each species. HPLC conditions as in Table 3. Background, $\approx 400$ counts $\mathrm{s}^{-1}$ 
PAPER II

SPECIATION OF MERCURY AND LEAD C.OMPOUNDS BY MICROBORE COLUMN LIQUID CHROMATOGRAPHY - INDUCTIVELY COUPLED PLASMA MASS SPECTROMETRY WITH DIRECT INJECTION NEBULIZATION 


\section{INTRODUCTION}

The toxicological and biological roles of trace elements depend on their chemical forms and/or oxidation states (1-4). Thus, analytical methodology for measuring trace element speciation is necessary. The atomic spectroscopic methods that are usually used for elemental analysis generally do not distinguish the various species present for each element. However, speciation information can re obtained by coupling chromatographic separations with element-selective detection by atomic spectroscopy (5-10). Inductively coupled plasma mass spectrometry (ICPMS) is one of the most attractive detection systems for elemental speciation because of its excellent detection limits, its multielement capability, and its ability to measure isotope ratios (11-28).

In most experiments with plasma detection for liquid chromatography (LC) separations, the nebulizer is one of the weakest links in the whole process because it causes band broadening and loss of much of the sample (29). Several recent papers $(30,31)$ describe the basic properties and analytical performance of a new version of the direct injection nebulizer (DIN), originally developed by Fassel and co-workers $(32,33)$. The DIN is a microconcentric pneumatic nebulizer placed inside the ICP torch. The DIN has a low dead volume $(<2 \mu \mathrm{L})$ and produces a mist of fine droplets (1 - 10- $\mu \mathrm{m}$ diameter) (34). Rinse-out times for memory-prone elements such as $\mathrm{Hg}, \mathrm{I}$, and $\mathrm{B}$ are also reduced greatly compared to those obtained with 
conventional nebulizers (30). When used for LC-ICPMS of As, Se, and Sn species, the DIN provides absolute detection limits that are superior by $1-2$ orders of magnitude to those obtained with conventional nebulizers. In addition, the low dead volume and absence of a spray chamber minimize postcolumn band broadening and facilitate the use of microscale LC columns and liquid flow rates $\left(30-100 \mu \mathrm{L} \mathrm{min}{ }^{-1}\right)$ that are low enough for all the column effluent to be introduced into the plasma $(24,31)$.

The present work reports the capabilities of LC-DIN-ICPMS for measuring charged species of $\mathrm{Hg}$ and $\mathrm{Pb}$. The species chosen $\left(\mathrm{Hg}^{+2}, \mathrm{MeHg}^{+}, \mathrm{EtHg}^{+}, \mathrm{PhHg}^{+}\right.$, $\mathrm{Pb}^{+2},(\mathrm{Me})_{3} \mathrm{~Pb}^{+}$, and $\left.(\mathrm{Et})_{3} \mathrm{~Pb}^{+}\right)$, where $\mathrm{Me}=$ methyl, $\mathrm{Et}=$ ethyl, and $\mathrm{Ph}=$ phenyl, are known or potential toxins and are of substantial interest in medical and environmental sciences $(1,35-39)$. Optimum chromatographic conditions for separating these species as ion pairs by reversed-phase LC are discussed. Finally, application of this methodology for the speciation of $\mathrm{Hg}$ and $\mathrm{Pb}$ directly in human urine with very little sample preparation is described. 


\section{EXPERIMENTAL SECTION}

\section{ICPMS and Direct Injection Nebulizer (DIN)}

The inductively coupled plasma mass spectrometer used was the Elan Model 250 (Perkin-Elmer SCIEX, Thornhill, ON, Canada). The instrumental system and conditions are described in Table I. The plasma and sampling conditions indicated with an asterisk were optimized daily to maximize the signal from the analyte of interest.

The DIN used in this work was similar to one described previously (Figure 1 of ref. 30). In order to operate at a liquid flow rate of $100 \mu \mathrm{L} \mathrm{min}{ }^{-1}$ while maintaining low backpressure $(<750$ psi), a 50- $\mu$ m-i.d. $\times 45-\mathrm{cm}$-long fused silica capillary was used. In addition, the $50-\mu \mathrm{m}$ DIN plugged less easily than the $30-\mu \mathrm{m}$ one used for the previous LC work (24). Tolerance to plugging was necessary for the analysis of urine, since the salt matrix was not removed beforehand. The width of the annular gap between the inner capillary and the nebulizer tip was $\approx 25 \mu \mathrm{m}$, the same as in the previous work.

Instrumentation, Columns, and Mobile Phases

A digital LC pump (SSI Model 222D) with a bioclean microflow pump head (Scientific Systems, Inc., State College, PA) was employed. Samples were injected using a Rheodyne 7410 microinjector with a $2-\mu \mathrm{L}$ internal sample loop disk. The 
analytical column used in most of this work was a 5-cm-long, 1.6-mm-i.d. PEEK column packed with reversed-phase $\mathrm{C}_{18}$ material (CETAC Technologies, Omaha, NE). A similar but longer column $(15 \mathrm{~cm})$ was used for $\mathrm{Hg}$ speciation in urine. A precolumn filled with Adsorbosil silica (Alltech Association, Inc., Deerfield, IL) was placed between the pump and the analytical column to saturate the mobile phase with silica and to extend the lifetime of the analytical column. The outlet of the analytical column was connected through a switching valve (Rheodyne 9010) to the DIN with a narrow bore polysil tube (50- $\mu \mathrm{m}$-i.d. x 5-cm-long, Scientific Glass Enginerring, Inc., Austin, TX). The narrowbore connecting capillary minimized extracolumn band broadening.

Standard solutions for optimizing ICPMS conditions were loaded to a $1-\mathrm{mL}$ loop on the switching valve and then injected to the nebulizer. The fused silica capillary of the DIN was connected to the outlet of the switching valve. The outlet of the analytical column was directed to the DIN at all times except during optimization. A solution containing $5 \mathrm{mM}$ ammonium pentanesulfonate in $20: 80 \mathrm{v} / \mathrm{v}$ acetonitrile (ACN) - water served as the mobile phase. Separations were performed isocratically at a flow rate of $100 \mu \mathrm{L} \mathrm{min}$.

\section{Data Acquisition}

New Elan 500 upgraded hardware and software have been installed on this ICPMS. Data were acquired by peak hopping in the multielement monitoring mode 
using 0.5-s measurement time, a 20-ms dwell time, and 1 measurement per peak. The mass spectral resolution was $0.9 \mathrm{amu}$ at $10 \%$ peak height. The most abundant isotopes of $\mathrm{Hg}^{+}(\mathrm{m} / \mathrm{z}=202)$ and $\mathrm{Pb}^{+}(\mathrm{m} / \mathrm{z}=208)$ were monitored. The ICP operating conditions and voltages applied to the ion lenses were optimized to provide maximum signal for inorganic $\mathrm{Pb}$ at $100 \mu \mathrm{g} \mathrm{L}^{-1}$ and inorganic $\mathrm{Hg}$ at $250 \mu \mathrm{g} \mathrm{L}^{-1}$ in $20: 80 \mathrm{v} / \mathrm{v}$ ACN- $\mathrm{H}_{2} \mathrm{O}$.

Chromatograms were recorded in real time and stored on the hard disk of an IBM PS/2 Model 70 computer. These data (as ASCII files) were then processed using a spread sheet program. The raw count rates were first smoothed with a fivepoint Savitzky - Golay routine (40). Peak area was determined by summing all the count rates under each peak. The background was measured while nebulizing only the mobile phase by summing the total counts in the particular chromatographic region corresponding to each peak. For this work, the detection limit was defined as the amount of the element necessary to give a peak area equal to three times the standard deviation of the background count rate at each analyte mass.

\section{$\underline{\text { Reagents and Samples }}$}

The mobile phases were prepared as follows. Ion-pairing reagents S5 $(0.5 \mathrm{M}$ sodium pentanesulfonate), $\mathrm{S} 7(0.5 \mathrm{M}$ sodium heptanesulfonate) and S12 (0.5 M sodium dodecanesulfonate) were purchased from Regis Chemical Co. (Morton Grove, IL). Sodium salts in the eluent would be expected to cause plugging of the DIN (24), 
plugging of the sampling orifice (41-43), and matrix effects (usually suppression) on the signal for $\mathrm{Hg}^{+}$and $\mathrm{Pb}^{+}(42,44-48)$. Therefore, the ion-pairing reagents were converted to their ammonium salts by passing them through a column filled with cation-exchange resin Dowex 50W - X8 in the ammonium form. The nitrogen and hydrogen present in the ammonium cation did not deposit as solids on the sampler and did not cause serious matrix effects. The resulting stock solutions of ammonium salts of S5, S7 and S12 were then diluted with ACN (HPLC grade) and deionized water (DW). Nitric acid (5\%) and ammonium hydroxide (1 M) were added to adjust the pH. All mobile phases were filtered through a $0.45-\mu \mathrm{m}$-pore nylon filter and degassed under light vacuum from an aspirator for $10 \mathrm{~min}$. At the end of each working day, the LC system was flushed overnight with $75 \%$ methanol in water as instructed by the supplier.

Chloride salts of $\mathrm{MeHg}^{+}, \mathrm{EtHg}^{+}, \mathrm{PhHg}^{+},(\mathrm{Me})_{3} \mathrm{~Pb}^{+}$, and $\left(\mathrm{Et}_{3}\right)_{3} \mathrm{~Pb}^{+}$were obtained from Alfa Products (Danvers, MA) and were used without further purification. Stock solutions of various $\mathrm{Hg}$ and $\mathrm{Pb}$ compounds at $\approx 300 \mathrm{mg} \mathrm{L}^{-1}$ each were prepared from the above reagent-grade compounds in DW. Stock solutions of inorganic $\mathrm{Hg}$ and $\mathrm{Pb}$ at $100 \mathrm{mg} \mathrm{L}^{-1}$ each were prepared by diluting $1000 \mathrm{mg} \mathrm{L}^{-1}$ standards (PLASMACHEM Associates, Inc., Bradley Beach, NJ) in DW. All standards were prepared fresh daily by diluiing stock solutions using DW. ACN was HPLC grade from Fisher Scientific, DW (resistance $\approx 18 \mathrm{M} \Omega$ ) was obtained from a Barnstead Nanopure-II system (Newton, MA), and ethylenediaminetetraacetic acid 
(EDTA) was reagent grade from Fisher Scientific.

Two urine samples were used. First, a freeze-dried urine standard reference material (SRM 2670, National Institute of Standards and Technology, Gaithersburg, MD) was reconstituted as instructed and used without further dilution for $\mathrm{Pb}$ speciation in urine. Second, a 24-h human urine specimen was collected from the first author for $\mathrm{Hg}$ speciation. 
RESULTS AND DISCUSSION

\section{System Dead Volume and System Variance}

The general advantages of microbore columns compared to conventional packed columns include high separation efficiencies, better detection limits, decreased solvent consumption and lower costs, compatibility with on-line detectors like MS, and the possibility of using exotic mobile phases or reagents $(49,50)$. However, attention must be paid to the extracolumn volumes in connecting tubes, injector devices, and detectors; otherwise, the efficiency of a separation may be compromised by extracolumn broadening $(51,52)$. This problem is especially important for microbore columns operated at low liquid flow rates.

In chromatography, peak broadening is often expressed in terms of peak variance (53). In the simplest terms, the total variance of a peak is

$$
\sigma^{2}=\sigma_{\text {col }}^{2}+\sigma_{\text {sys }}^{2}
$$

where $\sigma_{\text {col }}{ }^{2}$ represents the contribution of the analytical column and $\sigma_{\mathrm{sys}}{ }^{2}$ is the contribution of the rest of the system (injector, connecting tubing, detector, etc.) to the peak variance. Here $\sigma_{\text {sys }}{ }^{2}$ is the juxtaposition of all broadening occurring outside the analytical column. For Gaussian peaks, $\sigma$ can be calculated from the full width at half-maximum $\left(\mathrm{W}_{1_{2}}\right)$ of the peak:

$$
\mathrm{W}_{1 / 2}=2.35 \sigma
$$

In this section, both the system dead volume $(\mu \mathrm{L})$ and $\sigma_{\text {sys }}{ }^{2}\left(\mathrm{~s}^{2}\right)$ are estimated to 
evaluate the contribution of the nebulizer to peak broadening relative to that from the chromatographic column.

The system dead volume was determined by adding known dead volumes and measuring the resulting effect on peak variance. Tubing of different sizes was used to connect the outlet of the analytical column to the switching valve. A $2-\mu \mathrm{L}$ sample containing $\mathrm{MeHg}^{+}\left(500 \mu \mathrm{g} \mathrm{Hg} \mathrm{L}^{-1}\right)$ was introduced to the 5-cm-long column. The mobile phase was 20:80 v/v ACN- $\mathrm{H}_{2} \mathrm{O}$, and no pairing reagent was used. Under these conditions, $\mathrm{MeHg}^{+}$was not retained and eluted at the void time.

A plot of $\sigma^{2}$ vs added volume is shown in Figure 1. Extrapolation to $\sigma^{2}=0$ gave the system dead volume. The system dead volume was found to be $1.6 \mu \mathrm{L}$, which was close to the value of $2 \mu \mathrm{L}$ estimated previously for the $50-\mu \mathrm{m}$ DIN (30).

Two methods were used to estimate the system variance. First, $\sigma_{\mathrm{sys}}{ }^{2}$ was estimated from the $y$-intercept of the plot in Figure 1 and was found to be $4.1 \mathrm{~s}^{2}$. Second, $\sigma_{\text {sys }}{ }^{2}$ was estimated using flow injection peaks. In this method, the analytical column was removed from the HPLC system, that is, the injector was connected directly to the switching valve (by a polysil tube) which was connected to the DIN. A 2- $\mu \mathrm{L}$ sample of $\mathrm{MeHg}^{+}\left(500 \mu \mathrm{g} \mathrm{Hg} \mathrm{L}^{-1}\right)$ and $\mathrm{AuCl}_{4}^{-1}\left(100 \mu \mathrm{g} \mathrm{Au} \mathrm{L}^{-1}\right)$ was injected to the plasma. The carrier solvent contained $\mathrm{S} 5$ at $5 \mathrm{mM}$ in $20: 80 \mathrm{v} / \mathrm{v} A C N-\mathrm{H}_{2} \mathrm{O}$. The standard deviations of these measurements were determined by five replicate injections.

The peak asymmetry factors measured at $10 \%$ peak height (54) were $1.3 \pm$ 
0.2 for $\mathrm{MeHg}^{+}$and $1.2 \pm 0.1$ for $\mathrm{Au}$. Thus, the flow injection peaks were approximately Gaussian, and the $W_{1 / 2}$ values for these flow injection peaks could be used to calculate $\sigma_{\mathrm{xy}}$ and $\sigma_{\mathrm{zy}}{ }^{2}$ for $\mathrm{MeHg}^{+}$and Au respectively. The system variance was found to be $5.0 \pm 0.3 \mathrm{~s}^{2}$ for $\mathrm{MeHg}^{+}$and $4.0 \pm 0.2 \mathrm{~s}^{2}$ for Au. The chromatographic peak for $\mathrm{MeHg}^{+}$shown subsequently (e.g., Figure 2) had a variance of $\sigma^{2} \approx 56 \mathrm{~s}^{2}$. Thus, the estimated value of $\sigma_{\mathrm{xyt}}{ }^{2}=4-5 \mathrm{~s}^{2}$ indicated that most of the peak broadening was caused by the column, and less than $5 \%$ of the peak broadening was caused by the DIN.

\section{Chromatographic Conditions}

When coupling HPLC with ICPMS by the DIN, the separation conditions must be carefully selected so that the analytical performance of the nebulizer and plasma are not compromised. The composition and flow rate of the mobile phase are particularly important $(24,30)$.

The effect of the $\Lambda C N$ concentration $(v / v)$ in the mobile phase on the peak shape was studied. Results for $\mathrm{MeHg}^{+}$are given in Figure 2. A 2- $\mu \mathrm{L}$ sample containing $\mathrm{MeHg}^{+}, \mathrm{EtHg}^{+}$, and $\mathrm{PhHg}^{+}\left(500 \mu \mathrm{g} \mathrm{Hg} \mathrm{L}^{-1}\right.$ for each species) was injected to the $5-\mathrm{cm}-$ long column. The pairing reagent used was $5 \mathrm{mM} \mathrm{S5}$. Figure 2 shows that the overall peak broadening and retention time of $\mathrm{MeHg}^{+}$were sensitive to the percentage of $\mathrm{ACN}$ in the mobile phase. With more $\mathrm{ACN}$ present, the $\mathrm{MeHg}^{+}$peak became sharper and retention time was reduced. In fact, $\mathrm{W}_{1 / 2}$ increased by $150 \%$ 
from $40 \%$ ACN to $10 \%$ ACN. Although not shown in Figure 2, the same effect was also found for $\mathrm{EtHg}^{+}$and, to a lesser extent, for $\mathrm{PhHg}^{+}$.

Figure 3 shows the effect of various ion-pairing reagents on the peak shape of $\mathrm{MeHg}^{+}$. Each reagent was present at $5 \mathrm{mM}$ in 20:80 v/v ACN- $\mathrm{H}_{2} \mathrm{O}$. There were no significant differences in peak shapes obtained with S5 and S7. However, S12 broadened the peak greatly, so this reagent was not used further. When the concentration of S5 in $20 \%$ ACN (v/v) was varied from 5 to $20 \mathrm{mM}$, and the $\mathrm{pH}$ was varied from 3.0 to 6.5 , no significant effect on peak shape was observed.

The effect of the percentage of $\mathrm{ACN}$ in the mobile phase on retention time for two trialkyllead and three organomercury compounds was also studied (Figures 4a,b). As expected, the retention decreased as the concentration of the organic modifier increased. In particular, the percentage of $\mathrm{ACN}$ exerted a stronger effect on the retention times of the compounds with the large organic groups (i.e., $\mathrm{PhHg}^{+}$and $\left.(\mathrm{Et})_{3} \mathrm{~Pb}^{+}\right)$. In the separation of the organomercury compounds, even though good separations were achieved using $5 \% \mathrm{ACN}$, the peaks were broad (Figure 2). On the other hand, sharp peaks were achieved using $40 \% \mathrm{ACN}$, when each $\mathrm{Hg}$ species was injected individually, but the peaks from the mixture of the three $\mathrm{Hg}$ species could not be resolved.

The effect of flow rate and percentage of ACN on ion signal with the DIN has been described elsewhere (24). No green $C_{2}$ emission was observed visually from the plasma when the solvent contained less than $50 \% \mathrm{ACN}$. The plasma stayed on and 
remained stable when $75 \%$ ACN was nebulized, but carbon deposition $(55,56)$ on the sampling cone did cause substantial signal drift. In addition, maximum ion signal was attained when the DIN was operated at a liquid flow rate of $\approx 120 \mu \mathrm{L} \mathrm{min}{ }^{-1}$ and when a solvent containing $15-25 \%$ ACN was nebulized. Fortunately, this mobilephase composition also suppressed tailing of the chromatographic peak, as shown in curve $\mathrm{b}$ of Figure 2. Finally, at a liquid flow rate of $120 \mu \mathrm{L} \mathrm{min}{ }^{-1}$, the rinse-out time for $\mathrm{Hg}$ in $2 \% \mathrm{HNO}_{3}$ was $15 \mathrm{~s}$ or less (30).

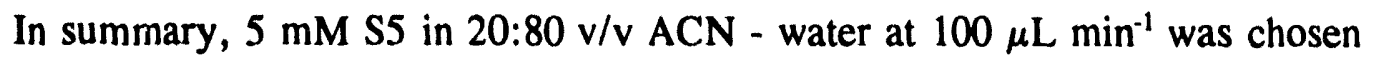
as the optimum mobile phase and liquid flow rate. These conditions represent a compromise between maximum sensitivity, reasonable rinse-out time, reasonable separation time, and resolution. The performance of plasma-based detection methods for LC is generally sensitive to the composition and flow rate of the mobile phase $(6,11)$, and ICPMS with the DIN is no exception.

\section{Speciation of $\mathrm{Hg}$ and $\mathrm{Pb}$ Compounds in a Test Mixture}

An aqueous test mixture containing $\mathrm{MeHg}^{+}, \mathrm{EtHg}^{+}, \mathrm{PhHg}^{+},(\mathrm{Me})_{3} \mathrm{~Pb}^{+}$, and $(\mathrm{Et})_{3} \mathrm{~Pb}^{+}$was prepared. A separation of these species in a single injection is shown in

Figure 5. The analytical figures of merit under these separation conditions are shown in Tables II and III.

The peaks for $(\mathrm{Me})_{3} \mathrm{~Pb}^{+}$and $(\mathrm{Et})_{3} \mathrm{~Pb}^{+}$were easily resolved, and the separation was completed in less than 3 min (Figure 5). Peak area measurements indicated that 
the $\mathrm{Pb}$ sensitivity (total counts / pg Pb) was similar (i.e., within 5\%) for the two forms (Table II). Precision based on five separate injections of $\approx 40 \mathrm{pg}$ (as $\mathrm{Pb}$ ) of each species and measurement of peak areas was better than 2\% RSD for both species. Calibration curves for each species based on peak areas from injections of $0.04,0.1,0.4$, and $1 \mathrm{ng}$ (as $\mathrm{Pb}$ ) were all linear with correlation coefficients of 0.9998 for $(\mathrm{Me})_{3} \mathrm{~Pb}^{+}$and 0.9993 for $(\mathrm{Et})_{3} \mathrm{~Pb}^{+}$. Absolute detection limits were $\approx 0.2 \mathrm{pg} \mathrm{Pb}$ for both species (Table II). These absolute detection limits were superior by $1-4$ orders of magnitude over those obtained previously by electrochemical detection (57), UV-vis absorption (58), ICPAES $(25,59)$, and LC-ICPMS (25). Relative detection limits for $\mathrm{Pb}$ species were $\approx 0.1 \mu \mathrm{g} \mathrm{L}$.

In the separation of organomercury species, previous work $(27,60)$ reported a high background for $\mathrm{Hg}$, presumably due to bleeding of species containing $\mathrm{Hg}$ from the column or to memory effects in the spray chamber or desolvation system of the nebulizer. For the present work, the $\mathrm{Hg}$ background was $\approx 100$ counts/s, which was comparable to the background usually seen at $\mathrm{m} / \mathrm{z} \approx 200$ when the DIN is used with this particular ICPMS device (30). The PEEK column and tubing used and the ability of the DIN to operate without a spray chamber probably helped keep the $\mathrm{Hg}$ background at a reasonable level. However, the $\mathrm{Hg}$ peaks had longer tails than the $\mathrm{Pb}$ peaks, presumably due to some memory for $\mathrm{Hg}$ in either the column or the DIN. Despite this tailing, the peaks for $\mathrm{MeHg}^{+}, \mathrm{EtHg}^{+}$, and $\mathrm{PhHg}^{+}$were resolved adequately (Figure 5). 
Peak area measurements indicated that sensitivity (total counts / pg $\mathrm{Hg}$ ) was similar for all three forms of $\mathrm{Hg}$ (Table III). Precision based on five separate injections of $\approx 2 \mathrm{ng}$ (as $\mathrm{Hg}$ ) of each species and measurement of peak areas was $\approx$ 3\% RSD for all three species. Calibration curves for each species based on injections of $0.2,0.5,2,5$, and $10 \mathrm{ng}$ (as $\mathrm{Hg}$ ) and peak areas were all linear with correlation coefficients 0.9995 or better. Absolute detection limits were $\approx 7 \mathrm{pg}$ of $\mathrm{Hg}$ for all three forms (Table III). These absolute detection limits were superior by factors of 5 - 1000 over those obtained previously by LC-cold vapor ICPMS (27), LC-ICPMS (27), and LC-ICPAES (61). The improvement in absolute detection limits is expected because all of the sample reaches the plasma with the DIN. Relative detection limits for all three forms were $\approx 4 \mu \mathrm{g} \mathrm{L}^{-1}$, which are comparable to those obtained with conventional nebulizers.

\section{Pb Speciation in Freeze-Dried Urine}

The proposed method was tested for measurement of $\mathrm{Pb}$ and $\mathrm{Hg}$ species in human urine. The NIST SRM 2670 freezed-dried urine (normal level) was used for experiments in $\mathrm{Pb}$ speciation. Inorganic $\mathrm{Pb}^{+2}$ was retained permanently on the column; presumably, the reversed-phase column was not completely end-capped, a problem noted previously (11). The $\mathrm{Pb}^{+2}$ was removed by flushing the column with EDTA, which yielded a substantial $\mathrm{Pb}$ signal that was well above the $\mathrm{Pb}$ background of $\approx 200$ counts $/ \mathrm{s}$ in EDTA. In order to elute the $\mathrm{Pb}^{+2}$, excess EDTA was added to 
the urine sample before injection to ensure a metal to ligand molar ratio of 1:50 or larger. Background was determined by injecting a blank containing the same amount of EDTA as in the urine sample.

Chromatograms for the separation of inorganic $\mathrm{Pb}$ and two trialkyllead species spiked into urine are given in Figure 6. Injection 1 shows the peak for $\mathrm{Pb}^{+2}$ in NIST SRM 2670 freeze-dried urine (normal level). Only the inorganic peak was found. Using a standard addition method, the sample was found to contain $10.3 \mu \mathrm{g} \mathrm{L}^{-1}$ of $\mathrm{Pb}$, which is close to the suggested value $\left(10 \mu \mathrm{g} \mathrm{L}^{-1}\right)$ from NIST.

Since the NIST SRM did not contain measurable levels of $(\mathrm{Me})_{3} \mathrm{~Pb}^{+}$and $(\mathrm{Et})_{3} \mathrm{~Pb}^{+}$, these compounds were spiked into the NIST urine to test the suitability of the method for this separation in the presence of a difficult matrix. Injection 2 of Figure 6 shows the separation of all three $\mathrm{Pb}$ species. The retention times for the two trialkyllead species remained the same as in their separation from a simple aqueous test mixture (Table II). Peak area measurements showed that sensitivity was similar for all three forms and was comparable (within 10\%) to those obtained for $\mathrm{Pb}$ species in the test mixture. The reproducibility of the peak areas was better than 3\% RSD (n =3). Absolute detection limits were $0.2 \mathrm{pg}$ for all three $\mathrm{Pb}$ compounds in urine. In injection 2, the peak height for $\mathrm{Pb}^{+2}$ was the same as that in injection 1. Also, reasonable chromatographic peaks were seen for $(\mathrm{Me})_{3} \mathrm{~Pb}^{+}$and $(\mathrm{Et})_{3} \mathrm{~Pb}^{+}$. These observations showed that the use of EDTA to prevent permanent retention of $\mathrm{Pb}^{+2}$ did not disturb the relative amounts of the alkyllead ions or perturb their chromatographic 
behavior. Undesired interconversions between different chemical forms of an element or inștability of particular species are common problems in speciation experiments. The simple procedure for preparing the sample (i.e., mere dilution) also may help prevent problems from interconversion or instability of the species present (62).

\section{He Speciation in 24-h Human Urine}

A 24-h (63) urine specimen ( $\approx 2 \mathrm{~L}$ ) from the first author was analyzed for $\mathrm{Hg}$ species. A chromatogram from one injection of the urine specimen is given in Figure 7. Only the inorganic mercury peak was found. Using a standard addition method, the specimen was found to contain $25 \mu \mathrm{g} \mathrm{L} \mathrm{L}^{-1}$ of inorganic mercury. The total mercury content of this urine sample was determined to be $28 \mu \mathrm{g} \mathrm{L}^{-1}$ by flow injection and standard addition, i.e., no chromatographic column was employed. None of the organomercury ions were present at sufficient concentrations to be observed directly in urine, as was the case for the organolead ions described in the preceding section. A preliminary preconcentration procedure would be required to see these species (64).

The chromatographic procedure described in the present work was evaluated further by the following spike experiment. Another urine aliquot was diluted by a factor of 10 with deionized water and spiked with $0.75 \mathrm{ng} \mathrm{of} \mathrm{Hg}^{+2}$ and $2 \mathrm{ng}$ (as $\mathrm{Hg}$ ) of each of the alkylmercury species. The dilution minimized the matrix effect of $\mathrm{Na}$ on $\mathrm{Hg}$ signal. A longer coiumn $(15 \mathrm{~cm})$ was also required to resolve the $\mathrm{Hg}^{+2}$ peak from that for $\mathrm{MeHg}^{+}$. 
Figure 8 shows the separation of these three $\mathrm{Hg}$ compounds in urine. Since a longer column was used, the retention times for $\mathrm{MeHg}^{+}$and $\mathrm{EtHg}^{+}$were almost twice as long as those reported for $\mathrm{Hg}$ speciation in the aqueous test mixture. Peak area measurements indicated that the sensitivity for $\mathrm{Hg}^{+2}$ was similar to that obtained for the $\mathrm{Hg}$ species in the simple aqueous solution. However, the sensitivities for $\mathrm{MeHg}^{+}$ and $\mathrm{EtHg}^{+}$were reduced by a factor of 2 in the urine matrix, presumably due to matrix suppression from $\mathrm{Na}(\approx 1000 \mathrm{ppm} \mathrm{Na})$. With the anionic pairing reagent in the eluent, $\mathrm{Na}^{+}$was weakly retained and eluted at $\approx 2 \mathrm{~min}$ after the sample was injected, i.e., after the $\mathrm{Hg}^{+2}$ peak but before the subsequent peaks for $\mathrm{MeHg}^{+}$and $\mathrm{EtHg}^{+}$. Thus, sensitivity for $\mathrm{Hg}^{+2}$ was not affected by the urine matrix, because the $\mathrm{Na}$ from the urine had not yet reached the plasma when $\mathrm{Hg}^{+2}$ eluted. In contrast, because of the tail on the $\mathrm{Na}^{+}$chromatographic peak, some $\mathrm{Na}$ was present in the plasma when $\mathrm{MeHg}^{+}$and $\mathrm{EtHg}^{+}$eluted. Hence, the $\mathrm{Hg}^{+}$signal from these species was diminished by a matrix effect caused by Na. For this separation, the precision was still $5 \%$ RSD or better $(n=3)$. Absolute detection limits were $7-18 \mathrm{pg}$ of $\mathrm{Hg}$ for the three $\mathrm{Hg}$ compounds in urine.

As a final note, the reversed-phase ion-pairing separation reported here proved remarkably robust and resilient even when a difficult matrix (urine) was analyzed. Chromatographic retention times were not affected by repeated injections of the urine matrix. Chromatographic resolution (53) was only slightly poorer in the presence of the urine matrix than that obtained for the test solutions. For example, the resolution 
between $(\mathrm{Me})_{3} \mathrm{~Pb}^{+}$and $(\mathrm{Et})_{3} \mathrm{~Pb}^{+}$peaks was 3.7 in Figure 5 (for the test solution) compared to 3.0 in Figure 6 (for the spiked urine matrix). 


\section{LITERATURE CITED}

1. Goyer, R. A. In Casarett and Doull's Toxicology: The Basic Science of Poisons, 4th ed.; Casarett, L. J.; Amdur, M. O.; Doull, J.; Klaassen, C. D., Eds.; Pergamon Press: New York, 1991; Chapter 19.

2. Cappon, C. J. LC/GC 1988, 6, 584-599.

3. Batley, G. E.; Low, G. K.-C. In Trace Element Speciation Analytical Methods and Problems; Batley, G. E., Ed.; CRC Press, Inc.: Boca Raton, Florida, 1989; Chapter 9.

4. Gardiner, P. E. J. Anal. At. Spectrom. 1988, 3, 163-168.

5. Uden P. C., Ed. Element - Specific Chromatographic Detection by Atomic Emission Spectroscopy; American Chemical Society: Washington, D.C., 1992.

6. Krull, I. S., Ed. Trace Metal Analysis and Speciation; Elsevier: New York, 1991.

7. Keliher, P. N.; Ibrahim, H.; Gerth, D. J. Anal. Chem. 1990, 62, 184R212R.

8. Harrison, R. M.; Rapsomanikis, S., Eds. Environmental Analysis Using Chromatography Interfaced with Atomic Spectroscopy; Ellis Horwood Ltd.: Chichester, U. K., 1989.

9. Keliher, P. N.; Gerth, D. J.; Snyder, J. L.; Wang, H.; Zhu, S. F. Anal. Chem. 1988, 60, 342R-368R. 
10. Ebdon, L.; Hill, S.; Ward, R. W. Analyst 1987, 112, 1-16.

11. Thompson, J. J.; Houk, R. S. Anal. Chem. 1986, 58, 2541-2548.

12. Jiang, S. J.; Houk, R. S. Spectrochim. Acta 1988, 43B, 405-411.

13. Dean, J. R.; Munro, S.; Ebdon, L.; Crews, H. M.; Massey, R. C. J. Anal. At. Spectrom. 1987, 2, 607-610.

14. Matz, S. G.; Elder, R. C.; Tepperman, K. J. Anal. At. Spectrom. 1989, 4, $767-771$.

15. Crews, H. M.; Dean, J. R.; Ebdon, L.; Massey, R. C. Analyst 1989, 114, 895-899.

16. Beauchemin, D.; Bednas, M. E.; Berman, S. S.; McLaren, J. W.; Siu, K. W. M.; Sturgeon, R. E. Anal. Chem. 1988, 60, 2209-2212.

17. Beauchemin, D.; Siu, K. W. M.; McLaren, J. W.; Berman, S. S. J. Anal. At. Spectrom. 1989, 4, 285-289.

18. Heitkemper, D.; Creed, J.; Caruso, J.; Fricke, F. L. J. Anal. At. Spectrom. $1989,4,279-284$.

19. Sheppard, B. S.; Shen, W.-L.; Caruso, J. A.; Heitkemper, D. T.; Fricke, F. L. J. Anal. At. Spectrom. 1990, 5, 431-435.

20. Shibata, Y.; Morita, M. Anal. Sci. 1989, 5, 107-109.

21. Shibata, Y.; Morita, M. Anal. Chem. 1989, 61, 2116-2118.

22. Suyani, H.; Creed, J.; Davidson, T.; Caruso, J. J. Chromatogr. Sci. 1989, $27,139-143$ 
23. Suyani, H.; Heitkemper, D.; Creed, J.; Caruso, J. Appl. Spectrosc. 1989, 43, 962-967.

24. Shum, S. C. K.; Neddersen, R.; Houk, R. S. Analyst 1992, 117, 571-575.

25. Al-Rashdan, A.; Heitkemper, D.; Caruso, J. J. Chromatogr. Sci. 1991, 29, 98-102.

26. Gercken, B.; Barnes, R. M. Anal. Chem. 1991, 63, 283-287.

27. Bushee, D. S. Analyst 1988, 113, 1167-1170.

28. Bushee, D. S.; Moody, J. R.; May, J. C. J. Anal. At. Spectrom. 1989, 4, 773-775.

29. Browner, R. F.; Boorn, A. W. Anal. Chem. 1984, 56, 786A-798A.

30. Wiederin, D. R.; Smith, F. G.; Houk, R. S. Anal. Chem. 1991, 63, 219225.

31. Houk, R. S.; Shum, S. C. K.; Wiederin, D. R. Anal. Chim. Acta 1991, 250, $61-70$.

32. Lawrence, K. E.; Rice, G. W.; Fassel, V. A. Anal. Chem. 1984, 56, 289292.

33. LaFreniere, K. E.; Fassel, V. A.; Eckels, D. E. Anal. Chem. 1987, 59, 879887.

34. Wiederin, D. R.; Houk, R. S. Appl. Spectrosc. 1991, 45, 1408-1412.

35. Cox, C.; Clarkson, T. W.; Marsh, D. O.; Amin-Zaki, L.; Tikriti, S.; Myers, G. G. Environ. Res. 1989, 49, 318-332. 
36. Friberg, L.; Vostal, J. Mercury in the Environment; CRC Press: Cleveland, 1972.

37. Grandjean, P. Biological Effects of Organolead Compounds; CRC Press: Boca Raton, FL, 1984.

38. Mahaffey, K. R., Ed. Dietary and Environmental Lead: Human Health Effects; Elsevier Scientific: New York, N. Y., 1985.

39. Beockx, R. L. Anal. Chem. 1986, 58, 274A-288A.

40. Savitzky, A.; Golay, M. J. E. Anal. Chem. 1964, 36, 1627-1639.

41. Olivares, J. A.; Houk, R. S. Anal. Chem. 1986, 58, 20-25.

42. Jiang, S. -J.; Houk, R. S. Anal. Chem. 1986, 58, 1739-1743.

43. Douglas, D. J.; Kerr, L. A. J. Anal. At. Spectrom. 1988, 3, 749-752.

44. Tan, S. H.; Horlick, G. J. Anal. At. Spectrom. 1987, 2, 745-763.

45. Beauchemin, D.; McLaren, J. W.; Berman, S. S. Spectrochim. Acta 1987, $42 B, 467-490$.

46. Gregoire, D. C. Spectrochim. Acta 1987, 42B, 895-907.

47. Vandecasteele, C.; Nagels, M.; Vanhoe, H.; Dams, R. Anal. Chim. Acta 1988, 211, 91-98.

48. Crain, J. S.; Houk, R. S.; Smith, F. G. Spectrochim. Acta 1988, 43B, 13551364.

49. Novotny, M. LC Mag. 1985, 3, 876-886. 
50. Guiochon, G.; Colin, H. In Microcolumn High-Performance Liquid

Chromatography; Kucera, P., Ed.; Elsevier: New York, 1984; Chapter 1.

51. Saito, M.; Hibi, K.; Ishii, D.; Takeuchi, T. In Introduction to Microscale

High-Performance Liquid Chromatography; Ishii, D., Ed.; VCH Publishers:

New York, N. Y., 1988; Chapter 2.

52. Gluckman, J. C.; Novotny, M. In Microcolumn Separations: Columns,

Instrumentation, and Ancillary Techniques; Novotny, M. V.; Ishii, D., Eds.; Elsevier: New Ycrk, 1985; pp. 57-72.

53. Fritz, J. S.; Schenk, G. H. Quantitative Analytical Chemistry; Allyn and Bacon, Inc.: Newton, MA, 1987; Chapter 21.

54 Kirkland, J. J.; Yau, W. W.; Stoklosa, H. J.; Dilks, C. H. J. Chromatogr. Sci. 1977, 15, 303-316.

55. Hutton, R. C. J. Anal. At. Spectrom. 1986, 1, 259-263.

56. Hausler, D. Spectrochim. Acta 1987, 42B, 63-73.

57. MacCrehan, W. A.; Durst, R. A.; Bellama, J. M. Anal. Lett. 1977, 10, 1175-1188.

58. Blaszkiewicz, M.; Baumhoer, G.; Neidhart, B. Fresenius' Z. Anal. Chem. 1984, 317, 221-225.

59. Ibrahim, M.; Nisamaneepong, W.; Hass, H. L.; Caruso, J. A. Spectrochim. Acta 1985, 40B, 367-376. 
60. Houk, R. S.; Jiang, S. J. In Trace Metal Analysis and Speciation; Krull, I. S., Ed.; Elsevier: New York, 1991; Chapter 5.

61. Krull, I. S.; Bushee, D. S.; Schleicher, R. G.; Smith, S. B., Jr. Analyst 1986, $111,345-349$.

62. Sheppard, B.; Caruso, J.; Heitkemper, D.; Wolnick, K. Analyst, i992, 117, 971-976.

63. Jacobs, D. S.; Kasten, B. L., Jr.; Demott, W. R.; Wolfson, W. L. Laboratory Test Handbook with DRG Index; Lexi-Comp Inc.: Ohio, 1984; p.514.

64. Blaszkiewicz, M.; Baumhoer, G.; Neidhart, B. Fresnius' Z. Anal. Chem. 1986, 325, 129-135. 
71

Table I. Instrument Conditions and Operating Procedures

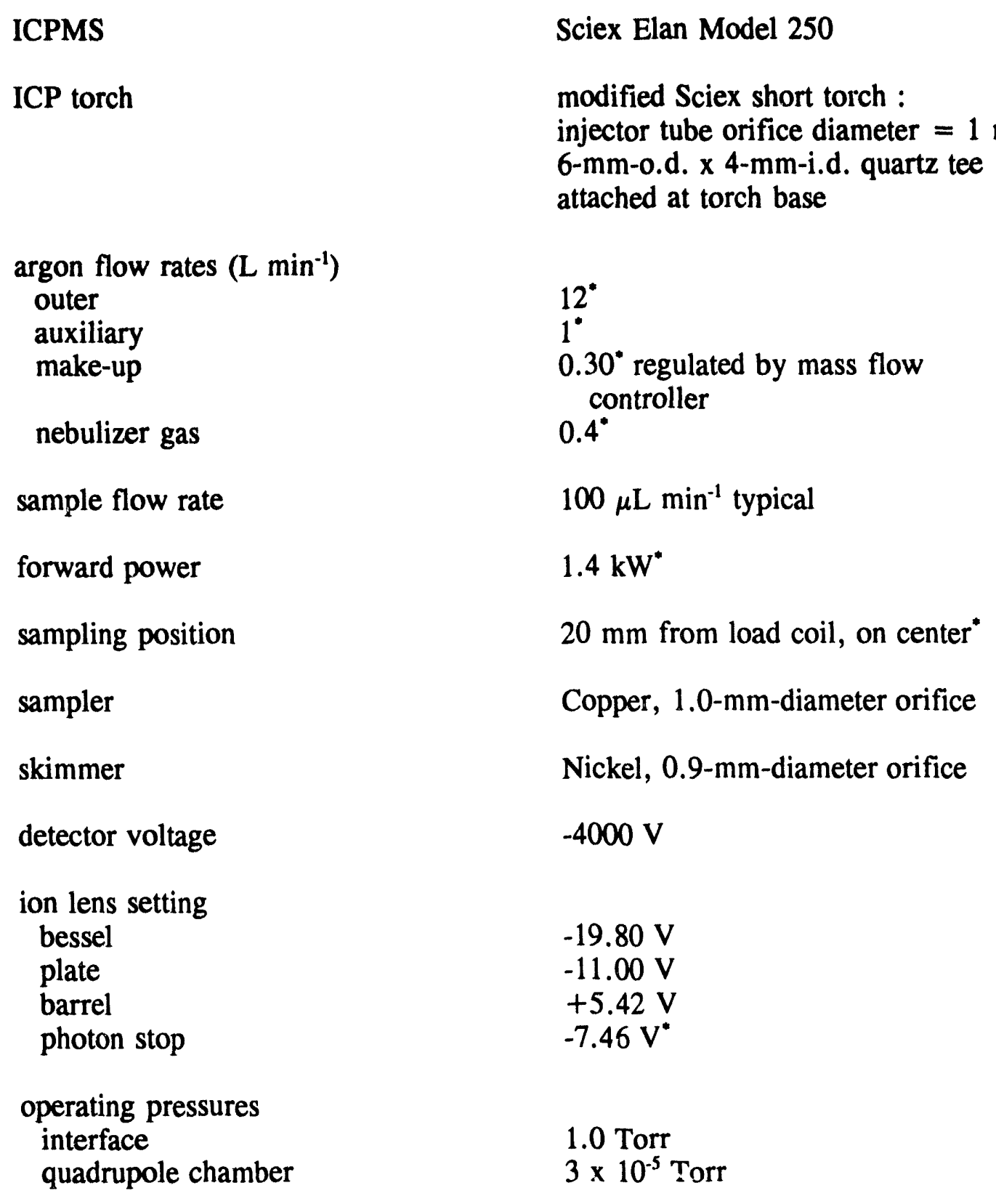

- Typical values cited. These parameters were adjusted daily to maximize ion signal (see text) and differed slightly from day to day. 
Table II. Analytical Figures of Merit for the Separation of Lead Species
$\mathrm{Pb}^{+2}$
$(\mathrm{Me})_{3} \mathrm{~Pb}^{+}$
$(\mathrm{Et})_{3} \mathrm{~Pb}^{+}$

(A) In Aqueous Sample (Figure 5)
retention time (min)
0.9
2.0
sensitivity^ (counts/pg of $\mathrm{Pb}$ )
$\operatorname{RSD}^{b}(\%)$
750
730
1.7
2.0
detection limits :
(pg of $\mathrm{Pb}$ )
$\left(\mu \mathrm{g} \mathrm{L}^{-1}, \mathrm{ppb}\right)$
$\begin{array}{ll}- & 0.2 \\ - & 0.1\end{array}$
0.2
0.1

(B) In Urine (Figure 6)

retention time (min)

0.6

9.9

2.0

sensitivity" (counts/pg of $\mathrm{Pb}$ )

850

800

750

$\operatorname{RSD}^{d}(\%)$

2.8

1.7

2.5

detection limits :

(pg of $\mathrm{Pb}$ )

$\left(\mu \mathrm{g} \mathrm{L}^{-1}, \mathrm{ppb}\right)$

0.2

0.2

0.2

0.1

0.1

0.1

- Sensitivity was calculated based on peak area and amount injected. ${ }^{\mathrm{b}}$ Relative standard deviation of peak area for five replicate injections of $40 \mathrm{pg}$ (as $\mathrm{Pb}$ ) of each species. See Figure 5 for LC conditions. ' Detection limit defined as amount of $\mathrm{Pb}$ required to yield a net peak that was 3 times the standard deviation of background. Peak areas were used in these calculations. ${ }^{d}$ Relative standard deviation of peak area for three replicate injections of SRM $2670+40 \mathrm{pg}$ (as $\mathrm{Pb}$ ) spike of each of the trialkyllead species. See Figure 6 for HPLC conditions. 
Table III. Analytical Figures of Merit for the Separation of Mercury Species

$\mathrm{Hg}^{+2} \quad \mathrm{MeHg}^{+} \quad \mathrm{EtHg}^{+} \quad \mathrm{PhHg}^{+}$

(A) In Aqueous Sample (Figure 5)

$\begin{array}{lllll}\text { retention time (min) } & - & 1.2 & 1.8 & 4.4 \\ \text { sensitivity (counts/pg of } \mathrm{Hg}) & - & 30 & 35 & 37 \\ \operatorname{RSD}^{\mathrm{b}}(\%) & - & 2.7 & 2.8 & 3.0 \\ \begin{array}{l}\text { detection limits } \\ (\mathrm{pg} \mathrm{of} \mathrm{Hg})\end{array} & - & & & \\ \left(\mu \mathrm{g} \mathrm{L}^{-1}, \mathrm{ppb}\right) & - & 7 & 7 & 6 \\ \end{array}$

B) In Urine (Figure 8)

\begin{tabular}{lcccc} 
retention time $(\mathrm{min})$ & 1.7 & 2.8 & 4.7 & - \\
sensitivity $($ counts/pg of $\mathrm{Hg})$ & 30 & 13 & 16 & - \\
$\operatorname{RSD}^{\mathrm{d}}(\%)$ & 3.7 & 3.8 & 4.1 & - \\
$\begin{array}{l}\text { detection limits } \\
(\mathrm{pg} \mathrm{of} \mathrm{Hg})\end{array}$ & 7 & 18 & 16 & - \\
$\left(\mu \mathrm{g} \mathrm{L}^{-1}, \mathrm{ppb}\right)$ & 4 & 9 & 8 & - \\
\hline
\end{tabular}

- Sensitivity was calculated based on peak area and amount injected. ${ }^{b}$ Relative standard deviation of peak area for five replicate injections of $2 \mathrm{ng}$ (as $\mathrm{Hg}$ ) of each species. See Figure 5 for LC conditions. ' required io yield a net peak that was 3 times the standard deviation of background. Peak areas were used in these calculations. ${ }^{\mathrm{d}}$ Relative standard deviation of peak area for three replicate injections of diluted urine spiked with $\mathrm{Hg}^{+2}, \mathrm{MeHg}^{+}$, and $\mathrm{EtHg}^{+}$. See Figure 7 for HPLC conditions. 


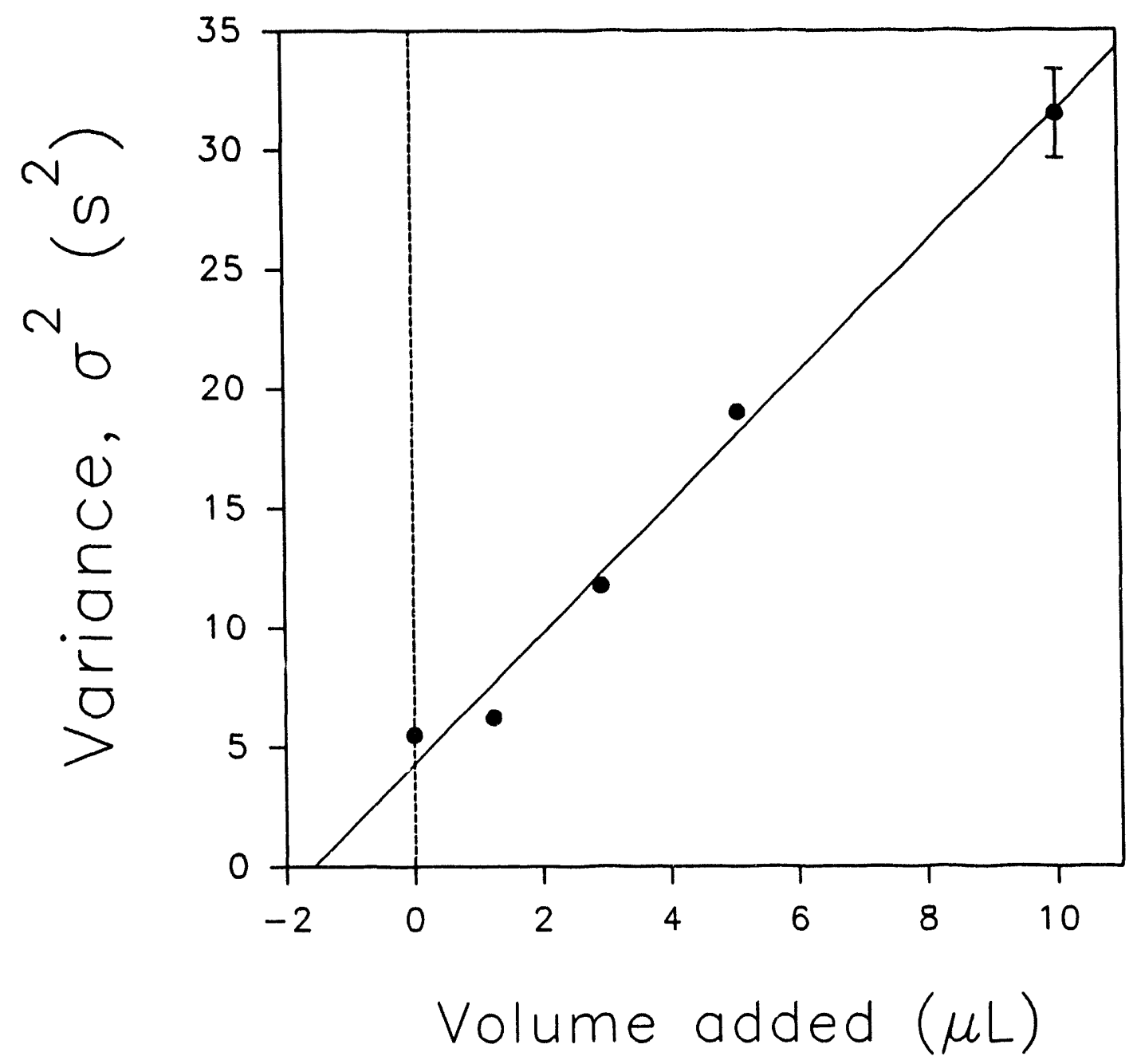

Figure 1. Determination of system dead volume and system variance. The line represents a least squares fit. See text for conditions 


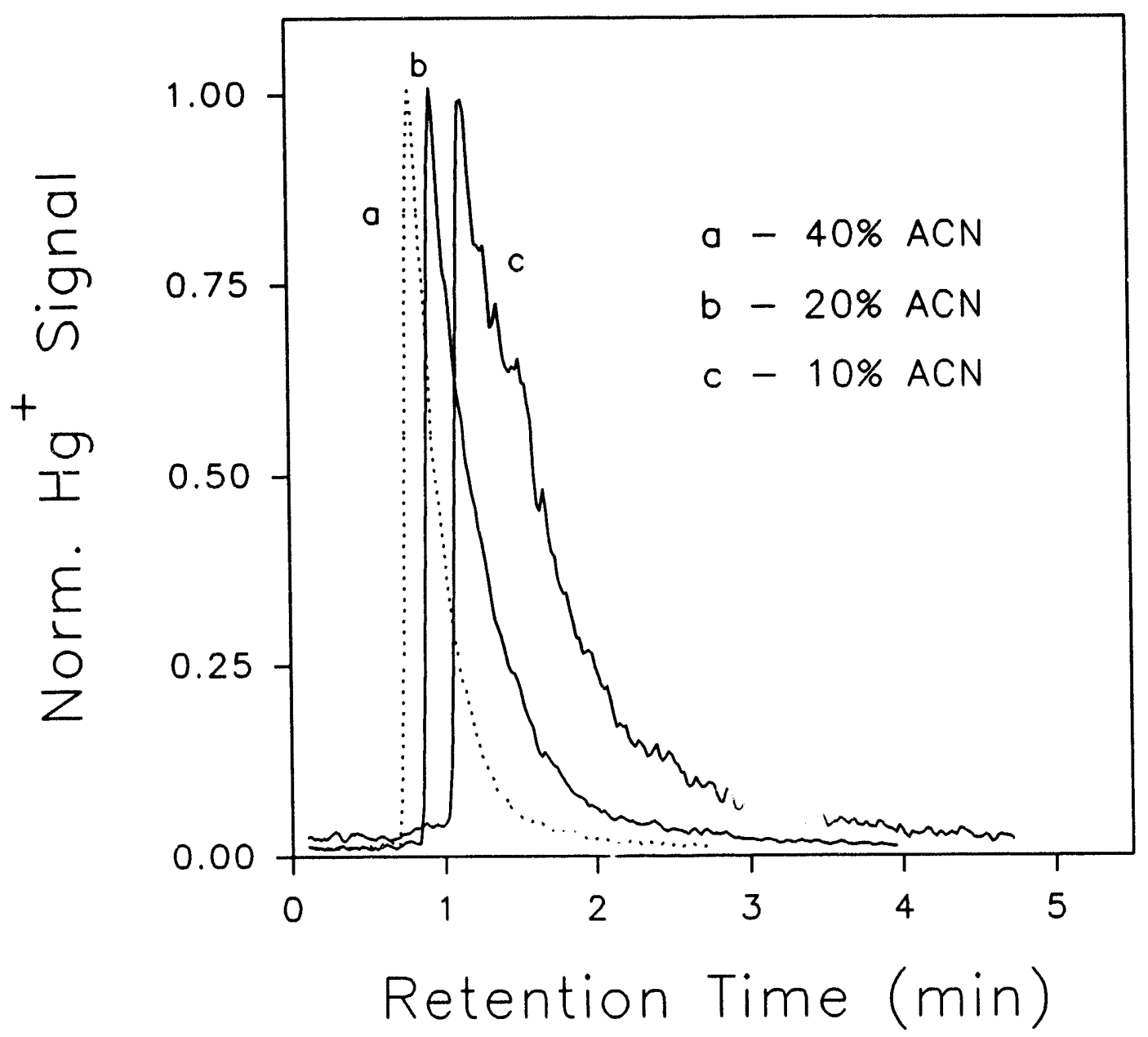

Figure 2. Effect of $\mathrm{ACN}$ percentage on peak shape for $\mathrm{MeHg}^{+}$. Each peak is normalized to the same maximum value so that the peak widths can be compared readily. See text for conditions. 


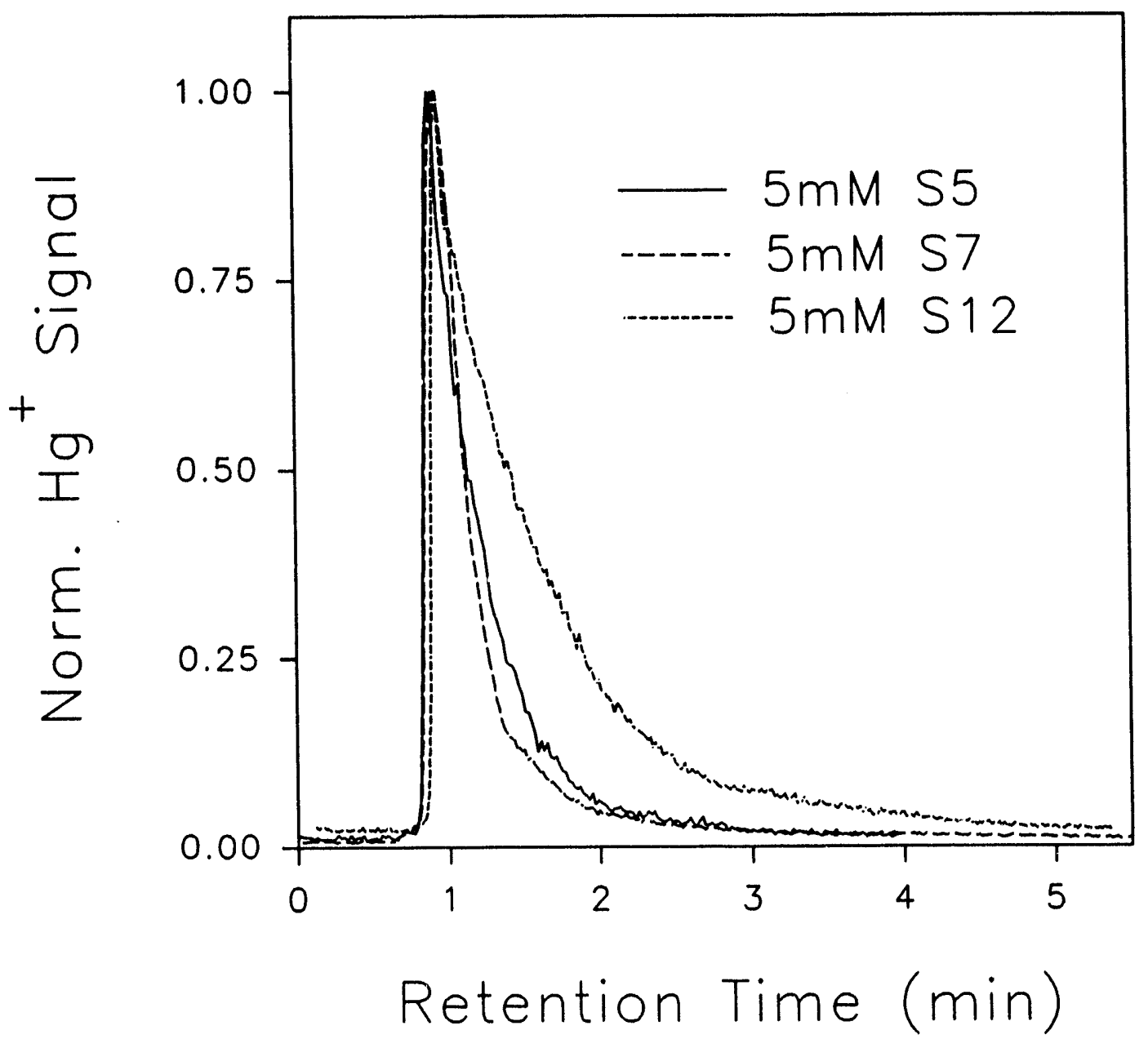

Figure 3. Effect of various ion pairing reagents on peak shape for $\mathrm{MeHg}^{+}$. Each peak is normalized to the same maximum value. See text for conditions. 


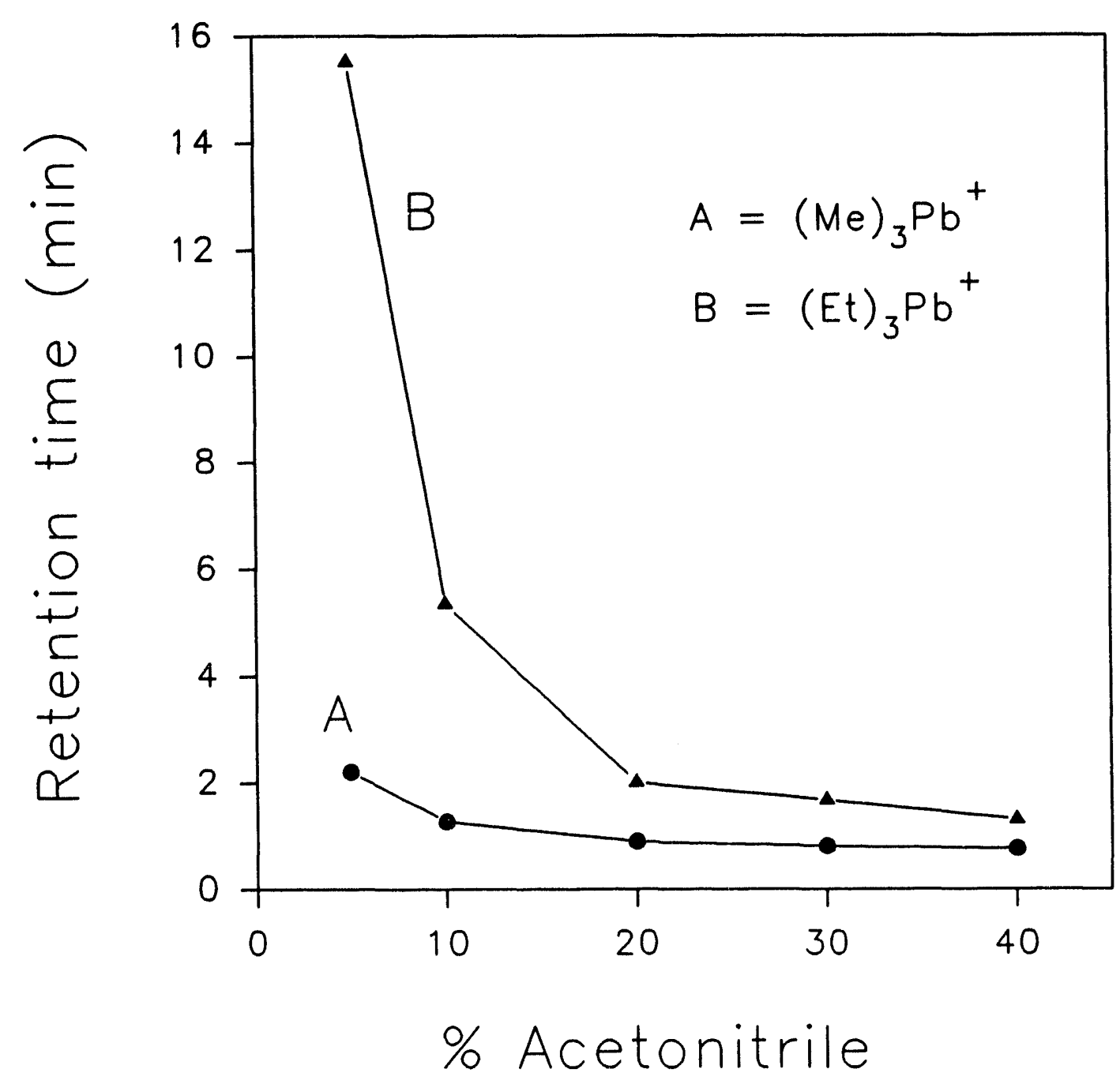

Figure 4a. Effect of mobile phase composition on the retention time for $(\mathrm{Me})_{3} \mathrm{~Pb}^{+}$ and $(\mathrm{Et})_{3} \mathrm{~Pb}^{+}$. Column, 1.6-mm-i.d. x 5-cm-long; flow rate, $100 \mu \mathrm{L}$ $\mathrm{min}^{-1}$; mobile phase, $5 \mathrm{mM}$ ammonium pentanesulfonate in various percentages of $A C N(v / v)$ in water; injection volume, $2 \mu \mathrm{L}$; sample size, $40 \mathrm{pg}$ (as $\mathrm{Pb})$ of each species. 


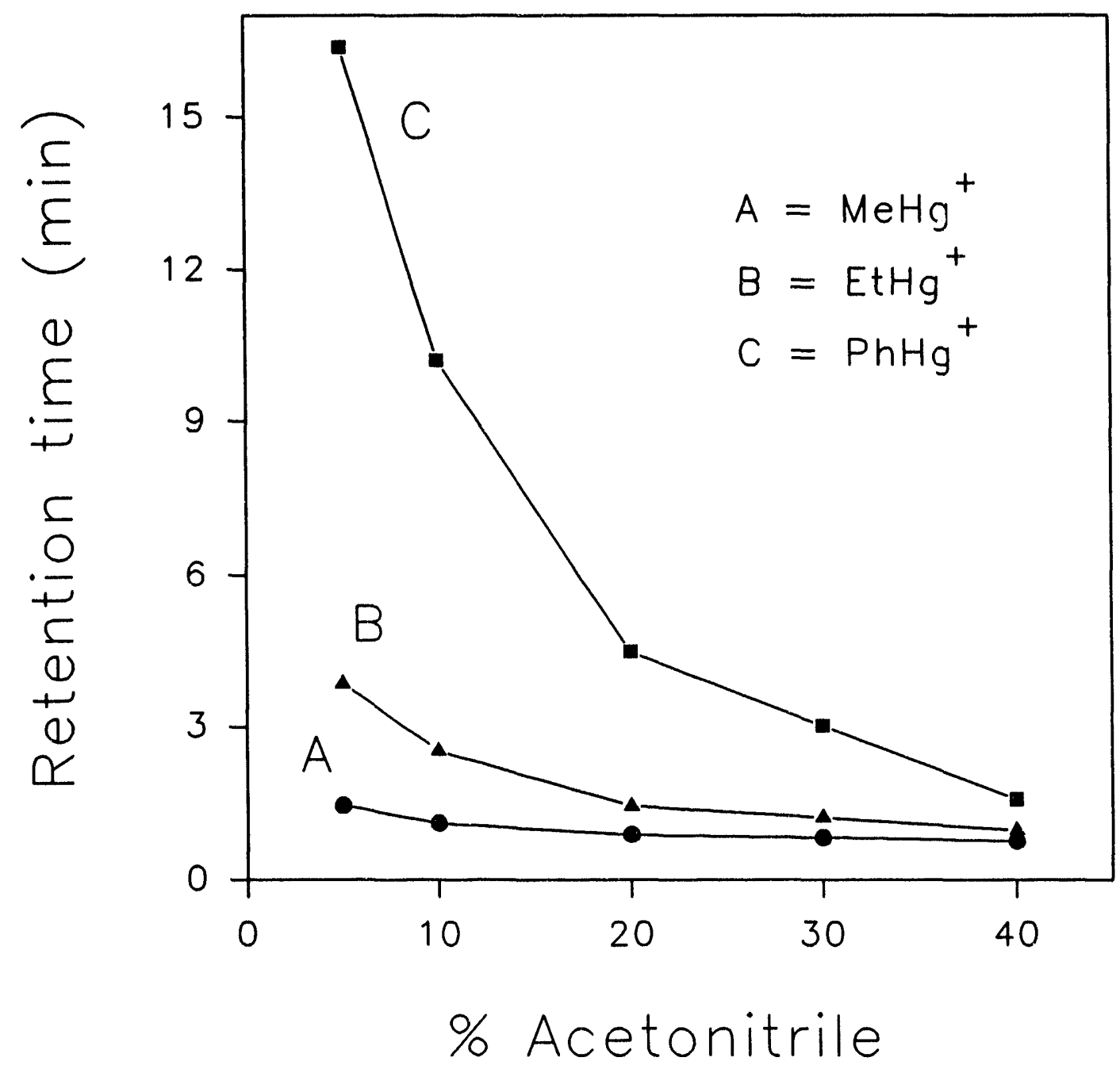

Figure 4b. Effect of mobile-phase composition on the retention time of $\mathrm{MeHg}^{+}$, $\mathrm{EtHg}^{+}$, and $\mathrm{PhHg}^{+}$. Conditions as in Figure 4a. Sample size: $2 \mathrm{ng}$ (as $\mathrm{Hg}$ ) of each species. 


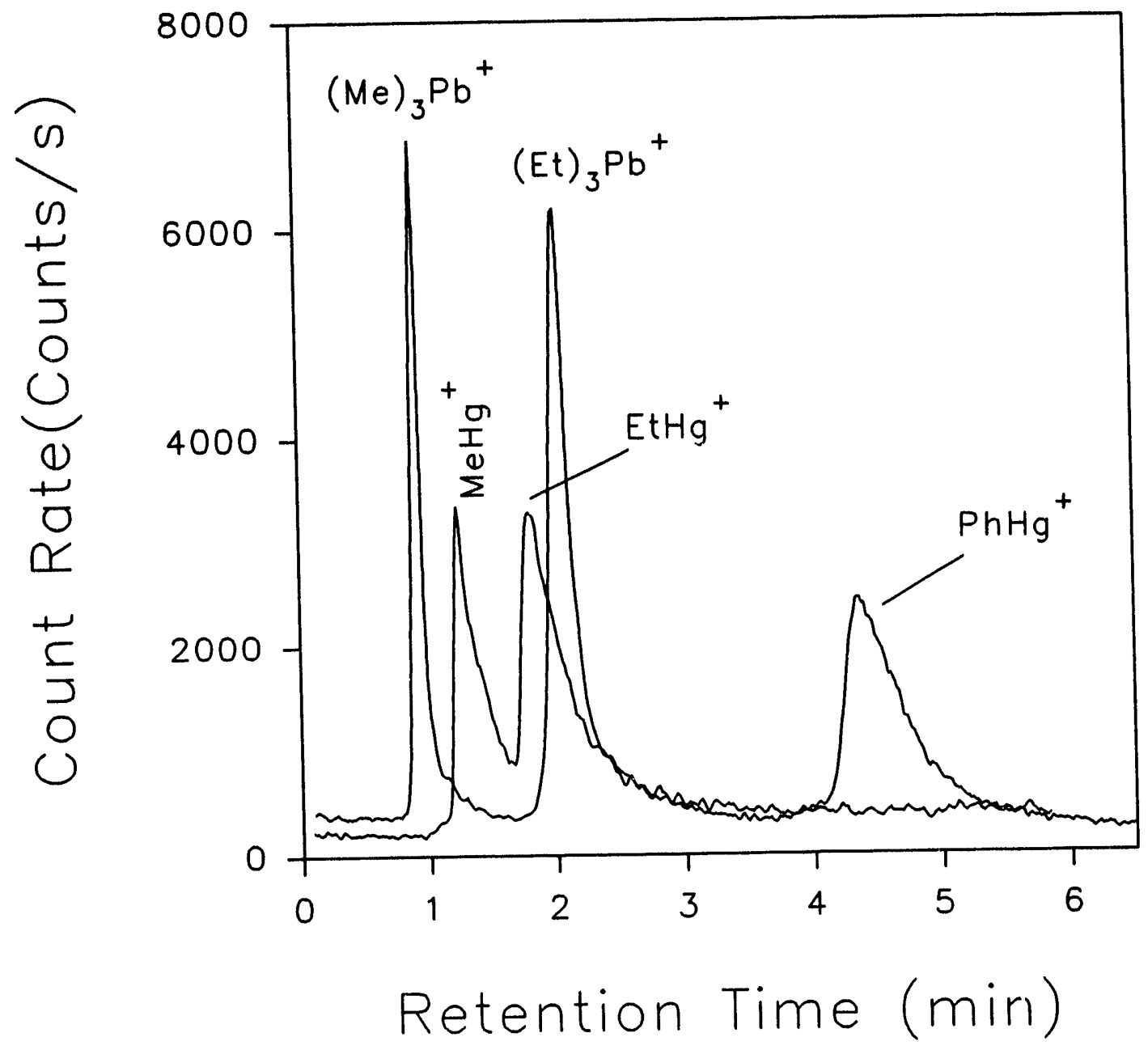

Figure 5. Separation of two trialkyllead and three organomercury species. Column,

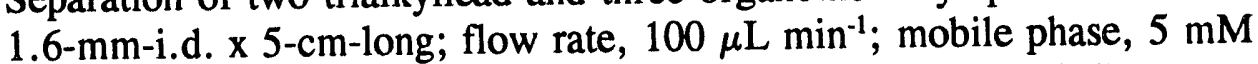
ammonium pentanesulfonate in $20: 80 \mathrm{v} / \mathrm{v} \mathrm{ACN}-\mathrm{H}_{2} \mathrm{O}(\mathrm{pH}=3.4)$; injection volume, $2 \mu \mathrm{L}$; sample size, $40 \mathrm{pg}$ (as $\mathrm{Pb}$ ) for $(\mathrm{Me})_{3} \mathrm{~Pb}^{+}, 80 \mathrm{pg}$ (as $\mathrm{Pb}$ ) for $(\mathrm{Et})_{3} \mathrm{~Pb}^{+}$, and $2 \mathrm{ng}$ (as $\mathrm{Hg}$ ) for each of the organomercury species. 


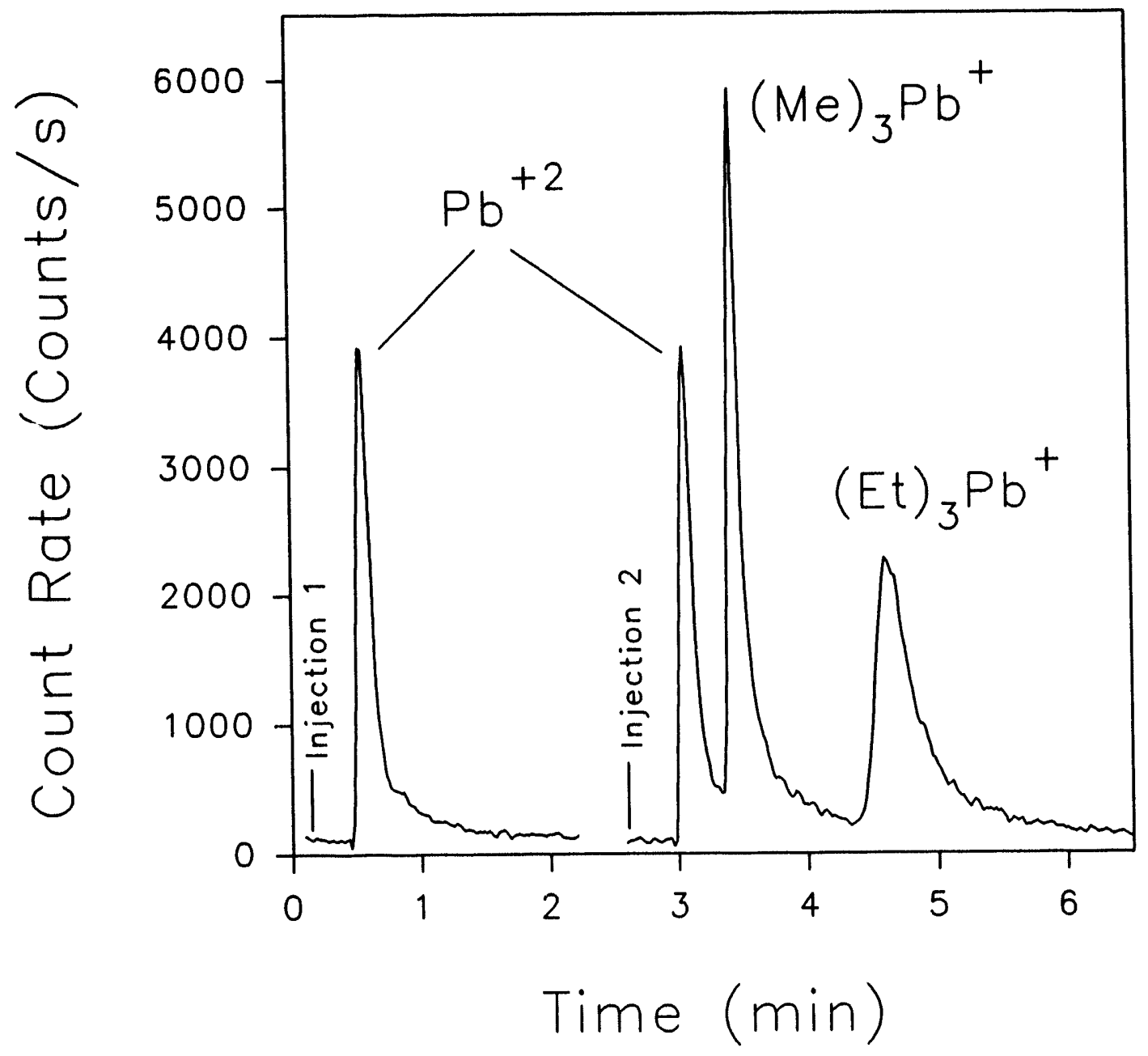

Figure 6. Separation of $\mathrm{Pb}$ species in NIST SRM 2670 freeze-dried urine (normal level). Conditions as in Figure 5. EDTA was added to the sample at 10 $\mathrm{mg} \mathrm{L}^{-1}$ before injection. Injection 1: NIST SRM 2670 freeze-dried urine (normal level). Injection 2: NIST SRM 2670 freeze-dried urine spiked with $40 \mathrm{pg}(\mathrm{as} \mathrm{Pb})$ of each of the trialkyllead species. 


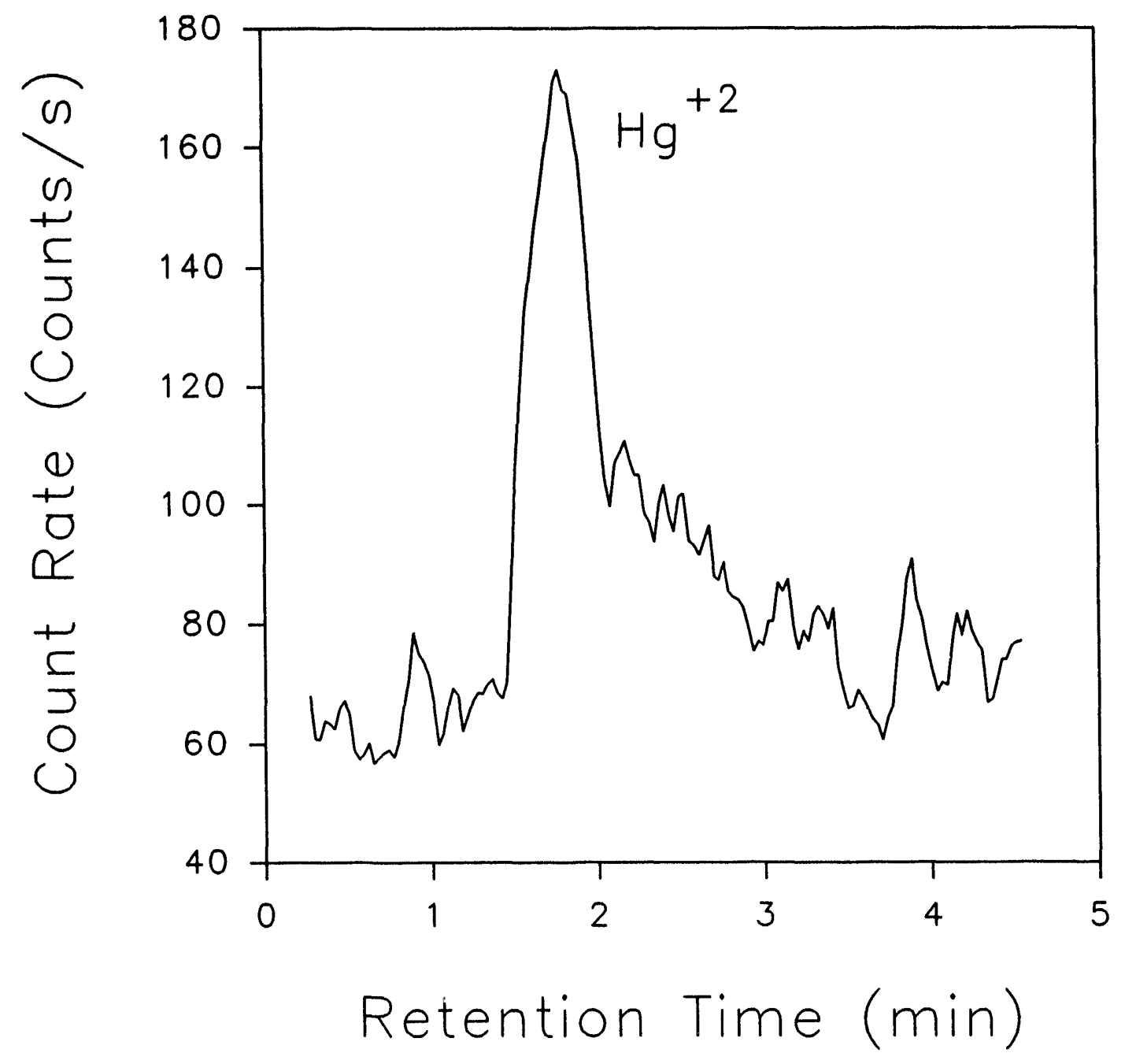

Figure 7. $\mathrm{Hg}^{+2}$ in a $24-\mathrm{h}$ human urine specimen. Conditions as in Figure 5. Column: 1.6-mm-i.d. x 15-cm-long. 


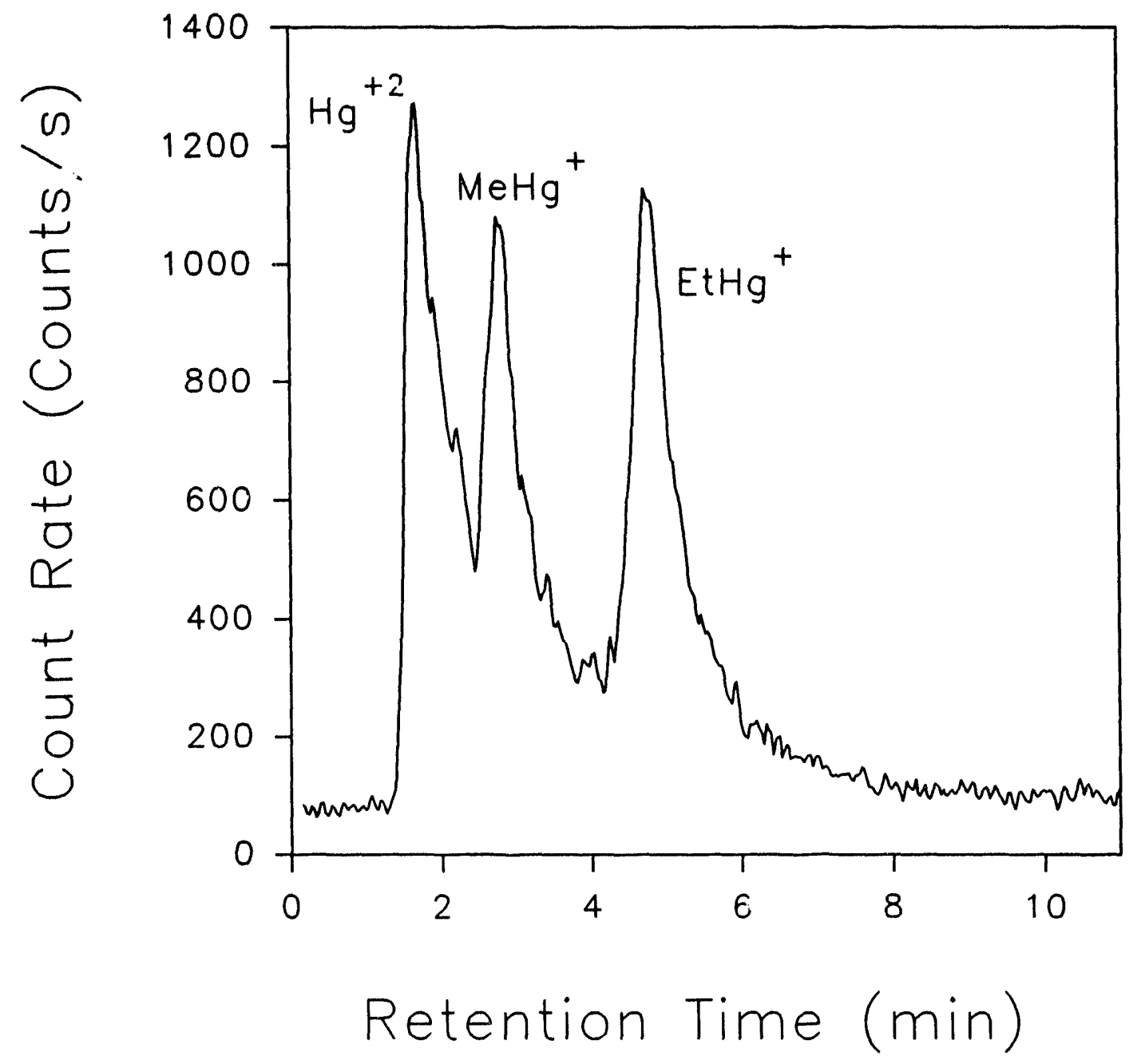

Figure 8. Separation of $\mathrm{Hg}$ species in a diluted 24-h human urine specimen. Conditions as in Figure 7. Sample: urine diluted by a factor of 10 with deionized water and spiked with $0.75 \mathrm{ng}$ (as $\mathrm{Hg}$ ) of $\mathrm{Hg}^{+2}$, and $2 \mathrm{ng}$ (as $\mathrm{Hg}$ ) of each of the organomercury species. 
PAPER III

SPATIALLY RESOLVED MEASUREMENTS OF SIZE AND VELOCITY DISTRIBUTIONS OF AEROSOL DROPLETS FROM A DIRECT INJECTION NEBULIZER 


\section{INTRODUCTION}

A new version of the direct injection nebulizer (DIN) has been developed recently for sample introduction in ICP spectroscopy, particularly ICP-MS (1-5). The advantages of the DIN include low sample and solvent consumption rates, excellent plasma stability when samples containing high concentrations of organic solvents are nebulized, good absolute detection limits, and low memory effects from difficult

elements such as $\mathrm{B}, \mathrm{I}$, and $\mathrm{Hg}(5)$. In addition, when used as an interface for liquid chromatography/ICP-MS, the DIN minimizes extra-column broadening of the chromatographic peaks $(2,6,7)$.

A DIN is essentially a micro-concentric pneumatic nebulizer and produces an axi-symmetric conical spray. When used in ICP experiments, the DIN is usually positioned inside the torch with its tip only $3-4 \mathrm{~mm}$ from the base of the plasma. Thus, virtually all sample is sprayed into the axial channel of the plasma. The size and velocity distributions of the DIN spray probably influence the vaporization, atomization, excitation, and ionization processes in the plasma. Hence, characterization of these fundamental properties of the DIN aerosol should prove valuable for optimization and for improvement of analytical performance.

A survey of possible techniques for measuring size and velocity distributions led to the choice of the phase Doppler particle analysis (PDPA) method for this work. Theory and applications of the PDPA have been described by Bachalo et al. $(8,9)$. 
Montaser and co-workers have used the PDPA method to characterize aerosols produced by conventional nebulizers (10) and by ultrasonic nebulizers (11). In PDPA, size and velocity distributions of aerosol droplets are measured in situ with the use of dual-beam light scattering interferometry. In addition, spatially resolved information on both size and velocity distributions can be obtained, which could prove very instructive. The aerosol produced by the DIN is generally sent immediately into the ICP. Spatial variations in droplet properties (such as size or velocity distributions) as the droplets traverse the ICP could then influence the conversion of droplets into atoms and ions in ways not seen with conventional nebulizers, where the aerosol is generally mixed up in a spray chamber before it reaches the plasma. The present work addresses these questions. In addition, the effect of solvent composition on droplet size distribution is also discussed. 


\section{EXPERIMENTAL SECTION}

$\underline{\text { DIN }}$

The DIN used throughout this work was constructed as described previously $(5,6)$. The sample transfer line was a fused-silica capillary $(50 \mu \mathrm{m}$ i.d. $\times 150 \mu \mathrm{m}$ o.d. $x 45 \mathrm{~cm}$ long). The width of the annular gap between the inner capillary and the nebulizer tip was $\approx 25 \mu \mathrm{m}$. An LC pump (SSI Model 222D, Scientific System, Inc., State College, PA) with a bioclean micro-flow pump head maintained a typical liquid flow rate of $100 \mu \mathrm{L} \mathrm{min}{ }^{-1}$. A Rheodyne 9010 high-pressure injector with a 2-mL PEEK sample loop was used for sample injection. For this work, deionized water or mixtures containing various percentages by volume of methanol in water were nebulized. The argon nebulizer gas flow rate was adjusted by varying the back pressure with a gas regulator.

\section{PDPA Measurements}

This instrument was manufactured by Aerometrics, Inc. (Model P/DPA). Figure 1 shows a schematic diagram of the optical system. The laser was split into two equal-intensity beams focused to an intersection point inside the aerosol spray. A receiver consisting of focusing lenses and three precisely spaced photomultiplier tubes (PMTs) was located $30^{\circ}$ off the axis of the transmitted beams. Droplets passing the intersection point of the beams scattered light independently from each beam. The 
scattered light then interfered to form a fringe pattern in the plane of the receiver lens. To determine the drop velocity, one of the PMTs measured the temporal frequency of the scattered fringe pattern. This temporal frequency was a function of the velocity of the drop, the beam intersection angle, and the light wavelength. For measurement of the drop size, the spatial frequency of the scattered fringe pattern was measured with the use of all three PMTs. The spatial frequency was inversely proportional to the droplet diameter but also depended upon the laser wavelength, the beam intersection angle, the droplet refractive index, and the spacing between different detectors on the receiver. Refractive indexes for DI water and various sample mixtures were determined with a refractometer (Bausch and Lomb). The measured refractive index for water was 1.3315 and that for $50 \%$ methanol:water was 1.3399 , so the change in refractive index with solvent composition was very slight and exerted little influence on the measured droplet sizes (8).

The DIN was mounted vertically on a translational stage with the spray pointed downward in the z-direction (Fig. 1). Unless specified otherwise, the beam intersection point was on center and $25 \mathrm{~mm}$ downstream from the nebulizer tip. In the subsequent discussion, this position is denoted $\mathrm{z}=25 \mathrm{~mm}, \mathrm{r}=0$ where $\mathrm{z}$ and $\mathrm{r}$ are the axial and radial positions, respectively. Spatial profiles were obtained by physically moving the DIN with the translation stage. A sample size of 10,000 validated aerosol droplets gave reproducible droplet size and velocity distributions. The detector voltage was $-450 \mathrm{~V}$ for each of the thrce PMTs, unless indicated 
otherwise.

The measured droplet size and velocity distributions were presented as histograms. Each histogram contained fifty discrete class bins covering the specified size or velocity range. No droplets larger than $40 \mu \mathrm{m}$ were detected, and the smallest size that could be measured by this instrument was $0.5 \mu \mathrm{m}$. Therefore, the $1-40 \mu \mathrm{m}$ size range was used for all measurements. Furthermore, because no droplets travelling faster than $50 \mathrm{~m} \mathrm{~s}^{-1}$ were detected, the upper limit of the velocity range was chosen to be $50 \mathrm{~m} \mathrm{~s}^{-1}$, while the lower limit was between -2 and $5 \mathrm{~m} \mathrm{~s}^{-1}$, depending on the application. The sign on the measured velocity was considered positive if the droplets were moving axially away from the nebulizer, i.e., downward in Fig. 1.

\section{Reagents and Samples}

Deionized water (resistance $\approx 18 \mathrm{M} \Omega$ ) was obtained from a Barnstead Nanopure-II system; methanol $(\mathrm{MeOH})$ was HPLC grade from Fisher Scientific. Mixtures of $\mathrm{MeOH} / \mathrm{H}_{2} \mathrm{O}(5-50 \% \mathrm{v} / \mathrm{v})$ were prepared by dilution. 


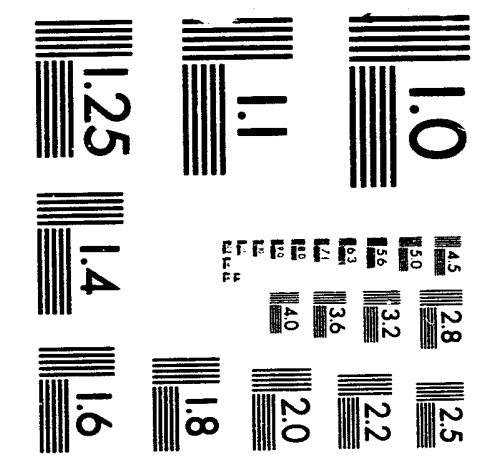



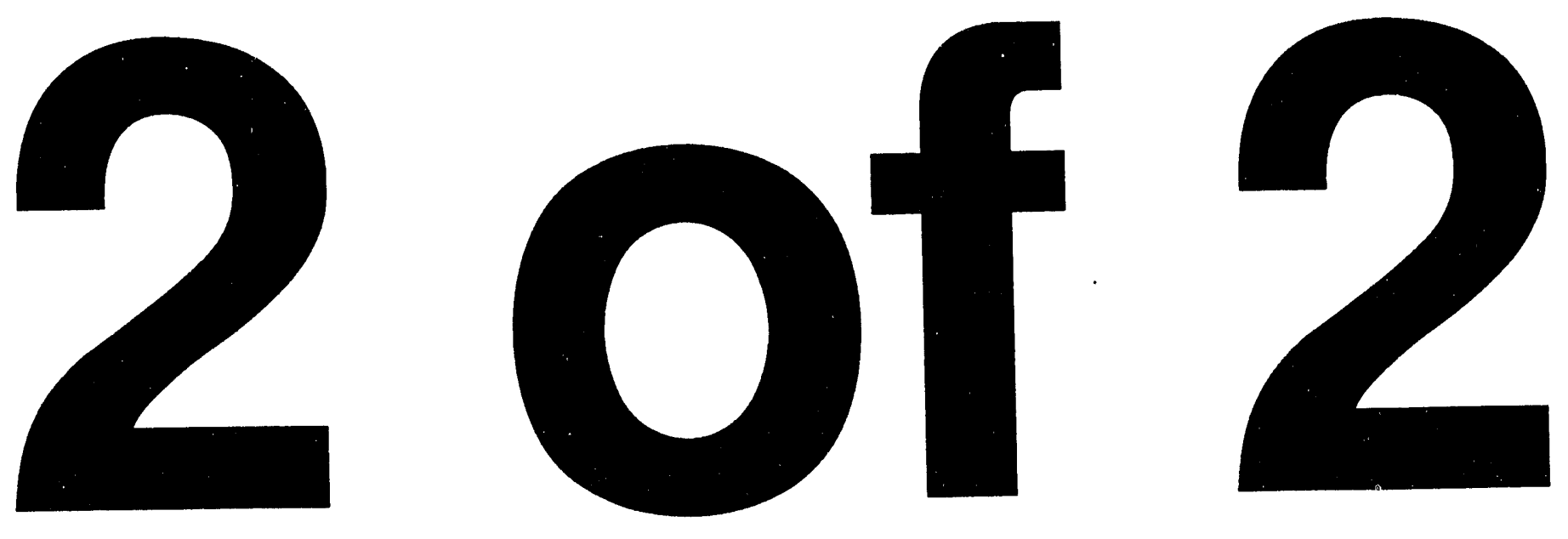


\section{RESULTS AND DISCUSSION}

\section{Terminology and Definitions}

Various representative diameters for aerosol droplet size measurements are reported in this work. Detailed mathematical definitions of these parameters have been given elsewhere $(11,12)$, and only general descriptions of their physical significance are necessary here. The Sauter mean diameter $\left(D_{3,2}\right)$ is the diameter of a drop whose volume-to-surface-area ratio is the same as that of the entire spray. Ten percent of the total liquid mass (or volume) is in drops smaller than the $10 \%$ mass diameter $\left(D_{0.1}\right)$. Half of the total liquid mass is in drops smaller than the mass median diameter $\left(D_{0.5}\right)$. Similarly, $90 \%$ of the total liquid mass is comprised of drops smaller than the $90 \%$ mass diameter $\left(D_{0.9}\right)$.

Volume flux (F) is the total volume of the droplets passing a cross-sectional area in a given direction per unit time and is a vector quantity. In droplet velocity measurements, the mean $(\mathrm{U})$ and the root mean square $(\mathrm{rms})$ velocities are reported. The rms, or velocity variance, is the standard deviation of the velocity distribution.

\section{Measurement of Aerosol Droplet Size Distribution by PDPA}

Figure $2 \mathrm{a}$ shows the aerosol droplet size distribution (at $\mathrm{z}=25 \mathrm{~mm}, \mathrm{r}=0$ ) when deionized water is being nebulized. Normal DIN operating conditions were employed; i.e., the nebulizer gas and liquid flow rates were $0.4 \mathrm{~L} \mathrm{~min} \operatorname{man}^{-1}$ and $100 \mu \mathrm{L}$ 
$\min ^{-1}$. The $D_{3,2}, D_{0.9}, D_{0.5}$, and $D_{0.1}$ values (see Table I) were found to be $\approx 14,28$, 18 , and $7 \mu \mathrm{m}$, respectively.

The droplet size distribution shown in Fig. $2 \mathrm{a}$ is substantially larger than that reported by Wiederin and Houk (13), as are the characteristic diameter values. In addition, the droplet size distribution is also distinctly bimodal, whereas that reported in Ref. 13 is not. There are several possible reasons for these discrepancies. First, the DIN used previously had a narrower annular gap (15 $\mu \mathrm{m}$ vs. $25 \mu \mathrm{m})$. Second, different methods were used for measuring droplet sizes in the two studies (14-16). A forward-scattering spectrometer probe was used previously (13), which produces a line-of-sight optical average (17) of the droplet size distribution, in contrast to the spatially resolved size distrihution provided by the PDPA. Finally, all laser scattering methods are subject to bias in the resulting droplet size distributions. In general, the smaller droplets are underrepresented relative to the larger ones (18). The size distributions produced by these two droplet measurement methods could be affected somewhat differently by these bias problems.

Using the PDPA method, Montaser and co-workers report droplet sizes for tertiary aerosols from five nebulization systems (10) and for desolvated aerosols from an ultrasonic nebulizer (11). Under normal operating conditions, their droplet diameters are $\approx 3$ times smaller than those reported in the present work. As expected, the use of a spray chamber with a conventional nebulizer produces a finer aerosol than the DIN, but at the cost of poorer sample transport efficiency, increased 
memory effects for memory-prone elements $(\mathrm{Hg}, \mathrm{I}$, and $\mathrm{B})$, and poorer precision $(1,3,5)$.

Effect of Solvent Composition on Aerosol Droplet Size Distribution

A curious effect was noted previously in chromatographic studies with this DIN. Some organic modifier, such as methanol or acetonitrile, is often necessary in the aqueous eluent to optimize the chromatographic separation. In general, the signal for atomic ions increases sharply (i.e., by $3 x$ to $5 x$ ) as the fraction of $\mathrm{MeOH}$ is raised from zero to $25 \%$. The signals for $\mathrm{Ga}^{+}, \mathrm{Nd}^{+}$, and $\mathrm{Tl}^{+}$then remain roughly constant as the $\mathrm{MeOH}$ fraction increases further to $80 \%$, whereas the signals for $\mathrm{Hg}^{+}, \mathrm{Sn}^{+}$and $\mathrm{Se}^{+}$diminish gradually (7). Other workers using conventional nebulizers have also reported enhancements in atomic ion signals when the usual aqueous samples are spiked with modest amounts of organic solvents (19) or other organic matrices (20).

Changes in the droplet size distribution with solvent composition could contribute to these observed enhancements in ion signal. Droplet size distributions for various solvent compositions are shown in Figs. $2 b-2 d$. In each case the usual nebulizer gas and liquid flow rates of $0.4 \mathrm{~L} \mathrm{~min}^{-1}$ and $100 \mu \mathrm{L} \mathrm{min}^{-1}$ are used, and the droplets are probed at the same spatial position $(z=25 \mathrm{~mm}, \mathrm{r}=0)$. As shown in Fig. 2, the "second" hump in the droplet size distribution (i.e., the one for the larger droplets) is attenuated as the $\mathrm{MeOH}$ concentration increases.

Table I summarizes the effects of the $\mathrm{MeOH} /$ water fraction on $\mathrm{D}_{3,2}, \mathrm{D}_{0.9}, \mathrm{D}_{0.5}$, 
and $D_{0.1}$. Note that both $D_{3,2}$ and $D_{0.9}$ decrease by $\approx 30 \%$ and $D_{0.5}$ decrease by $\approx$ $40 \%$ when the $\mathrm{MeOH}$ fraction increases from 0 to $30 \%$. However, $D_{0.1}$ remains relatively constant ( $7 \mu \mathrm{m}$ for water and $6 \mu \mathrm{m}$ for $20 \% \mathrm{MeOH}$ ), which suggests that the fraction of aerosol with diameters less than $6 \mu \mathrm{m}$ changes only slightly as the MeOH fraction increases. Thus, the net effect of nebulizing solvents containing up to $\approx 30 \% \mathrm{MeOH}$ is 1) elimination of large droplets, 2) production of finer droplets with diameters between 5 and $15 \mu \mathrm{m}$, and 3) reduction of the width of the droplet size distribution.

These findings can be attributed to changes in viscosity, surface tension, and liquid density of the various $\mathrm{MeOH} / \mathrm{H}_{2} \mathrm{O}$ mixtures (21-24), which in turn affect the droplet sizes of the ensuing aerosol. In general, viscosity forces tend to oppose the disintegration of liquids into drops and to resist further breakup of drops already formed, while surface tension forces tend to oppose distortion of the liquid surface. Browner and co-workers (21) suggest that, of the various solvent physical properties, surface tension exerts the principal influence on $D_{3,2}$. Others $(23,24)$ show that $D_{3,2}$ increases as viscosity and surface tension increase and as liquid density decreases. In our experiment, viscosity increases while surface tension and liquid density decrease when the concentration of $\mathrm{MeOH}$ in water increases (25). The observed reduction in $\mathrm{D}_{3,2}$ as $\mathrm{MeOH}$ fraction increases reinforces Browner's viewpoint (21).

When solvents containing more than $30 \% \mathrm{MeOH}$ are nebulized, the resulting droplet size distributions are similar to Fig. $2 d$. In fact, $D_{3,2}, D_{0.9}, D_{0.5}$, and $D_{0.1}$ (see 
Table I) differ by less than 5\% when the solvent contains from $30 \%$ to $50 \% \mathrm{MeOH}$ in water. Thus, a significant reduction in $\mathrm{D}_{3,2}, \mathrm{D}_{0.9}$, and $\mathrm{D}_{0.5}$ is observed only when water containing up to $30 \% \mathrm{MeOH}$ is nebulized. Increasing the concentration of $\mathrm{MeOH}$ further does not yield appreciably finer droplets. Thus, the observed enhancement in ion signal when solvents containing up to $20 \%$ of $\mathrm{MeOH}$ in water (7) are being nebulized may be due to the production of finer droplets in the aerosol. The gradual decrease in ion signal when solvents with $\geq 30 \% \mathrm{MeOH}$ are nebulized is presumably due to cooling of the plasma by the additional organic solvent.

\section{Effect of Nebulizer Gas Flow Rate on Droplet Size Distribution}

The effect of nebulizer gas flow rate on aerosol size distribution of a DIN spray was also studied. Here only deionized water was introduced to the DIN at 100 $\mu \mathrm{L} \mathrm{min}{ }^{-1}$, and nebulizer gas flow rates of $0.3-0.9 \mathrm{~L} \mathrm{~min}^{-1}$ were employed. Detector voltages were $-400 \mathrm{~V}$ for all three PMTs. The aerosol was probed at the usual position $(\mathrm{z}=25 \mathrm{~mm}, \mathrm{r}=0)$.

For various nebulizer gas flow rates, histograms of the aerosol droplet size distribution obtained were similar to the one shown in Fig. 2a. The $D_{3,2}, D_{0.9}, D_{0.5}$, and $D_{0.1}$ obtained were $\approx 16-17,28,21-24$, and $8-10 \mu \mathrm{m}$, respectively. Contrary to expectation, these parameters do not change much with nebulizer gas flow rate. In general, increasing the nebulizer gas flow rate would be expected to increase both the nebulizer gas velocity and the gas/liquid mass flow ratio, resulting in the 
formation of finer aerosol droplets $(21,23,26)$. The lack of dependence of droplet sizes on nebulizer gas flow rate can be explained in terms of gas dynamics in nebulizers.

When the DIN is operated at a nebulizer gas flow rate $\geq 0.3 \mathrm{~L} \mathrm{~min}^{-1}$, the ratio of the upstream pressure $\left(P_{0} \geq 75\right.$ psi) to the downstream pressure $\left(P_{d}=15\right.$ psi) is $\geq 5$. According to Sharp (27), the DIN should therefore behave as a choked nozzle. The maximum gas velocity from a choked nozzle cannot exceed the sonic velocity; i.e., the gas velocity obtainable at the tip of the DIN remains constant at the sonic velocity as long as $P_{0} / P_{d} \geq 5$. If the DIN behaves as a choked nozzle at all the gas flow rates tested, the gas velocity would then be the same in each case, and the droplet-size distribution would not vary much with the nebulizer gas flow rate.

Additional reinforcement comes from other studies of the effect of gas/liquid mass flow ratio on droplet size distributions from pneumatic nebulizers $(23,26)$. According to these results from the literature, $D_{3,2}$ decreases sharply as the gas/liquid mass flow ratio increases to about five. A further increase in the ratio above a value of about five does not yield appreciably finer aerosol droplets (see Figure 6 in Ref. 23). For the DIN, the calculated gas/liquid mass flow ratio exceeds 5 at all of the flow rates used. Thus, increasing the gas/liquid mass flow ratio by increasing the nebulizer gas flow rate does not affect the aerosol droplet size greatly, as shown previously for the DIN (13). In contrast, a conventional concentric pneumatic nebulizer, of the type generally used with ICPs, uses a much higher liquid flow rate 
( $\approx 0.5$ to $1.0 \mathrm{~mL} \mathrm{~min} \mathrm{~min}^{-1}$ ) and a somewhat higher gas flow rate $\left(0.5\right.$ to $\left.1.0 \mathrm{~L} \mathrm{~min}^{-1}\right)$ than the DIN. Such conventional nebulizers have a gas/liquid mass flow ratio of between one and three; hence they operate in a regime where an increase in gas flow rate does yield somewhat finer droplets $(23,26)$.

\section{Effect of Nebulizer Gas Flow Rate on Aerosol Droplet Velocity Distribution}

Fig'ıres $3 a-3 c$ show the velocity distributions (based on count percent) for aerosol droplets produced by the DIN operated at three different nebulizer gas flow rates $\left(0.3,0.4\right.$, and $\left.0.9 \mathrm{~L} \mathrm{~min}^{-1}\right)$. As the nebulizer gas flow rate increases, the mean velocity and the width of the velocity distribution both increase. These trends are also shown in Fig. 4.

This type of DIN is generally operated at a gas flow rate of $\approx 0.4 \mathrm{~L} \mathrm{~min}^{-1}$. The mean droplet velocity (at $z=25 \mathrm{~mm}, \mathrm{r}=0$ ) is $\approx 16 \mathrm{~m} \mathrm{~s}^{-1}$ (Fig. 3b and Fig. 4) at this gas flow rate, which is on the low end of the range of values usually cited for flow velocity into the axial channel of the ICP $\left(\approx 10\right.$ to $\left.30 \mathrm{~m} \mathrm{~s}^{-1}\right)(28-30)$. Our reported velocity values are much slower than those estimated previously by Lawrence et. al. for the original DIN (31). The present work shows that the droplets from the DIN should reside in the axial channel for $2-3 \mathrm{~ms}$ before they reach the sampling orifice of the MS. This range of residence times is comparable to that seen with conventional nebulizers and torches, and there is no reason to believe that the DIN blows the sample through the plasma too quickly for proper atomization and 
ionization.

\section{Radial Profiles of Aerosol Droplet Size and Velocity Distributions}

Figure 5 shows the variation in the value of $D_{3,2}$ with $r$. The nebulizer gas flow rate is $0.4 \mathrm{~L} \mathrm{~min}{ }^{-1}$, and two liquid flow rates $\left(100\right.$ and $\left.300 \mu \mathrm{L} \mathrm{min}{ }^{-1}\right)$ are used. The aerosol is probed at $\mathrm{z}=25 \mathrm{~mm}$ downstream from the nebulizer tip.

At a liquid flow rate of $100 \mu \mathrm{L} \mathrm{min}{ }^{-1}, D_{3,2}$ increases from $12 \mu \mathrm{m}$ at the center ( $\mathrm{r}=0$ ) to $23 \mu \mathrm{m}$ at $\mathrm{r}=6 \mathrm{~mm}$. For a liquid flow rate of $300 \mu \mathrm{L} \mathrm{min}{ }^{-1}, \mathrm{D}_{3,2}$ also increases from $11 \mu \mathrm{m}$ at the center to $28 \mu \mathrm{m}$ at $\mathrm{r}=7 \mathrm{~mm}$. These results suggest that $D_{3,2}$ increases with distance from the center of the spray, as reported by others $(32,33)$. The small aerosol droplets tend to lose their radial momentum component rapidly upon leaving the origin of the spray. These smaller droplets then travel axially with the gas flow. In contrast, the large aerosol droplets move further out into the fringes of the spray because of their larger inertia. This pattern sorts the aerosol droplets by size across the spray cross section.

Figure 6 shows the variation in the volume flux $(F)$ as a function of $r$. At a liquid flow rate of $100 \mu \mathrm{L} \mathrm{min}{ }^{-1}$, no significant change in $\mathrm{F}$ is observed for radial positions up to $5 \mathrm{~mm}$ from the center; $\mathrm{F}$ then increases sharply to $0.011 \mathrm{~cm}^{3} \mathrm{~s}^{-1} \mathrm{~cm}^{-2}$ at $\mathrm{r}=6 \mathrm{~mm}$. About $60 \%$ of the total volume flux is included in the central region $(0$ $<\mathrm{r}<4 \mathrm{~mm})$ of the spray. At the higher liquid flow rate $\left(300 \mu \mathrm{L} \mathrm{min}{ }^{-1}\right), \mathrm{F}$ increases moderately from $0.0034 \mathrm{~cm}^{3} \mathrm{~s}^{-1} \mathrm{~cm}^{-2}$ at the center to $0.006 \mathrm{~cm}^{3} \mathrm{~s}^{-1} \mathrm{~cm}^{-2}$ at $\mathrm{r}$ 
$=4 \mathrm{~mm} ; \mathrm{F}$ then increases sharply to $0.047 \mathrm{~cm}^{3} \mathrm{~s}^{-1} \mathrm{~cm}^{-2}$ at $\mathrm{r}=7 \mathrm{~mm}$. If each curve in Fig. 6 is integrated from $r=0$ to $r=4 \mathrm{~mm}$, the integrated volume flux is $\approx$ $0.022 \mathrm{~cm}^{3} \mathrm{~s}^{-1} \mathrm{~cm}^{-2}$ at either of the two liquid flow rates. Thus, the same integrated volume flux enters the plasma from the central region of the spray at the two liquid flow rates tested.

These results indicate that an increase in liquid flow rate produces a wider cone of spray. At $300 \mu \mathrm{L} \mathrm{min}{ }^{-1}$, about $80 \%$ of the total volume flux is outside ( $r>$ $4 \mathrm{~mm}$ ) the central region of the spray. The Sauter mean diameters of these off-axis droplets are larger than $20 \mu \mathrm{m}$ (see Fig. 5). Presumably, these large droplets are not properly atomized and ionized as they traverse the ICP. Furthermore, these large offcenter droplets are probably along the outer rim of the axial channel, where they likely cool the plasma or otherwise interfere with the transfer of energy to the axial channel. These effects probably explain why a high liquid flow rate $(\geq 120$ $\mu \mathrm{L} \min ^{-1}$ ) into the DIN causes a decrease in signal for analyte ions (5).

Figure 7 shows the radial profile of mean flow velocity. Note that similar profiles are observed at both liquid flow rates $(100$ and $300 \mu \mathrm{L} \mathrm{min}-1)$. The mean velocity decreases with distance from the center of the spray. A similar trend is commonly observed for sprays produced by low-flow air-assisted concentric nozzles (33) and is attributed to air entrainment and aerodynamic drag on the droplets. Finally, droplets produced at higher liquid flow rate (i.e., $300 \mu \mathrm{L} \mathrm{min}-1$ ) move slightly more slowly at all locations. 


\section{Axial Profiles of Aerosol Droplet Size and Velocity Distributions}

Figure 8 shows the variation in $D_{3,2}$ as a function of $z$. The nebulizer gas and liquid flow rates are $0.4 \mathrm{~L} \mathrm{~min}{ }^{-1}$ and $100 \mu \mathrm{L} \mathrm{min}{ }^{-1}$. The aerosol droplets are probed along the central axis $(r=0)$. The value of $D_{3,2}$ decreases by $40 \%$ from $\approx 14 \mu \mathrm{m}$ (at $\mathrm{z}=2.5 \mathrm{~mm}$ ) to $\approx 9 \mu \mathrm{m}($ at $z=10 \mathrm{~mm})$. Apparently, large droplets are still being shattered into smaller ones at axial positions up to $\approx 10 \mathrm{~mm}$ from the nebulizer tip. The $D_{3,2}$ value then increases from $\approx 9 \mu \mathrm{m}$ (at $\mathrm{z}=10 \mathrm{~mm}$ ) to $\approx 12 \mu \mathrm{m}$ (at $\mathrm{z}$ $=25 \mathrm{~mm}$ ), which indicates that some of the smaller droplets coalesce into large ones as they proceed further downstream. Sharp (27) has described this recombination phenomenon. This is not much of a problem when the DIN is used with the ICP, where the hot environment undoubtedly desolvates the droplets before they recombine appreciably.

The large $D_{3,2}$ reported at $z<5 \mathrm{~mm}$ could also be partly due to measurement error. One source of error is caused by coincidences, i.e., two or more droplets that are present simultaneously in the measuring volume. Near the nebulizer tip where the droplet number density is high, the probability of coincidences is also high. In general, coincidences shift the measured distributions to coarser particle sizes in comparison with the true distribution (34). Another source of error is the possible presence of nonspherical droplets such as liquid ligaments or oscillating droplets near the nebulizer tip ( $z \leq 5 \mathrm{~mm})$. Measurement errors of up to $45 \%$ on diameters have been reported from these problems (35). Furthermore, the increase in $D_{3,2}$ for 
droplets at $\mathrm{z}>10 \mathrm{~mm}$ could also be partly due to evaporation (32). Although evaporation decreases the size of all droplets, smaller droplets evaporate faster, and this pattern weights the average toward larger droplets. Therefore, $D_{3,2}$ increases as evaporation becomes more extensive further downstream in a spray. This problem should not be severe in the present work, because most of our measurements are performed along the central axis of the spray, where evaporation should not be extensive because the atmosphere there also contains plenty of solvent vapor.

Droplet size distributions close to the nebulizer tip $(z=2.5 \mathrm{~mm})$ and somewhat further downstream $(z=10 \mathrm{~mm})$ are compared in Fig. 9. The droplets are much larger and their size distribution is much broader closer to the nebulizer tip, as expected from the $D_{3,2}$ data shown previously (Fig. 8).

This large decrease in droplet size as axial position increases could be partly responsible for the following analytical observation. When this particular DIN is used for ICP-MS, the auxiliary gas flow rate must be quite high $\left(\approx 1.4 \mathrm{~L} \mathrm{~min}^{-1}\right)$ to maximize the analyte ion signal (6). Powell et al., who use a somewhat different DIN, likewise report that the auxiliary gas flow rate should be $0.6 \mathrm{~L} \mathrm{~min}-1$ to maximize $\mathrm{Hg}^{+}$signal (1). Traditionally, the auxiliary gas flow keeps the plasma from contacting and melting the inner tubes of the torch. This role is certainly important with the DIN. In addition, we propose that a high auxiliary gas flow rate also pushes the base of the plasma further downstream away from the DIN. The initially large droplets then have more opportunity to be shattered into smaller, more uniform ones, 
either before they reach the plasma or in the upstream reaches of the axial channel. Thus, use of a high auxiliary gas flow rate delays the injection of droplets into the plasma, which may actually be desirable.

An axial profile of mean droplet velocity is given in Fig. 10. The nebulizer gas flow rate is $0.4 \mathrm{~L} \mathrm{~min}-1$ and the liquid flow rate is $100 \mu \mathrm{L} \mathrm{min}$. The two leftmost points, at axial positions of 2.5 and $5 \mathrm{~mm}$, are probably not appreciably different, so the mean dreplet velocity near the nebulizer tip is probably $15-17 \mathrm{~m} \mathrm{~s}^{-1}$. The droplet velocity then quickly reaches a maximum of $25 \mathrm{~m} \mathrm{~s}^{-1}$ at $\mathrm{z}=10 \mathrm{~mm}$, after which velocity drops smoothly to $15 \mathrm{~m} \mathrm{~s}^{-1}$ at $\mathrm{z}=25 \mathrm{~mm}$.

This behavior is attributed to the following processes. Consider an individual droplet leaving the tip of the nebulizer. The droplet takes some time to be accelerated by the gas jet issuing from the nebulizer, so its velocity increases at first. The fastmoving gas from the nebulizer slows down as it encounters the stationary gas in the surrounding air (or the slower gas in the ICP), so the droplet also slows down as it moves further from the nebulizer tip. 


\section{CONCLUSION}

The PDPA method provides a wealth of information concerning droplet sizes and velocities. These parameters change spatially within the spray issuing from the DIN, which could prove very important because the DIN aerosol goes directly into the ICP, without first being mixed up in a spray chamber. Addition of $\mathrm{MeOH}$ at up to $30 \%$ in water provides smaller droplets with a narrower size distribution, which probably accounts for the substantial increase in ion signal seen at this methanol composition (7). As indicated by Etkin et al. in their work with dried, monodisperse particulates (36), the spread of droplet or particle sizes is particularly important in ICP-MS, as this spread influences the range of axial positions in the plasma over which atomic ions are generated. If a given particle atomizes too far upstream, the resulting vapor cloud expands too much before it reaches the sampler, and some of the resulting ions are too far from the central axis to pass successfully through both the sampler and skimmer. Thus, the sensitivity in ICP-MS falls off if the sampler is positioned too far downstream from the initial radiation zone $(37,38)$. The present work supports the premise of Jong et al. that monodisperse droplets are particularly advantageous for ICP-MS (36), perhaps more so than for the more-common emission measurements. 


\section{LITERATURE CITED}

1. M. J. Powell, E. S. K. Quan, D. W. Boomer, and D. R. Wiederin, Anal. Chem. 64, 2253 (1992).

2. R. S. Houk, S. C. K. Shum, and D. R. Wiederin, Anal. Chim. Acta 250, 61 (1991).

3. F. G. Smith, D. R. Wiederin, R. S. Houk, C. B. Egan, and R. E. Serfass, Anal. Chim. Acta 248, 229 (1991).

4. D. R. Wiederin, R. E. Smyczek, and R. S. Houk, Anal. Chem. 63, 1626 (1991).

5. D. R. Wiederin, F. G. Smith, and R. S. Houk, Anal. Chem. 63, 219 (1991).

6. S. C. K. Shum, H. Pang, and R. S. Houk, Anal. Chem. 64, 2444 (1992).

7. S. C. K. Shum, R. Neddersen, and R. S. Houk, Analyst 117, 577 (1992).

8. W. D. Bachalo and M. J. Houser, Opt. Eng. 23, 583 (1984).

9. W. D. Bachalo, Appl. Opt. 19, 363 (1980).

10. R. H. Clifford, I. Ishii, A. Montaser, and G. A. Meyer, Anal. Chem. 62, 390 (1990).

11. R. H. Clifford, P. Sohal, H. Liu, and A. Montaser, Spectrochim. Acta 47B, 1107 (1992).

12. A. H. Lefebvre, Atomization and Sprays (Hemisp' ere Publishing Corp., New York, 1989), Chap. 1.

13. D. R. Wiederin and R. S. Houk, Appl. Spectrosc. 45, 1408 (1991). 
14. L. G. Dodge, D. J. Rhodes, and R. D. Reitz, Appl. Opt. 26, 2144 (1987).

15. T. A. Jackson and G. S. Samuelsen, J. Eng. Gas Turbines Power 108, 196 (1986).

16. D. C. Hammond, Jr., Appl. Opt. 20, 493 (1981).

17. American Society for Testing Materials (ASTM) Standard E799.

18. R. W. Sellens, "Phase-Doppler Measurements Near the Nozzle in a LowPressure Water Spray" in Liquid Particle Size Measurement Techniques, E. D. Hirleman, W. D. Bachalo, and P. G. Felton, Eds (ASTM STP 1083, American Society for Testing and Materials, Philadelphia, 1990), Vol. 2, p. 193.

19. P. Allain, L. Jaunault, Y. Mauras, J. Mermet, and T. Delaporte, Anal. Chem. 63, 1499 (1991).

20. G. F. Wallace, Enhancement of Some Analyte Signals by Carbon Compounds in ICP-MS, FACSS Conference (Philadelphia, PA, September 1992), Paper No. 458.

21. A. Canals, J. Wagner, and R. F. Browner, Spectrochim. Acta 43B, 1321 (1988).

22. R. F. Browner and A. W. Boorn, Anal. Chem. 56, 787A (1984).

23. G. E. Lorenzetto and A. H. Lefebvre, AIAA Journal 15, 1006 (1977).

24. A. A. Rizkalla and A. H. Lefebvre, ASMS J. Fluids Eng. 97, 316 (1975).

25. C. Robles, J. Mora, and A. Canals, Appl. Spectrosc. 46, 669 (1992).

26. K. Y. Kim and W. R. Marshall, Jr., AIChE Journal 17, 575 (1971).

27. B. L. Sharp, J. Anal. At. Spectrom. 3, 613 (1988). 
28. R. K. Winge, J. S. Crain, and R. S. Houk, J. Anal. At. Spectrom. 6, 601 (1991).

29. M. T. Cicerone and P. B. Farnsworth, Spectrochim. Acta 44B, 897 (1989).

30. R. M. Barnes and J. L. Genna, Spectrochim. Acta 36B, 299 (1981).

31. K. E. Lawrence, G. W. Rice, and V. A. Fassel, Anal. Chem. 56, 289 (1984).

32. R. D. Reitz, "Effect of Vaporization and Turbelence on Spray Drop-Size and Velocity Distributions" in Liquid Particle Size Measurement Techniques, E. D. Hirleman, W. D. Bachalo, and P. G. Felton, Eds (ASTM STP 1083, American Society for Testing and Materials, Philadelphia, 1990), Vol. 2, p. 225.

33. T. A. Jackson and G. S. Samuelsen, Appl. Opt. 26, 2137 (1987).

34. J. Raasch and H. Umhauer, Part. Charact. 1, 53 (1984).

35. T. A. Jackson, "Droplet Sizing Interferometry" in Liquid Particle Size Measurement Techniques, E. D. Hirleman, W. D. Bachalo, and P. G. Felion, Eds (ASTM STP 1083, American Society for Testing and Materials, Philadelphia, 1990), Vol. 2, p. 151.

36. B. Etkin, J. B. French, and R. Jong, Monodisperse Dried Microparticulate Injection, FACSS Conference (Philadelphia, PA, September 1992), Paper No. 218.

37. S. H. Tan and G. Horlick, J. Anal. At. Spectrom. 2, 745 (1987).

38. M. A. Vaughan, G. Horlick, and S. H. Tan, J. Anal. At. Spectrom. 2,765 (1987). 
Table I. Effect of MeOH percentage in water on $D_{3,2}, D_{0.9}, D_{0.5}$, and $D_{0.1}$ for the aerosol droplets produced by the DIN $^{*}$

\begin{tabular}{ccccc}
\hline \% MeOH $(\mathrm{v} / \mathrm{v} \%)$ & $\mathrm{D}_{3,2}(\mu \mathrm{m})$ & $\mathrm{D}_{0.9}(\mu \mathrm{m})$ & $\mathrm{D}_{0.5}(\mu \mathrm{m})$ & $\mathrm{D}_{0.1}(\mu \mathrm{m})$ \\
\hline 0 & 14.1 & 28.1 & 18.3 & 6.7 \\
5 & 12.0 & 27.3 & 14.4 & 5.9 \\
10 & 12.2 & 29.7 & 14.8 & 5.9 \\
20 & 9.5 & 18.6 & 10.3 & 5.9 \\
30 & 8.8 & 18.6 & 9.6 & 5.1 \\
40 & 8.6 & 17.8 & 9.4 & 5.1 \\
50 & 9.2 & 19.4 & 10.0 & 5.1 \\
\hline
\end{tabular}

- The nebulizer gas flow rate was $0.4 \mathrm{~L} \mathrm{~min}^{-1}$ and the liquid flow rate was $100 \mu \mathrm{L} \mathrm{min}$. PDPA detectors were operated at $-450 \mathrm{~V}$. The probe beam was located at $\mathrm{z}=25 \mathrm{~mm}, \mathrm{r}=0$. 


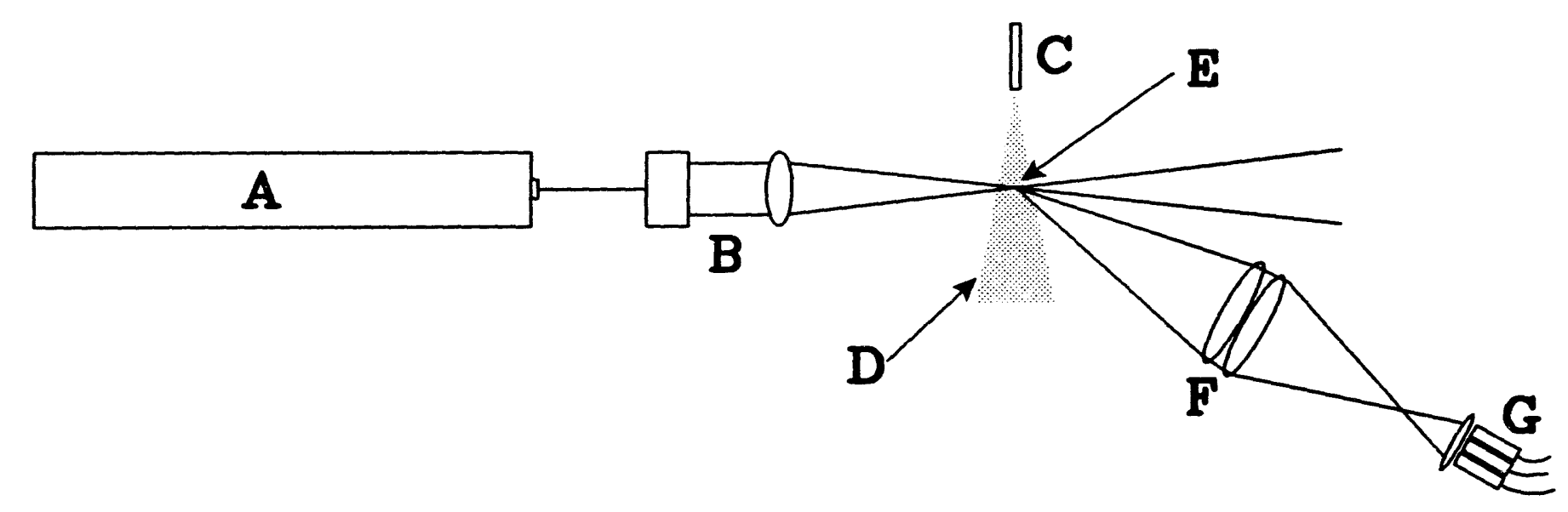

Figure 1. Schematic diagram of the optical system for the PDPA: (A) He-Ne laser; (B) beamsplitter; (C) DIN; (D) DIN spray; (E) beam intersection point; (F) focusing lenses; (G) PMTs. 


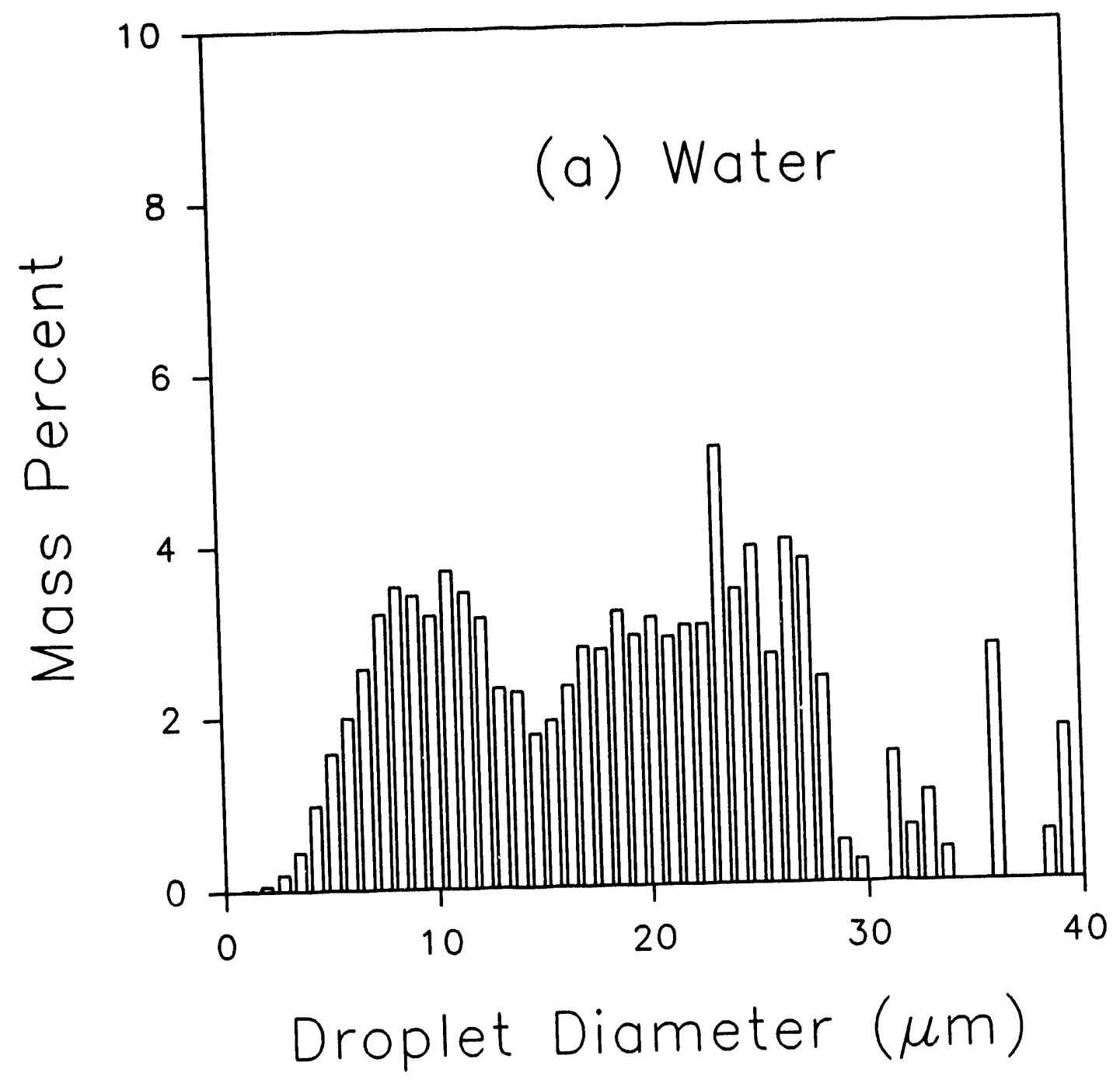

Figure 2. The effect of methanol concentration in water on the aerosol droplet size distribution. Experimental conditions are given in the text. The methanol concentrations. were: (a) $0 \%$ (Water), (b) $10 \% \mathrm{MeOH}$, (c) $20 \% \mathrm{MEOH}$, and (d) $30 \% \mathrm{MeOH}$. 


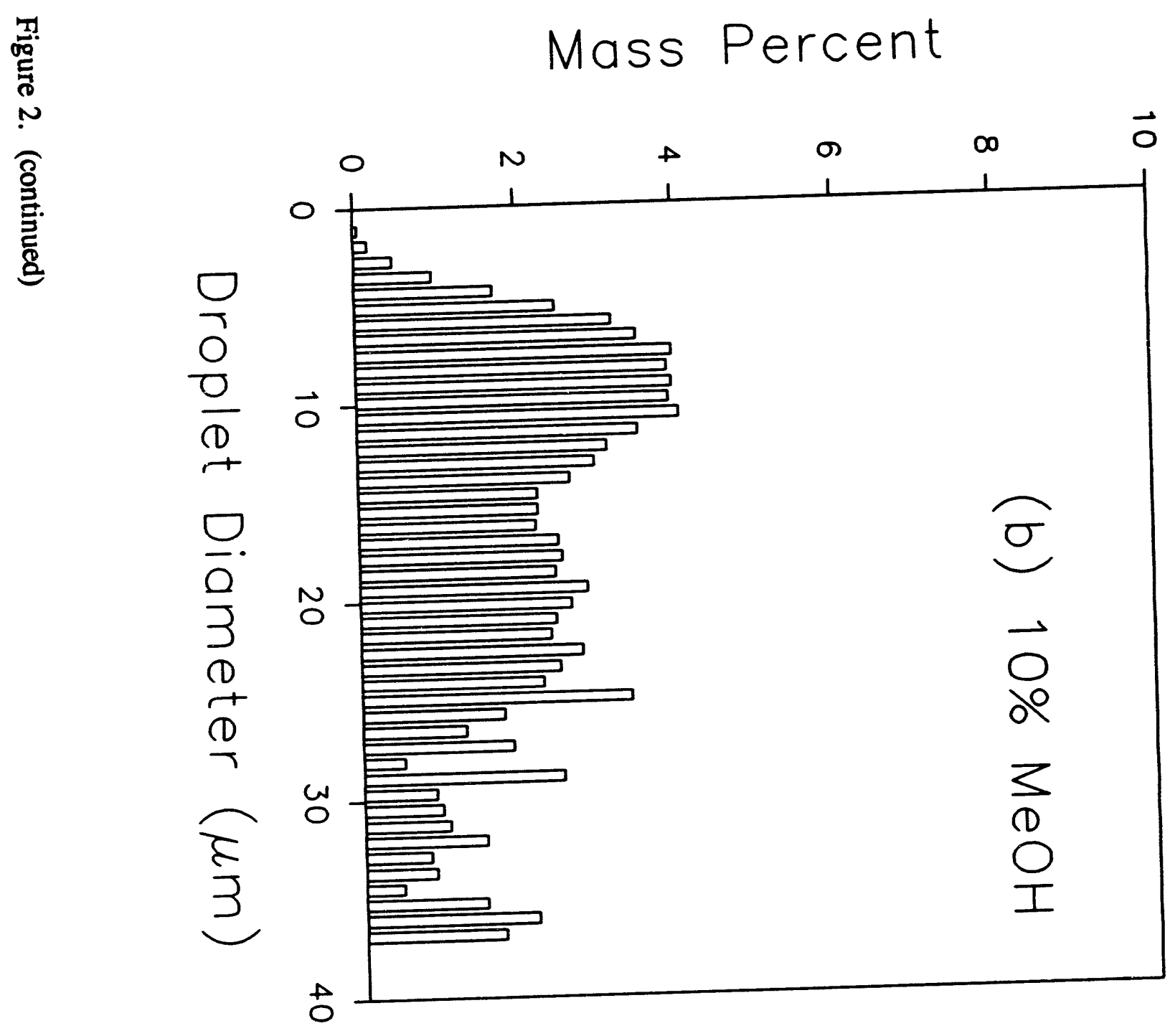




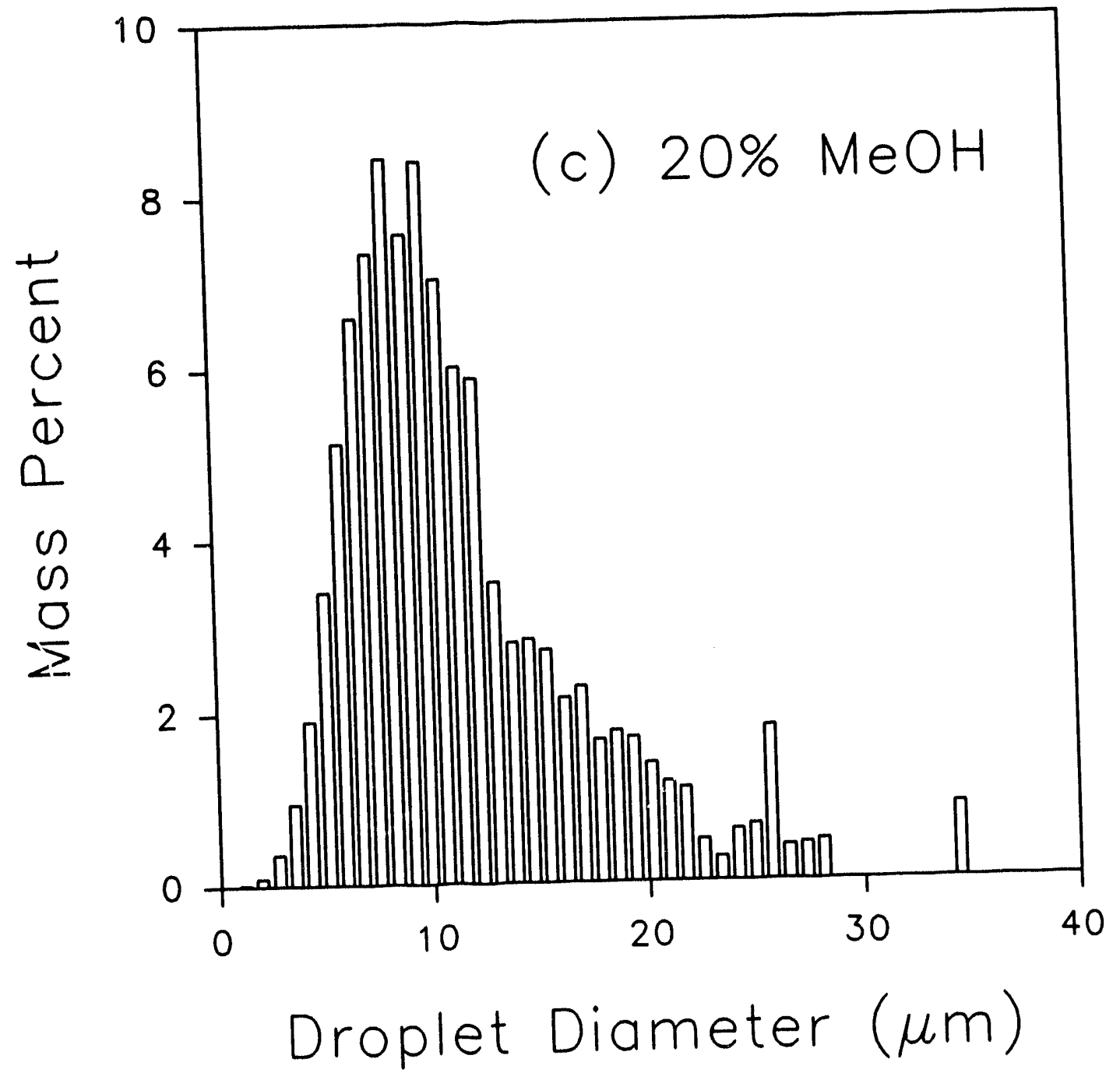

Figure 2. (continued) 


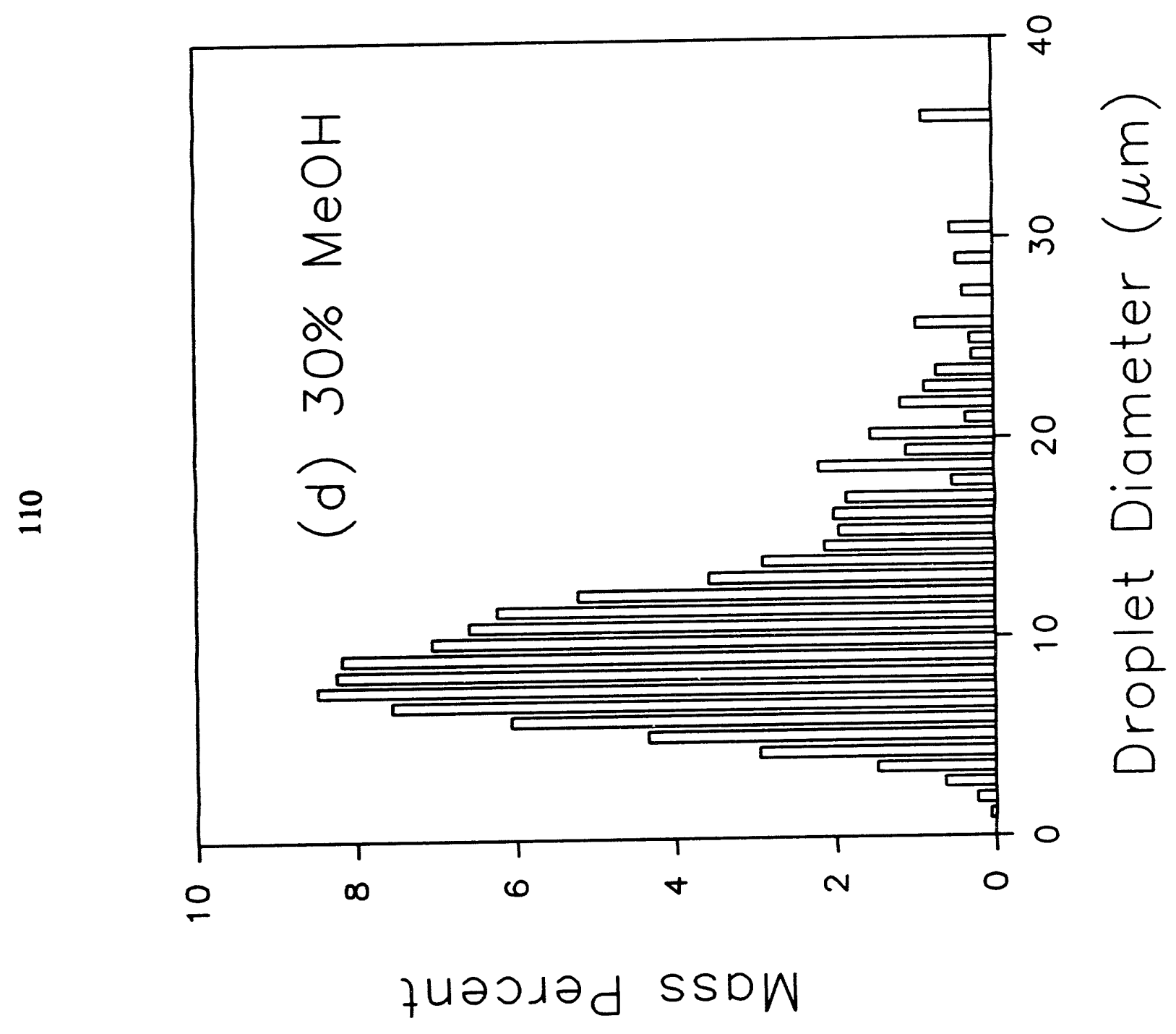

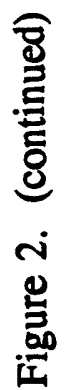




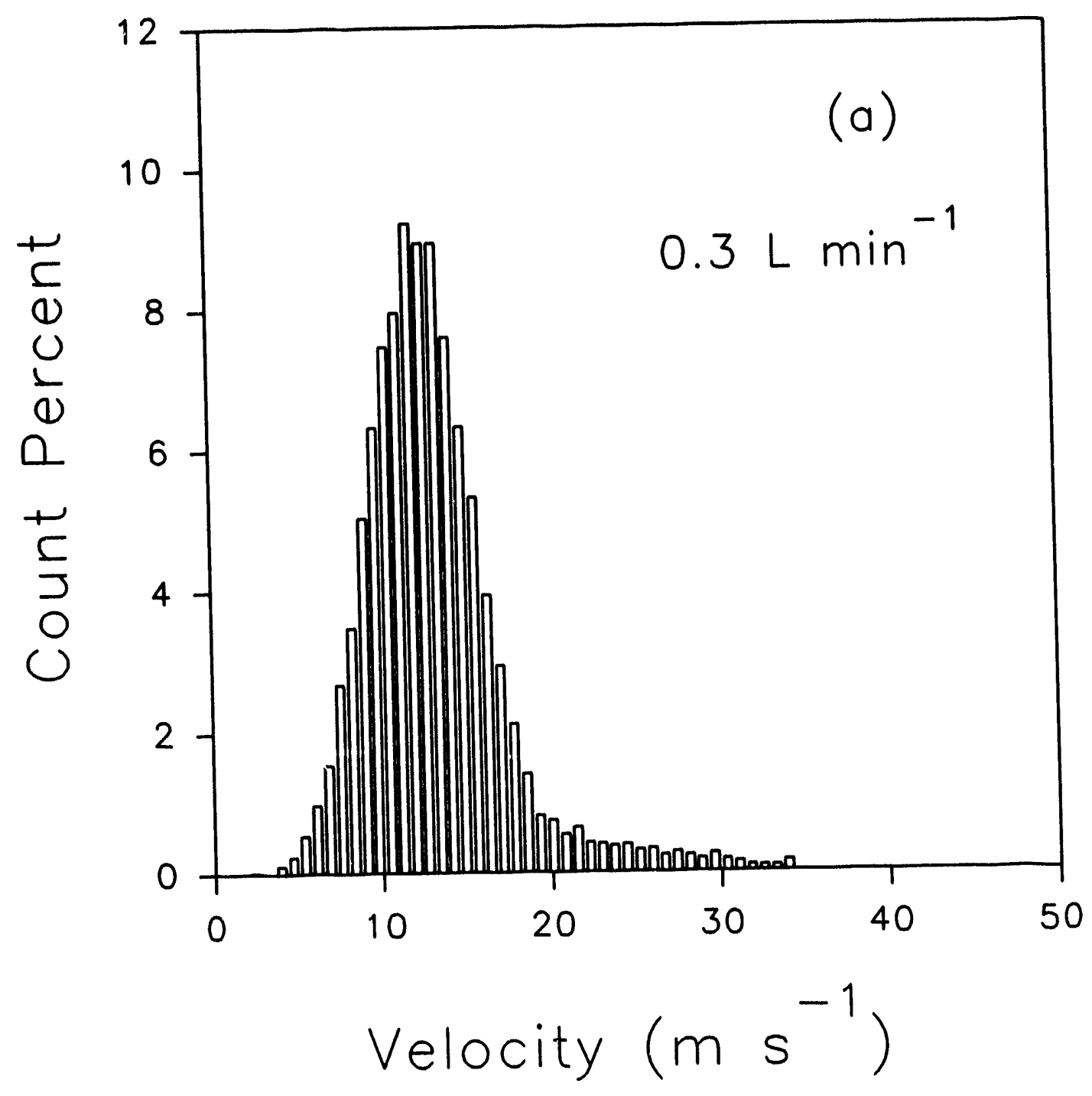

Figure 3. The effect of nebulizer gas flow rate on the aerosol droplet velocity distribution. Experimental conditions are given in the text. The nebulizer gas flow rates were: (a) 0.3 , (b) 0.4 , and (c) $0.7 \mathrm{~L} \mathrm{~min}^{-1}$. 


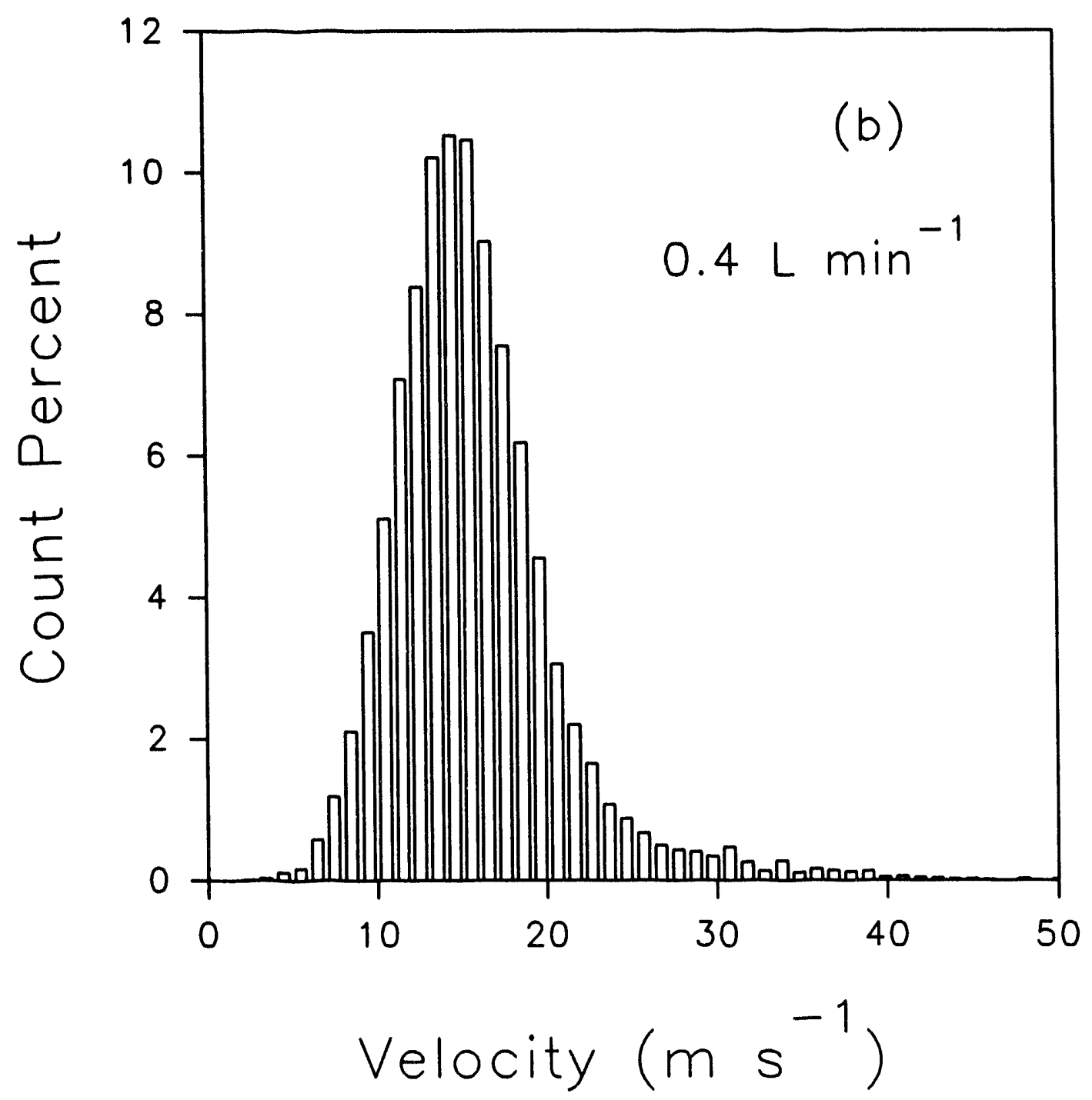

Figure 3. (continued) 


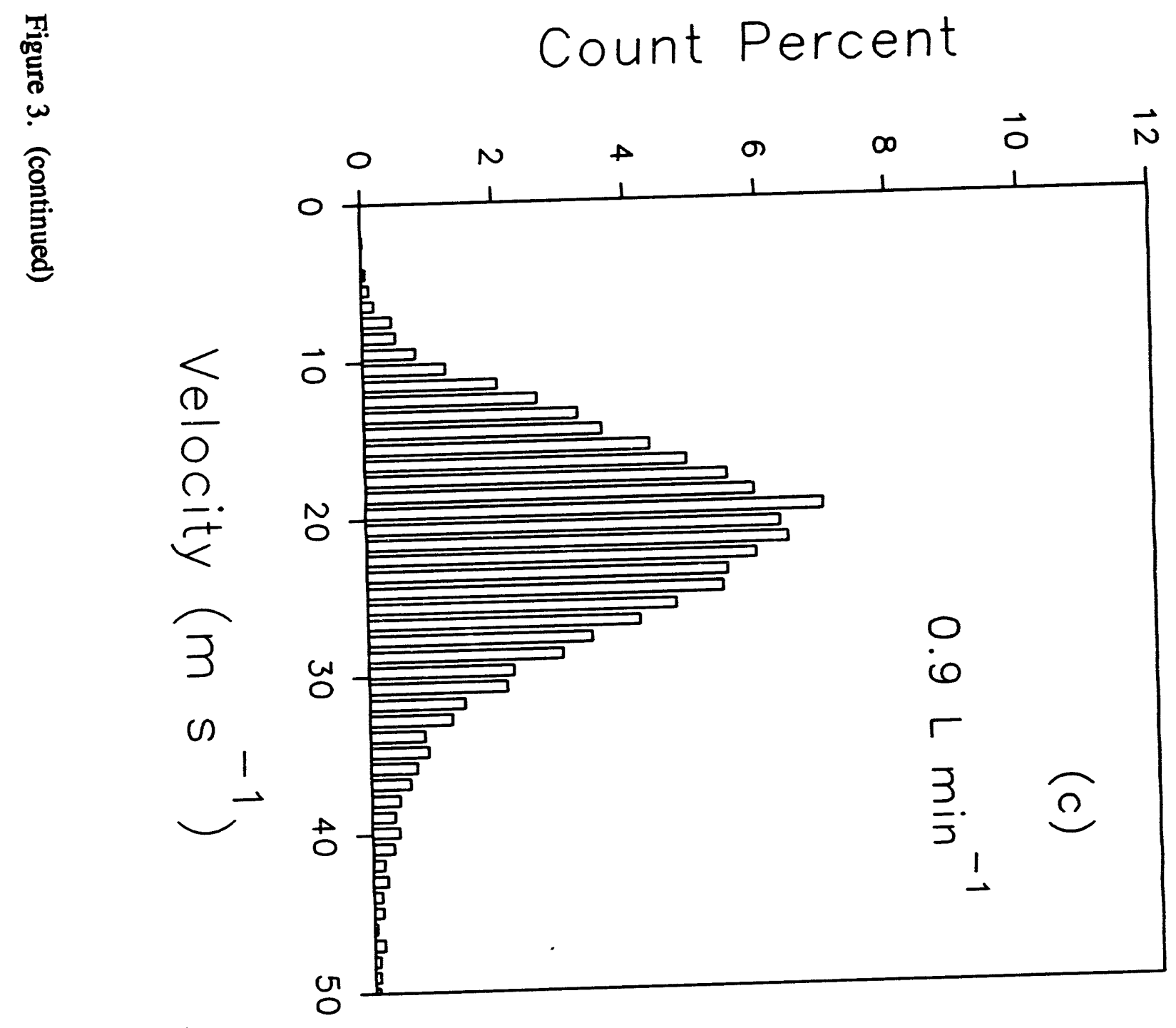

$\bar{\omega}$ 


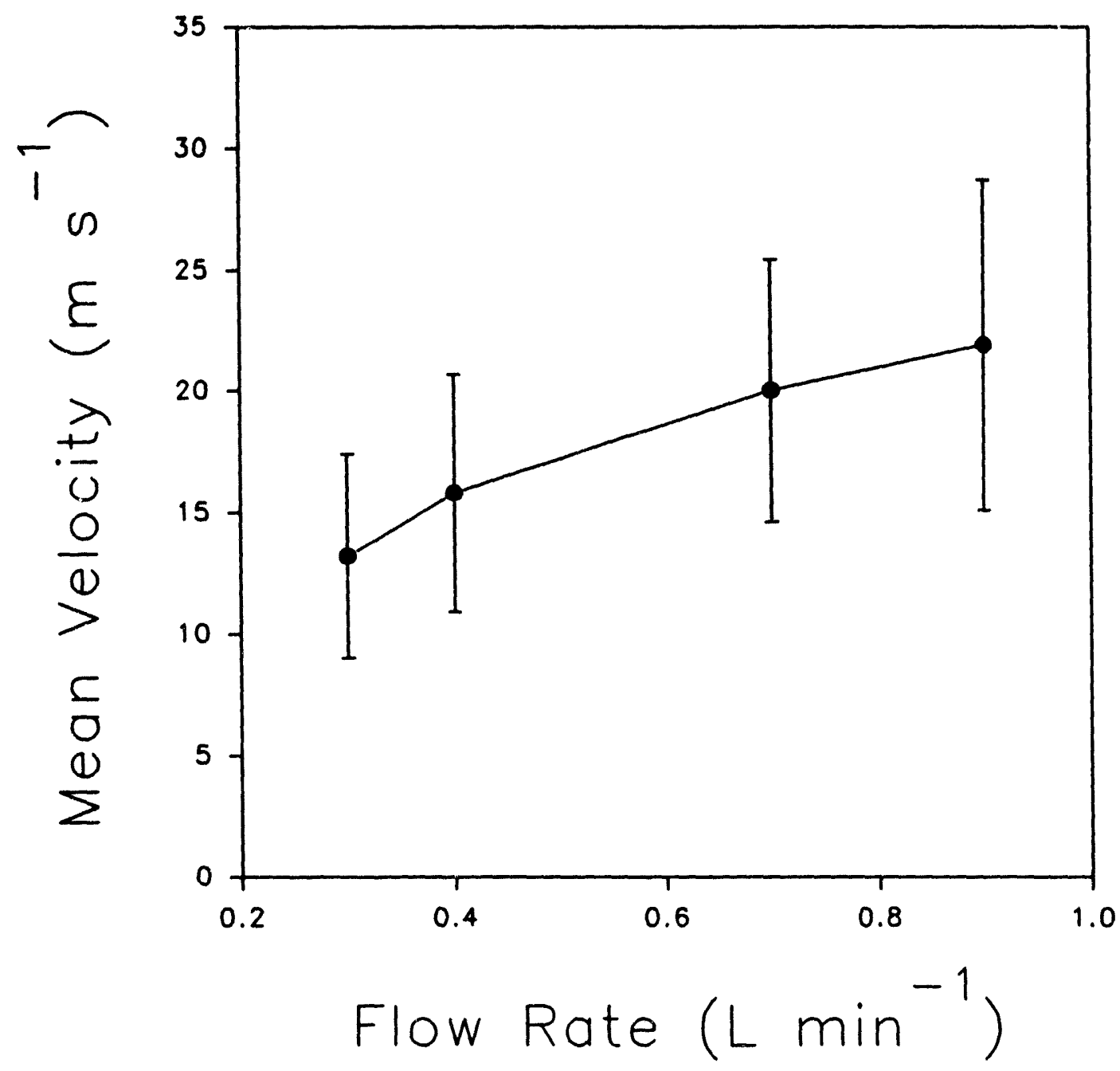

Figure 4. The effect of nebulizer gas flow rate on droplet velocity distribution. Error bars indicate \pm one standard deviation. 


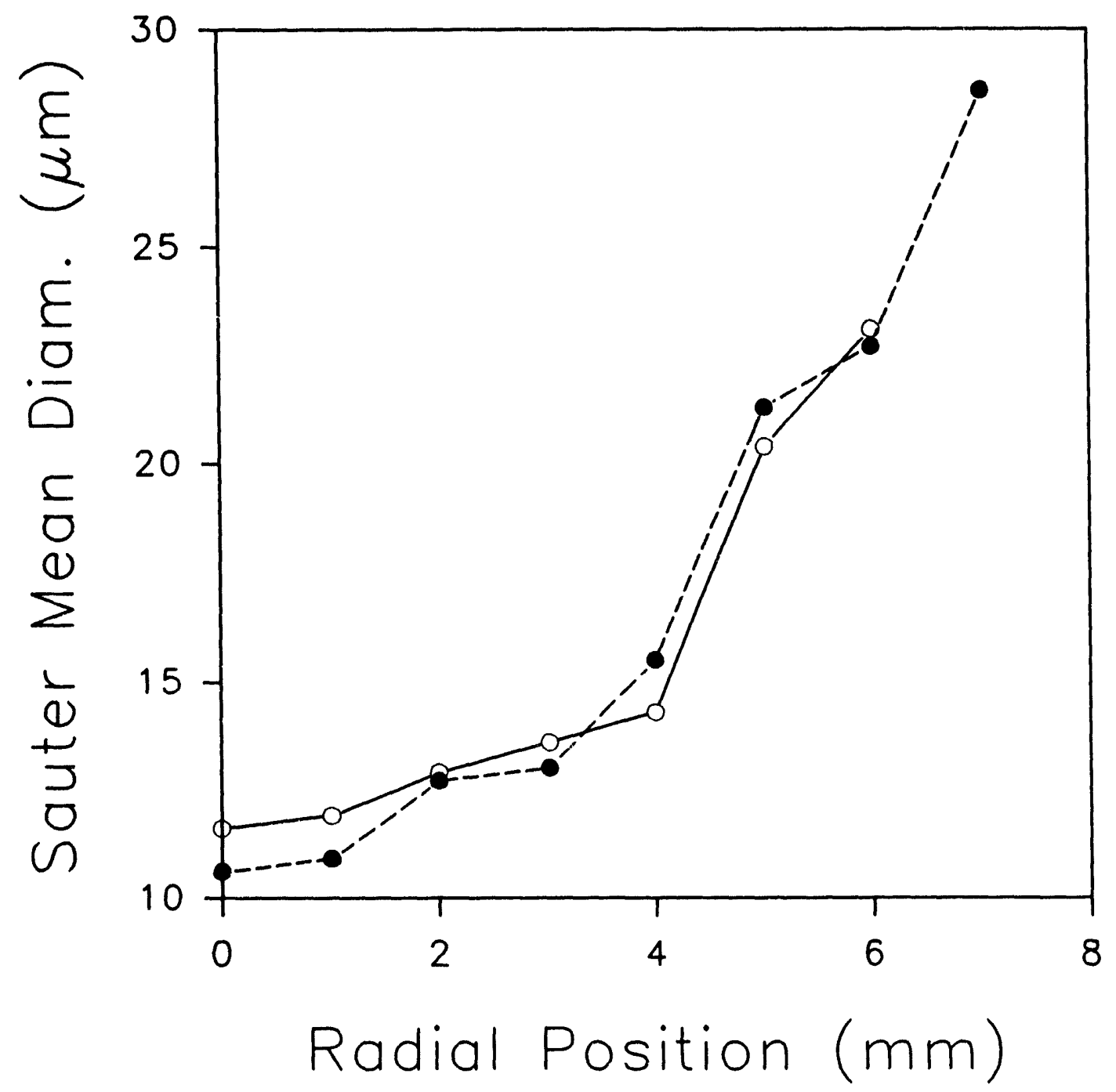

Figure 5. Radial profile of Sauter mean diameter $\left(D_{3,2}\right)$ at $\mathrm{z}=25 \mathrm{~mm}$ for two liquid

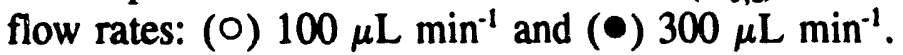




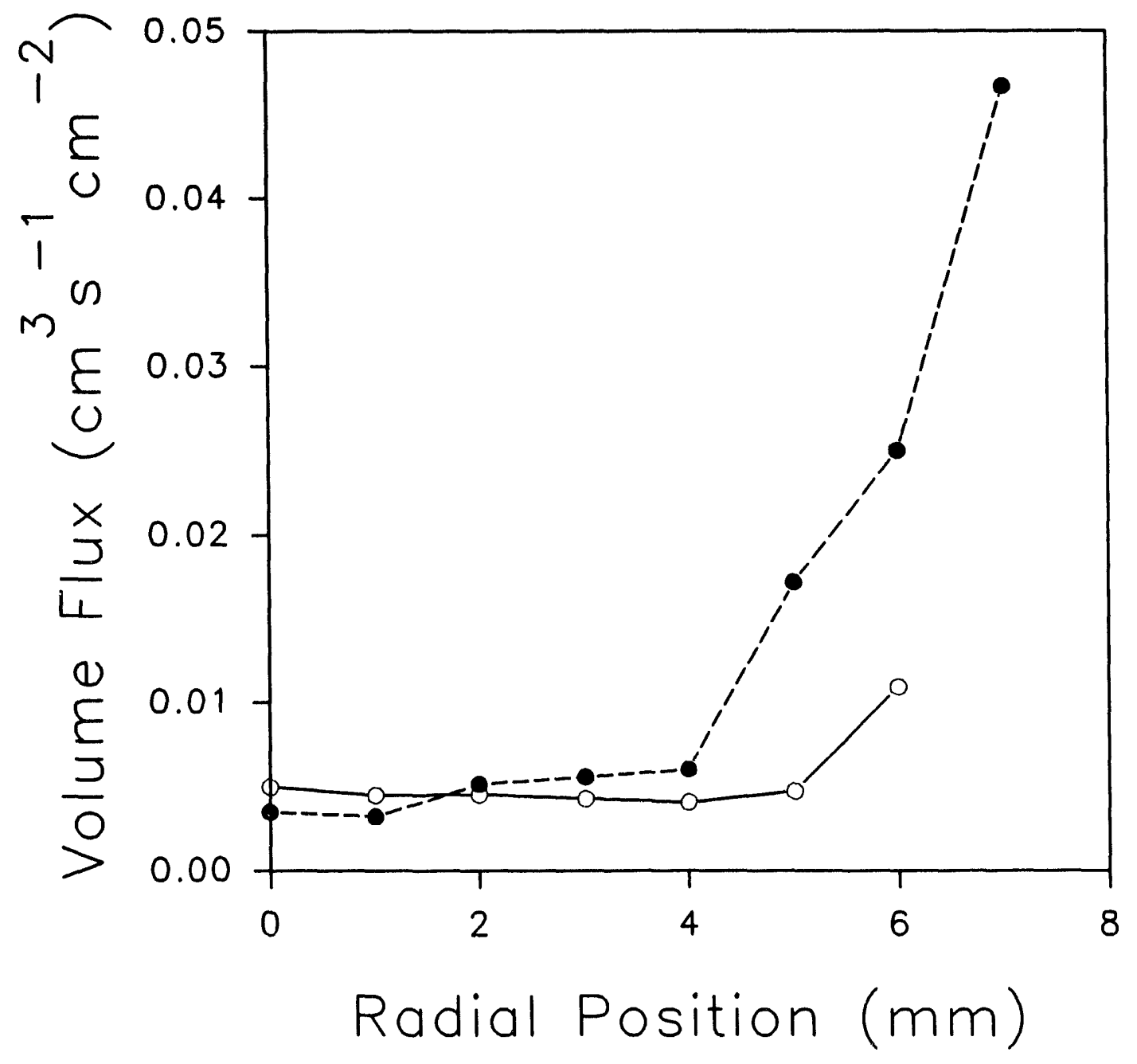

Figure 6. Radial profile of droplet volume flux $(\mathrm{F})$ at $\mathrm{z}=25 \mathrm{~mm}$ for two liquid flow rates: (O) $100 \mu \mathrm{L} \mathrm{min}{ }^{-1}$ and $(\bullet) 300 \mu \mathrm{L} \mathrm{min}$. 


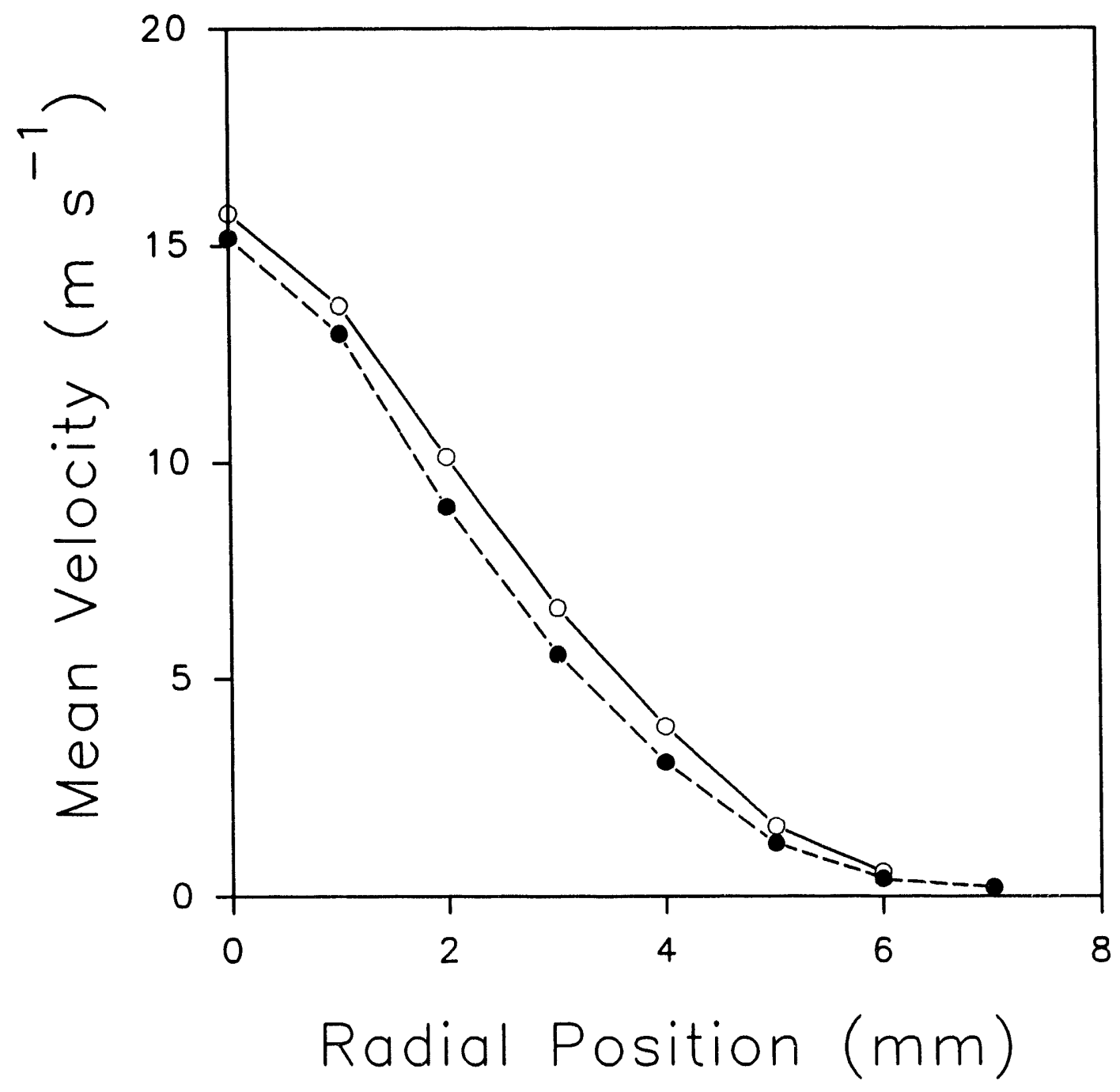

Figure 7. Radial profile of droplet mean velocity at $\mathrm{z}=25 \mathrm{~mm}$ for two liquid flow

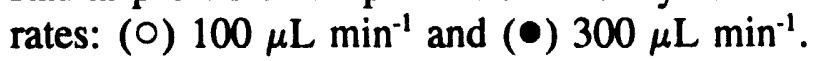




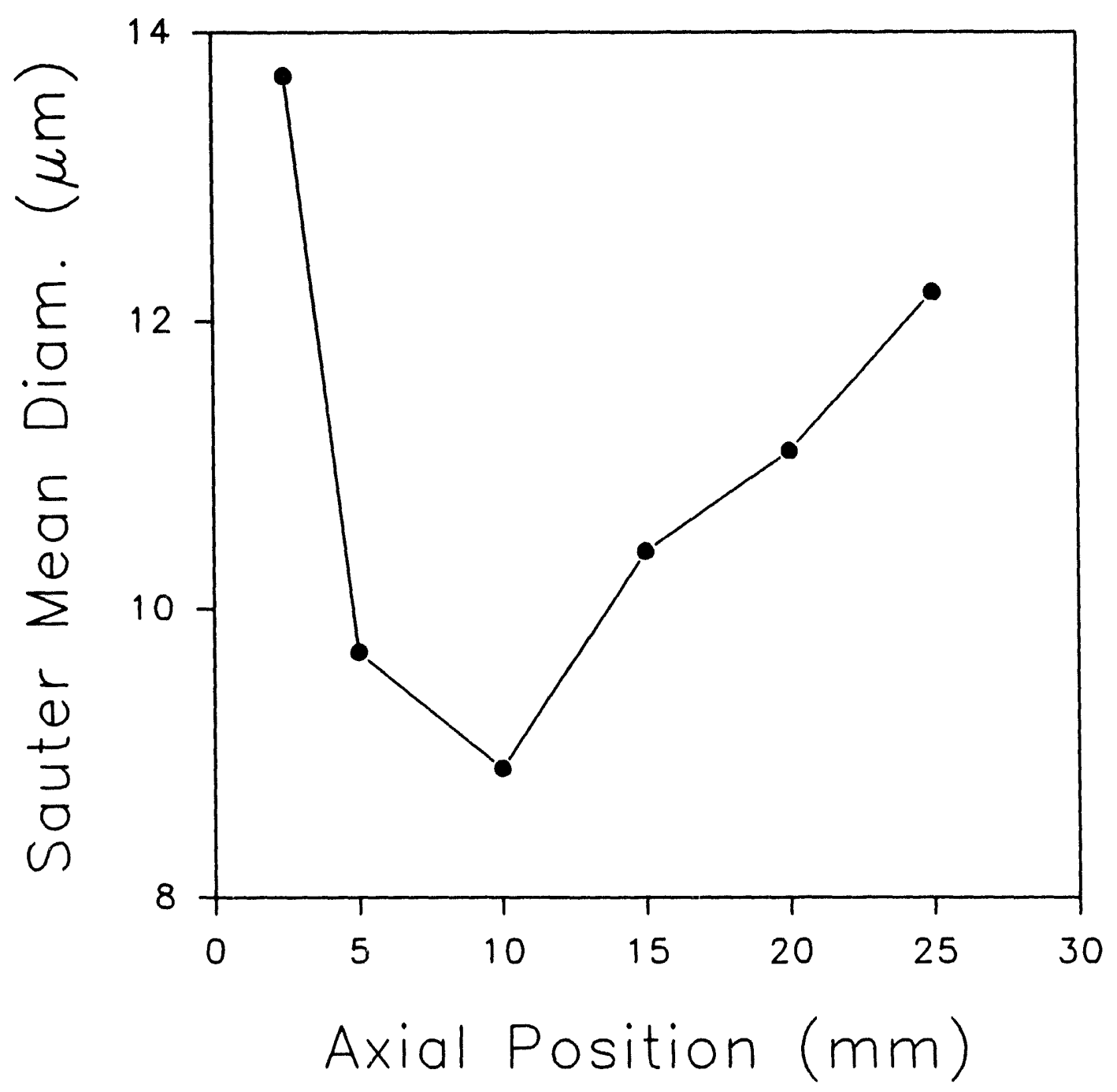

Figure 8. Axial profile of Sauter mean diameter $\left(D_{3,2}\right)$ at $r=0$. 


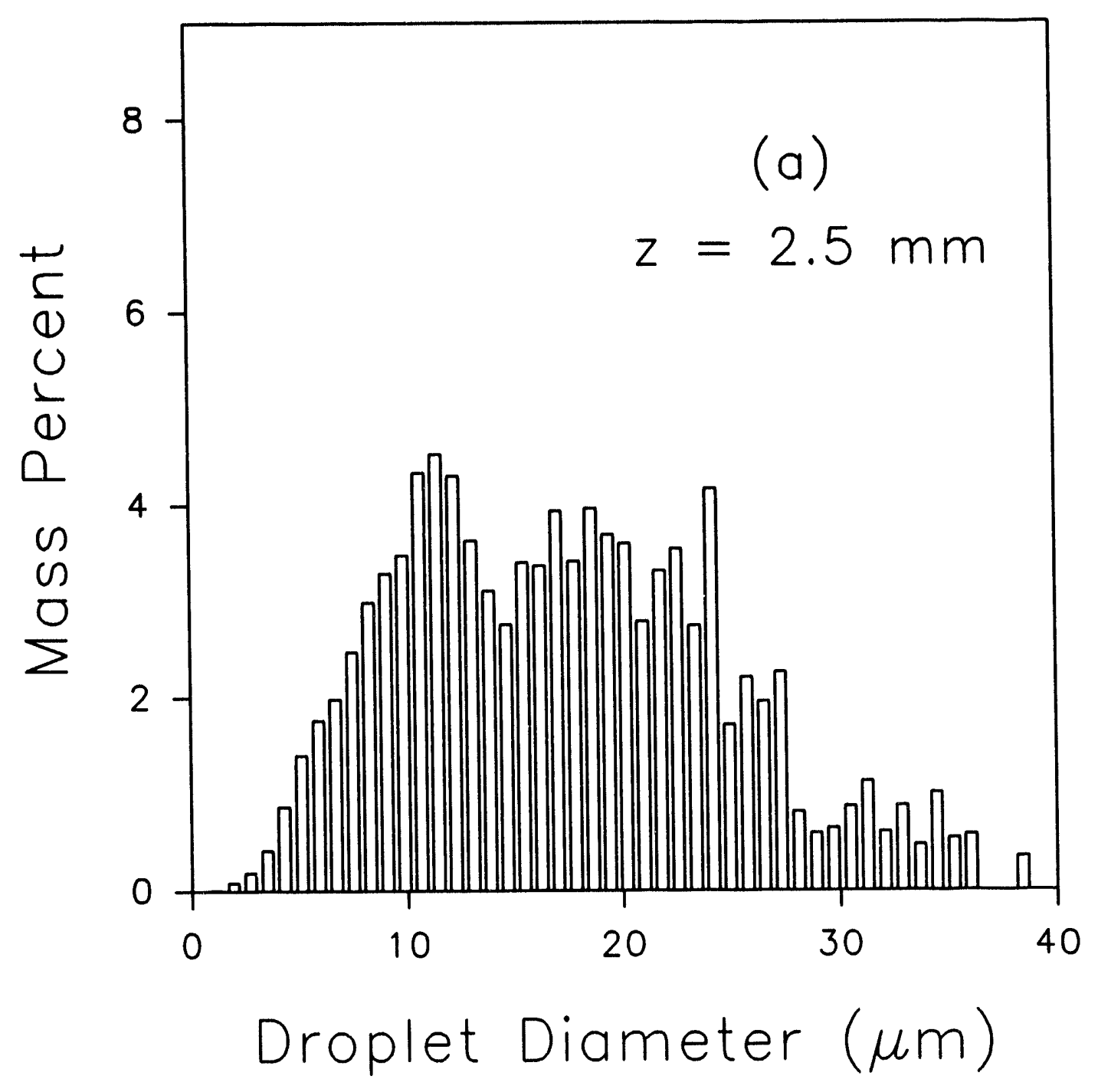

Figure 9. Droplet size distributions measured at two different axial position: (a) $z=$ $2.5 \mathrm{~mm}, \mathrm{r}=0$ and (b) $\mathrm{z}=10 \mathrm{~mm}, \mathrm{r}=0$. Experimental conditions are given in the text. 


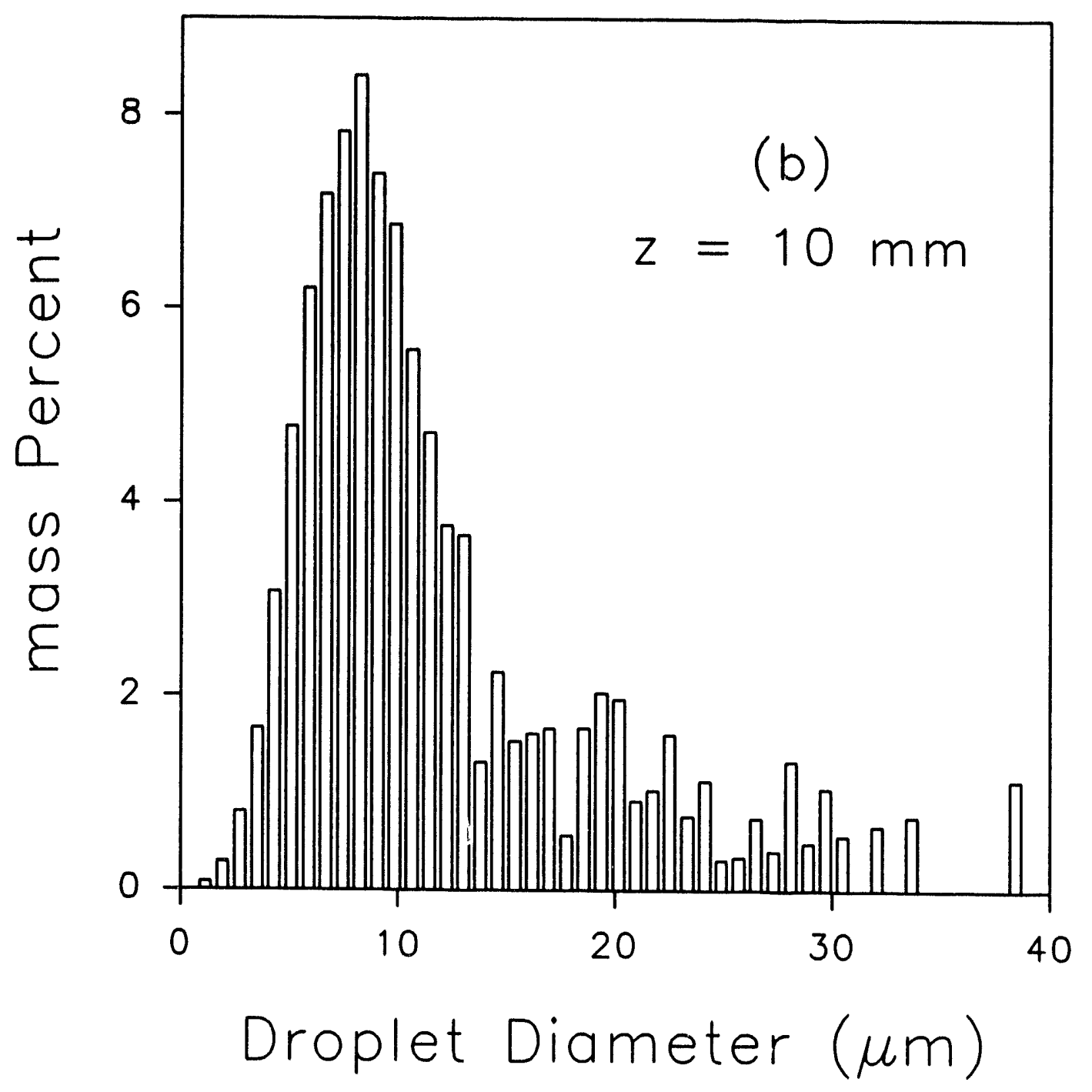

Figure 9. (continued) 

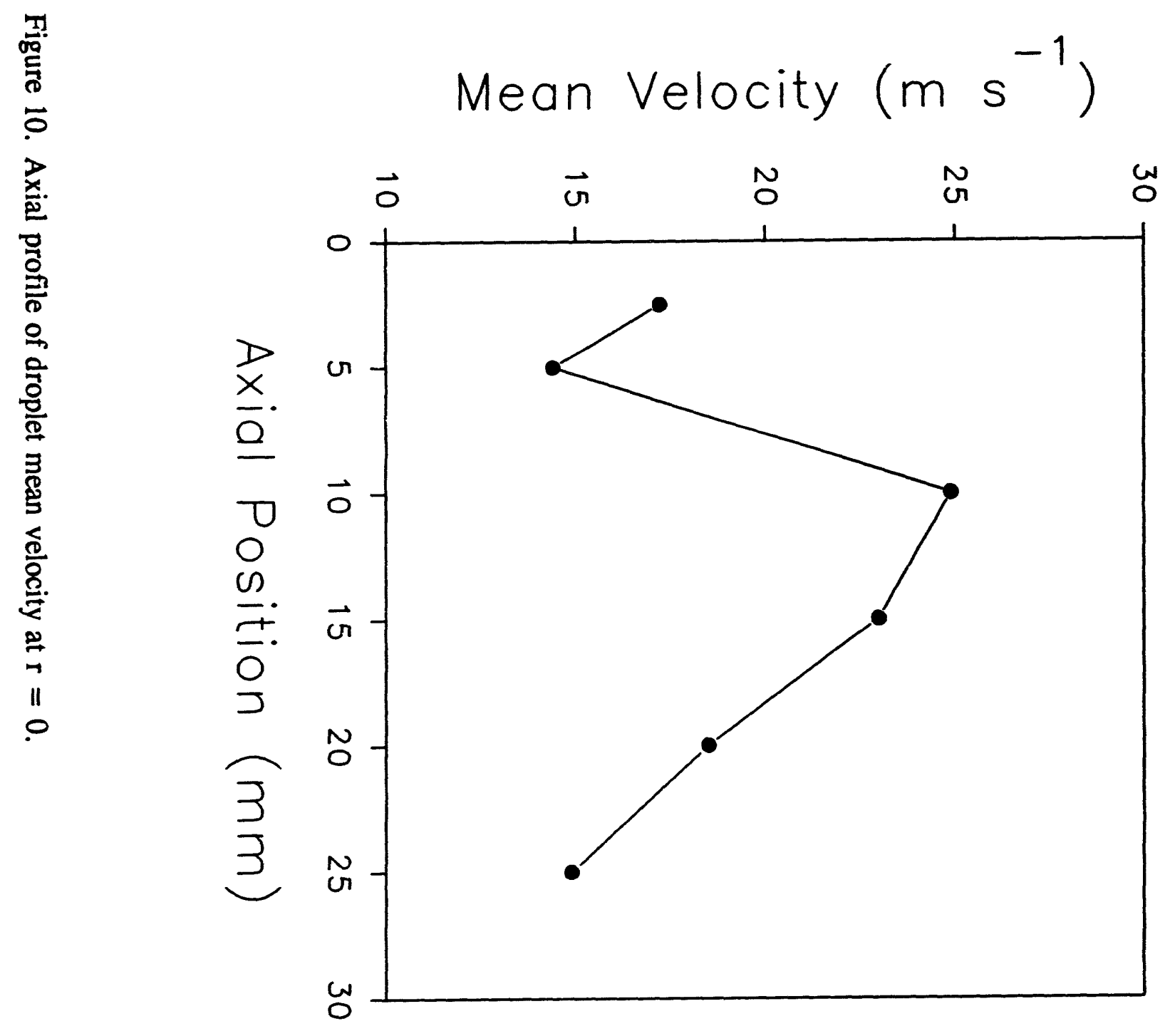
PAPER IV

ELEMENTAL SPECIATION BY ANION EXCHANGE AND SIZE EXCLUSION CHROMATOGRAPHY WITH DETECTION BY INDUCTIVELY COUPLED PLASMA MASS SPECTROMETRY WITH DIRECT INJECTION NEBULIZATION 


\section{INTRODUCTION}

The toxicological and biological roles of trace elements depend on their chemical forms and/or oxidation states (1-4). Thus, analytical methodology for measuring trace element speciation is necessary. Liquid chromatography (LC) has been coupled to inductively coupled plasma mass spectrometry (ICP-MS) to provide such speciation information (5-33). So far, various modes of LC including reversedphase (RP) (6-10), reversed-phase ion-pairing (RP-IP) (11-19), anion chromatography (AC) $(6,13,20-23)$, cation chromatography $(C C)(15,24-25)$, and size exclusion chromatography (SEC) $(6,26-33)$ have been combined with ICP-MS.

Fassel and co-workers originally described the direct injection nebulizer (DIN), which is a microconcentric pneumatic nebulizer placed inside the ICP torch

(34) Recently, a new version of the DIN has been successfully used as an interface for LC-ICP-MS experiments $(17,19,35)$ and has shown substantial improvement in terms of chromatographic resolution and detection limits, compared to those obtainable with conventional nebulizers. The DIN has a low dead volume $(0.5-2$ $\mu \mathrm{L})(19)$ and produces a mist of fine droplets (Sauter mean diameter $\approx 15 \mu \mathrm{m})(36)$. When used for LC-ICP-MS of $\mathrm{As}, \mathrm{Hg}, \mathrm{Pb}$, and $\mathrm{Sn}$ species, the DIN provides absolute detection limits that are superior by $1-2$ orders of magnitude to those obtained with conventional nebulizers $(17,19)$. In addition, the low dead volume and absence of a spray chamber minimize postcolumn band broadening and facilitate the use of 


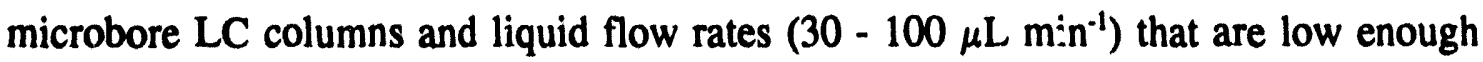
for all the column effluent to be introduced into the plasma.

Metals are found in many forms in human blood serum, and the distribution of a metal in serum between amino acids, proteins, enzymes, etc. often has important pathological implications. For example, iron exists in porphyrins in hemoglobin, myoglobin, cytochromes, peroxidases and catalases, is associated with sulfur in ferredoxins, and in invertebrates is present as the oxygen-carrying pigment, hemerythrin (37). Speciation analysis of a biological sample with its complex organic matrix is a difficult task. Nevertheless, it is essential that analytical capabilities in this area be improved if we are to understand in more detail the role of trace elements in health and disease (38).

A case in point is selenium, which is an essential element. However, not all selenium species are considered useful. In general, both of the common inorganic selenium species (selenite and selenate) are toxic, while organoselenium species, in particular the Se-containing amino acids, are biologically useful. Furthermore, ICPMS detection for chromatography should also permit isotope ratio measurements for individual elemental species for isotope tracer studies. Isotope tracer studies of the nutritional and medical role of Se and Se species have recently been of great interest $(39,40)$.

The present work demonstrates the separation and measurement of various metalloproteins in human serum and two selenium species $\left(\mathrm{SeO}_{3}{ }^{2-}\right.$ and $\left.\mathrm{SeO}_{4}{ }^{2 \cdot}\right)$ by 
SEC-DIN-ICP-MS and AC-DIN-ICP-MS, respectively. In addition, preliminary results of isotope ratio measurements on chromatographically separated species of Se are presented. 


\section{EXPERIMENTAL SECTION}

\section{HPLC-DIN-ICP-MS}

The HPLC system was composed of an SSI Model 222D metal-free microflow pump (Scientific Systems, Inc., State College, PA), a Rheodyne 9010 metal-free high-pressure sample injector with a $2 \mu \mathrm{L}$ PEEK injection loop, and an appropriate analytical column. A 1.6-mm-i.d. x 10-cm-long anion-exchange column (MCANX1710, CETAC Technologies, Omaha, NE) was used for the separation of Se species. A 2.0-mm-i.d. $\times$ 25-cm-long size exclusion column (GPC 300, SynChrom, Inc., Lafayette, IN) was used for separation of metalloproteins.

The conditions for both separations are summarized in Table I. The analytical column was equilibrated with the mobile phase prior to use. Several different combinations of mobile phase concentration, type and concentration of counter ion, $\mathrm{pH}$, etc. were evaluated to optimize chromatographic performance. The conditions listed in Table I are those that yielded the best chromatographic resolution of the various sets tested.

The design and the construction of the DIN have been discussed elsewhere $(17,41)$. A $50-\mu \mathrm{m}$-i.d. $\times 40$-cm-long fused silica capillary was used to transport effluent from the column into the plasma. The $50-\mu \mathrm{m}$ DIN is more resistant to plugging than the $30-\mu \mathrm{m}$ one used previously (19). The width of the annular gap between the inner capillary and the nebulizer tip was $\approx 25 \mu \mathrm{m}$, as in the previous 
work $(17,19)$.

The ICP-MS used was the Elan Model 250 (Perkin-Elmer Sciex, Thronhill, ON, Canada). Table II summarizes the instrumental operating conditions of the ICPMS device. The plasma and sampling conditions indicated with an asterisk were optimized daily to maximize the signal from the analyte of interest.

\section{Data Acquisition}

For the separation of metalloproteins, ten isotopes were measured during the chromatographic separation, as listed in Table I. To achieve compromise operating conditions over the whole mass range, the plasma, sampling conditions, and ion lens voltages were optimized to give maximum signal for ${ }^{103} \mathrm{Rh}^{+}$. The data were acquired in the multielement mode by peak hopping over ten $\mathrm{m} / \mathrm{z}$ positions using a $0.2 \mathrm{~s}$ measurement time, a $10 \mathrm{~ms}$ dwell time, and 1 measurement per peak.

For the separation of $\mathrm{SeO}_{3}{ }^{2-}$ and $\mathrm{SeO}_{4}{ }^{2-}$, two isotopes $\left({ }^{44} \mathrm{Se}\right.$ and $\left.{ }^{78} \mathrm{Se}\right)$ were monitored during the chromatographic separation. The data were acquired by peak hopping over the two isotopes using a $1 \mathrm{~s}$ measurement time, a $20 \mathrm{~ms}$ dwell time, and 1 measurement per mass peak. Several different combinations of measurement time (0.1 - $3 \mathrm{~s})$, dwell time $(1-100 \mathrm{~ms})$, and measurements per mass peak $(1-3)$ were evaluated for precision studies. The conditions reported for this work yielded the best precision of the various sets tested.

Chromatograms were recorded in real time and stored on the hard disk of an 
IBM PS/2 Model 70 computer. These data (as ASCII files) were then processed using a spread sheet program. The raw count rates were first smoothed with a fivepoint Savitzky - Golay routine (42). Peak area was determined by summing all the count rates under each peak. The background was measured while nebulizing only the mobile phase by summing the total counts in the particular chromatographic region corresponding to each peak. For this work, the detection limit was defined as the amount of the element necessary to give a peak area equal to three times the standard deviation of the background count rate at each analyte mass.

\section{Reagents and Samples}

Deionized water $\left(18 \mathrm{M} \Omega \mathrm{cm}\right.$ at $25^{\circ} \mathrm{C}$ ) obtained from a Barnstead Nanopure-II system (Newton, MA) was used throughout. For the separation of metalloproteins, a tris(hydroxymethyl)aminomethane/hydrochloric acid (Tris/ $\mathrm{HCl}$ ) buffer was used as the mobile phase. Eluent of high ionic strength, such as $0.1 \mathrm{M} \mathrm{NaCl}$, was not used to avoid plugging of the DIN. A $0.1 \mathrm{M} \mathrm{Tris} / \mathrm{HCl}$ solution was prepared by dissolving certified A.C.S. grade Tris (Fisher Scientific, Fair Lawn, NJ) in deionized water. The $\mathrm{pH}$ was adjusted to 6.9 with concentrated Ultrex II grade $\mathrm{HCl}$ (J. T. Baker, Inc., Phillipsburg, NJ). The relation between molecular weight (MW) and retention time for the size exclusion column was calibrated by monitoring the retention times of several pure protein standards including thyroglobulin (MW $\left.6.7 \times 10^{5} \mathrm{~g} \mathrm{~mol}^{-1}\right)$, ferritin (MW $4.4 \times 10^{5}$ ), $\beta$-amylase (MW $2.0 \times 10^{5}$ ), alcohol dehydrogenase (MW 1.5 
$\times 10^{5}$ ), and carbonic anhydrase (MW $\left.2.9 \times 10^{4}\right)$. These standards were obtained from Sigma Chemicals (St. Louis, MO). A human serum standard reference material (SRM 909a-1, National Institute of Standards and Technology, Gaithersburg, MD) was reconstituted in $10 \mathrm{~mL}$ of $0.1 \mathrm{M}$ Tris/ $\mathrm{HCl}$ buffer and used without further dilution.

For the separation of Se species, a mixture of $5 \mathrm{mM}\left(\mathrm{NH}_{4}\right)_{2} \mathrm{CO}_{3} / 5 \mathrm{mM}$ $\mathrm{NH}_{4} \mathrm{HCO}_{3}$ was used as the mobile phase. Pure samples (Certified A.C.S. grade) of these compounds were obtained from Fisher Scientific. Carbonate and hydrogen carbonate in their ammonium form were chosen, rather than the usual sodium form, to avoid matrix effects (43-47) and clogging of the DIN: $(17,19)$. 


\section{RESULTS AND DISCUSSION}

\section{Calibration of the Size Exclusion Column}

In this study, approximately $2 \times 10^{-5} \mathrm{M}$ solutions of each of the metalloprotein standards in $0.1 \mathrm{M} \mathrm{Tris} / \mathrm{HCl}$ were prepared. Mass spectra $(\mathrm{m} / \mathrm{z}=20-220)$ of these metalloprotein standard solutions were obtained. The unique elements (i.e., those other than $\mathrm{C}, \mathrm{N}, \mathrm{O}, \mathrm{H}$, and $\mathrm{Cl}$ ) present in each protein standard were identified and are given in Table III. For example, three metals $(\mathrm{Fe}, \mathrm{Cu}$, and $\mathrm{Zn}$ ) werc found to be associated with ferritin (48).

Next, the calibration curve for the size exclusion column was obtained. The retention times for each of the protein standards were determined by operating the ICP-MS device in the peak-hopping mode while monitoring the isotopes of interest. These results are also given in Table III. Relative standard deviations $(n=3)$ for the measured retention times were under $1.5 \%$. Figure 1 shows a typical column calibration curve obtained by plotting log (molecular weight) vs retention time. The correlation coefficient equals 0.997 . Note that the selective permeation (linear) range of this gel column was $\approx 4.5-5.75 \mathrm{~min}$ and was rather small. In principle, this range can be extended by using either several columns in series, each containing gel of different pore size, or a mixed gel column (49). 


\section{Separation of Metalloproteins by SEC-DIN-ICP-MS}

Chromatograms for the separation of metalloproteins are given in Figure 2. Pertinent separation conditions are given in Table I. Six metal-binding molecular weight fractions ( $>650,300,130,85,50$, and $15 \mathrm{kDa}$ ) were observed. Table IV summarizes and sorts the metal contents of these molecular weight fractions. Four of these molecular weight fractions ( $>650,300,130$, and $15 \mathrm{kDa}$ ) contained $\mathrm{Pb}$. Gercken and Barnes (28), in a similar study, reported three molecular weight fractions ( $>600,260$, and $140 \mathrm{kDa}$ ) of $\mathrm{Pb}$ species. The major $\mathrm{Pb}$-containing molecular weight fraction (130 kDa) also contained $\mathrm{Cd}, \mathrm{Zn}, \mathrm{Ba}, \mathrm{Cu}$, and $\mathrm{Na}$. One possible protein responsible for this molecular weight fraction is ceruloplasmin, a well known glycoprotein for metal storage and electron transfer $(28,50)$. There was only one Febinding molecular weight fraction found at $\approx 85 \mathrm{kDa}$, which could be serum transferrin, a well known iron glycoprotein in physiological fluids (51). The proteins responsible for the other molecular weight fractions await identification by techniques such as immunological reactions or other types of MS.

At about $6.7 \mathrm{~min}$ after injection (Figure 2), a $\mathrm{Pb}$, two $\mathrm{Cd}$ and two Ba peaks were observed. These peaks coeluted with $\mathrm{Na}$ from the sample. The $\mathrm{Pb}$ peak was determined to be inorganic lead $\left(\mathrm{Pb}^{+2}\right)$ by adding some $\mathrm{Pb}^{2+}$ to the sample. However, the addition of $\mathrm{Cd}^{+2}$ and $\mathrm{Ba}^{+2}$ to the sample yielded peaks at retention times longer than $8.5 \mathrm{~min}$; that is, those $\mathrm{Cd}$ and $\mathrm{Ba}$ peaks found at about $6.7 \mathrm{~min}$ were not from $\mathrm{Cd}^{+2}$ and $\mathrm{Ba}^{+2}$. In a previous study with the DIN (52), the 
background across the upper end of the mass range $(\mathrm{m} / \mathrm{z}>45)$ shifted to higher values as the salt content of the solvent increased. Perhaps the unknown $\mathrm{Cd}$ and $\mathrm{Ba}$ peaks were artifacts from a background shift when the highly concentrated Na matrix eluted.

Elevated backgrounds for $\mathrm{Zn}, \mathrm{Ba}, \mathrm{Cu}, \mathrm{Fe}$, and $\mathrm{Na}$ were observed (Figure 2). The elevated $\mathrm{Ba}$ and $\mathrm{Na}$ background was caused by the presence of $\mathrm{Ba}$ and $\mathrm{Na}$ impurities in the buffer. The elevated ${ }^{54} \mathrm{Fe},{ }^{63} \mathrm{Cu}$, and ${ }^{64} \mathrm{Zn}$ backgrounds were caused by the formation of ${ }^{40} \mathrm{Ar}^{14} \mathrm{~N}^{+},{ }^{40} \mathrm{Ar}^{23} \mathrm{Na}^{+}$, and ${ }^{40} \mathrm{Ar}^{24} \mathrm{C}_{2}{ }^{+}$polyatomic ions resulting from the nitrogen, carbon and sodium in the buffer solution. The high background (at $\mathrm{m} / \mathrm{z}=64)$ could also be due to the formation $\mathrm{SO}_{2}{ }^{+}$from S-containing amino acids in sample.

\section{Estimated Detection Limits}

The detection limits for $\mathrm{Fe}, \mathrm{Cu}, \mathrm{Zn}, \mathrm{Cd}$, and $\mathrm{Pb}$ in metalloproteins were estimated from their peak heights for the molecular weight fraction at $130 \mathrm{k} \mathrm{Da}$. The total concentrations of $\mathrm{Fe}, \mathrm{Cu}, \mathrm{Zn}, \mathrm{Cd}$, and $\mathrm{Pb}$ in the serum sample measured by standard addition were $113,107,163,6.3$, and $6.5 \mu \mathrm{g} \mathrm{L}^{-1}$, respectively. The appropriate amount of analyte responsible for each peak in the molecular weight fraction $(130 \mathrm{k} \mathrm{Da})$ was determined by proportion.

Calculated detection limits are given in Table V. The absolute detection limits for $\mathrm{Fe}, \mathrm{Cu}, \mathrm{Zn}, \mathrm{Cd}$, and $\mathrm{Pb}$ in metalloproteins were 3, 0.7, 1, 0.5, and $0.5 \mathrm{pg}$, 
respectively. These absolute detection limits are comparable to those obtained for the same metals in aqueous samples with the DIN and are superior by $1-2$ orders of magnitude over those obtained previously by SEC-ICP-MS (Table V). The relative detection limits for $\mathrm{Fe}, \mathrm{Cu}, \mathrm{Zn}, \mathrm{Cd}$ and $\mathrm{Pb}$ were $2,0.4,0.5,0.3$, and $0.3 \mu \mathrm{g} \mathrm{L}^{-1}$, respectively. These relative detection limits are comparable with those obtained previously by SEC-ICP-MS with conventional nebulizers (Table V).

\section{Separation of Se Species by AC-DIN-ICP-MS}

Figure 3 shows a typical chromatogram for the separation of $\mathrm{SeO}_{3}{ }^{2 \cdot}$ and $\mathrm{SeO}_{4}{ }^{2-}$. Pertinent separation conditions are given in Table I. The amount of Se for each species used per injection was $5 \mathrm{ng}$. The analytical figures of merit for this separation method are given in Table VI. Peak area measurements indicated that the Se sensitivity (total counts / ng Se) was similar (i.e., within 5\%) for the two forms of Se (Table VI). Precision based on five separate injections and measurement of peak areas was $\approx 3 \%$ RSD for both species. Absolute detection limits calculated using ${ }^{78} \mathrm{Se}$ and peak area measurements were $\approx 15 \mathrm{pg}$ for both of the species. These absolute detection limits were superior by an order of magnitude over those obtained previously by LC-ICP-MS with ultrasonic nebulizer (11). Relative detection limits for both forms were $\approx 7-8 \mu \mathrm{g} \mathrm{L}^{-1}$, which are comparable to those obtained previously (11).

Isotope ratios for each selenium species were determined by measuring the 
area of the appropriate chromatographic peaks for each isotope. Table VII summarizes the results on isotope ratio measurements of the two selenium species. When only $5 \mathrm{ng}$ of Se for each Se species was used, the relative standard deviations obtainable was $\approx 2 \%$. High RSDs obtainable was caused by the low total counts for ${ }^{74} \mathrm{Se}$ and ${ }^{78} \mathrm{Se}\left(\approx 80000\right.$ and 2800 counts for ${ }^{78} \mathrm{Se}$ and ${ }^{74} \mathrm{Se}$, respectively). The RSD expected from counting statistics on the minor isotope $\left({ }^{4} \mathrm{Se}\right)$ would be $(\sqrt{ }(2800) / 2800)$ or $1.8 \%$. This value is comparable to the $2 \%$ precision cited above for the isotope ratio, so counting statistics limited the precision in this case. When the amount of Se for each selenium species was increased to $25 \mathrm{ng}$, the RSDs improved to 0.3 and $0.5 \%$. Therefore, the amount of sample injected had a significant effect on the precision in the present work, as expected because of the low abundance of ${ }^{74} \mathrm{Se}$.

With conventional nebulizers, expericnce has shown that $1-10 \mu \mathrm{g}$ of analyte is required for isotope ratio measurements with RSDs of $\pm 0.5 \%$ or better, using either flow injection or continuous flow sample introductions (53-55). In the present work the amount of analyte used per injection was $25 \mathrm{ng}$. Suppose 10 injections were needed to evaluate the precision of the isotope ratio measurement. These injections would require a total of $\approx 0.25 \mu \mathrm{g}$ of the analyte. The DIN is therefore attractive for isotope ratio measurements when the amount of analyte available is below $\approx 1$ $\mu \mathrm{g}$. 


\section{CONCLUSION}

The analytical merits of SEC-DIN-ICP-MS and AC-DIN-ICP-MS are demonstrated. The absolute detection limits for Se in a test mixture and for metals $(\mathrm{Fe}, \mathrm{Cu}, \mathrm{Zn}, \mathrm{Cd}$, and $\mathrm{Pb})$ in protein fractions in human serum are improved by $1-2$ orders of magnitude, relative to those obtained with conventional nebulizers. Metalloproteins were measured directly in human serum without preliminary extraction or preconcentration. The low dead volume $(<2 \mu \mathrm{L})$ associated with the DIN resulted in low extracolumn broadening and good chromatographic resolution.

The capability of using chromatographic peak areas for isotope ratio measurements on Se species is also demonstrated. A relative standard deviation of less than $0.5 \%$ is obtainable in cases where precision is not limited by counting statistics. The feasibility of applying the same method to measure isotope ratios for elements of interest in tough matrix such as urine, serum, and seawater warrants further investigation. 


\section{LITERATURE CITED}

1. Goyer, R. A. In Casarett and Doull's Toxicology: The Basic Science of Poisons, 4th ed.; Casarett, L. J.; Amdur, M. O.; Doull, J.; Klaassen, C. D., Eds.; Pergamon Press: New York, 1991; Chapter 19.

2. Cappon, C. J. $L C / G C$ 1988, 6, 584-599.

3. Batley, G. E.; Low, G. K.-C. In Trace Element Speciation Analytical Methods and Problems; Batley, G. E., Ed.; CRC Press, Inc.: Boca Raton, Florida, 1989; Chapter 6.

4. Gardiner, P. E. J. Anal. At. Spectrom. 1988, 3, 163-168.

5. Houk, R. S.; Jiang, S. J. In Trace Metal Analysis and Speciation; Krull, I. S., Ed.; Elsevier: New York, 1991; Chapter 5.

6. Elder, R. C.; Jones, W. B.; Tepperman, K. In Element - Specific Chromatographic Detection by Atomic Emission Spectroscope; Uden, P. C., Ed.; ACS Symposium Series 479: Washington, DC, 1992, Chapter 18.

7. Braverman, D. S. J. Anal. At. Spectrom. 1992, 7, 43-46.

8. Suyani, H.; Heitkemper, D.; Creed, J.; Caruso, J. Appl. Spectrosc. 1989, 43 962-967.

9. Bushee, D. S. Analyst 1988, 113, 1167-1170.

10. Bushee, D. S.; Moody, J. R.; May, J. C. J. Anal. At. Spectrom. 1989, 4, 773-775. 
11. Thompson, J. J.; Houk, R. S. Anal. Chem. 1986, 58, 2541-2548.

12. Jiang, S. J.; Houk, R. S. Spectrochim. Acta 1988, 43B, 405-411.

13. Beauchemin, D.; Siu, K. W. M.; McLaren, J. W.; Berman, S. S. J. Anal. At. Spectrom. 1989, 4, 285-289.

14. Shibata, Y.; Morita, M. Anal. Chem. 1989, 61, 2116-2118.

15. Suyani, H.; Creed, J.; Davidson, T.; Caruso, J. J. Chromatogr. Sci. 1989, 27, 139-143.

16. Al-Rashdan, A.; Vela, N. P.; Caruso, J. A.; Heitkemper, D. T. J. Anal. At. Spectrom. 1992, 7 551-555.

17. Shum, S. C. K.; Neddersen, R.; Houk, R. S. Analyst 1992, 117, 577-582.

18. Zhao, Z.; Jones, W. B.; Tepperman, K.; Dorsey, J. G.; Elder, R. C. J. Pharm. Biomed. Anal. 1992, 10, 279-287.

19. Shum, S. C. K.; Pang, H. M.; Houk, R. S. Anal. Chem. 1992, 64, 24442450.

20. Sheppard, B. S.; Caruso, J. A.; Heitkemper, D. T.; Wolnik, K. A. Analyst 1992, 117, 971-975.

21. Sheppard, B. S.; Shen, W.-L.; Caruso, J. A.; Heitkemper, D. T.; Fricke, F. L. J. Anal. At. Spectrom. 1990, 5, 431-435.

22. Heitkemper, D.; Creed, J.; Caruso, J.; Fricke, F. L. J. Anal. At. Spectrom. $1989,4,279-284$. 
23. Suzuki, S.; Tsuchihashi, H.; Nakajima, K.; Matsushita, A.; Nagao, T. J. Chromatogr. 1988, 437, 322-327.

24. Kawabata, K.; Kishi, Y.; Kawaguchi, O.; Watanabe, Y.; Inoue, Y. Anal. Chem. 1991, 63, 2137-2140.

25. Boomer, D. W.; Powell, M. J.; Hipfner, J. Talanta 1990, 37, 127-134.

26. Takatera, K.; Watanabe, T. Anal. Sci. 1992, 8, 469-474.

27. Owen, L. M. W.; Crews, H. M.; Hutton, R. C.; Walsh, A. Analyst 1992, $117,649-655$.

28. Gercke- B.; Barnes, R. M. Anal. Chem. 1991, 63, 283-287.

29. Takatera, ४.; Watanabe, T. Anal. Sci., 1991, 7, 695-698.

30. Mason, A. .; Storms, S. D.; Jenkins, K. D. Anal. Biochem. 1990, 186, 187201.

31. Crews, H. M.; Dean, J. R.; Ebdon, L.; Massey, R. C. Analyst 1989, 114, 895-899.

32. Matz, S. G.; Elder, R. C.; Tepperman, K. J. Anal. At. Spectrom. 1989, 4, 767-771.

33. Dean, J. R.; Munro, S.; Ebdon, L.; Crews, H. M.; Massey, R. C. J. Anal. At. Spectrom. 1987, 2, 607-610.

34. LaFreniere, K. E.; Fassel, V. A.; Eckels, D. E. Anal. Chem. 1987, 59, 879887. 
35. Houk, R. S.; Shum, S. C. K.; Wiederin, D. R. Anal. Chim. Acta 1991, 250, 61-70.

36. Shum, S. C. K.; Pang, H. M.; Johnson, S. K.; Houk, R. S. Appl. Spectrosc., 1993, in press.

37. Otsuka, S.; Yamanaka, T., Eds. Metalloproteins Chemical Properties and Biological Effects; Kodansha Ltd.: Tokyo, 1988; Chapter 5.

38. Florence, T. M. In Trace Element Speciation Analytical Methods and Problems; Batley, G. E., Ed.; CRC Press, Inc.: Boca Raton, Florida, 1989; Chapter 9.

39. Janghorbani, M.; Lynch, N. E.; Movers, C. S.; Ting, B. T. G. J. Nutr., 1990, 120, 190-199.

40. Janghorbani, M.; Young, V. R. In Selenium in Biology and Medicine, Third International Symposium; Combs, G. F., Jr.; Spallholz, J. E.; Lewander, O. A.; Oldfield, J., Eds.; Van Nostrand Reinhold: New York, 1987; pp. 450471.

41. Wiederin, D. R.; Smith, F. G.; Houk, R. S. Anal. Chem. 1991, 63, 219-225.

42. Savitzky, A.; Golay, M. J. E. Anal. Chem. 1964, 36, 1627-1639.

43. Olivares, J. A.; Houk, R. S. Anal. Chem. 1986, 58, 20-25.

44. Jiang, S. -J.; Houk, R. S. Anal. Chem. 1986, 58, 1739-1743.

45. Douglas, D. J.; Kerr, L. A. J. Anal. At. Spectrom. 1988, 3, 749-752.

46. Tan, S. H.; Horlick, G. J. Anal. At. Spectrom. 1987, 2, 745-763. 
47. Beauchemin, D.; McLaren, J. W.; Berman, S. S. Spectrochim. Acta 1987, 42B, 467-490.

48. Shinjo, S. In Metalloproteins Chemical Properties and Biological Effects;

Otsuka, S.; Yamanaka, T., Ed.; Kodansha Ltd.: Tokyo, 1988; pp. 249-255.

49. Hunt, B. J. In Size Exclusion Chromatography; Hunt, B. J.; Holding, S. R., Ed.; Blackie: London, 1989; p. 10.

50. Nakamura, T. In Metalloproteins Chemical Properties and Biological Effects; Otsuka, S.; Yamanaka, T., Eds.; Kodansha Ltd.: Tokyo, 1988; pp. 291-307.

51. Brock, J. H. In Metalloproteins, Part 2; Harrison, P. M., Ed.; Macmillan: London, 1985; Chapter 5.

52. Wiederin, D. R.; Smyczek, R. E.; Houk, R. S. Anal. Chem. 1991, 63, 16261631.

53. Janghorbani, M.; Ting, B. T. G.; J. Nutr. Biochem. 1990, 1, 4-19.

54. Viczián, M.; Lásztity, A.; Barnes, R. M. J. Anal. At. Spectrom. 1990, 5, 293-300.

55. Date, A. R.; Cheung, Y. Y. Analyst 1987, 112, 1531-1540. 
Table I. Chromatographic conditions

\begin{tabular}{|c|c|c|}
\hline & $\begin{array}{l}\text { Separation of } \\
\text { selenium species }\end{array}$ & $\begin{array}{l}\text { Separation of } \\
\text { metalloproteins }\end{array}$ \\
\hline Column & $\begin{array}{l}\text { CETAC Technologies } \\
\text { PEEK column } \\
\text { 1.6-mm-i.d. x 100-mm-long }\end{array}$ & $\begin{array}{l}\text { SynChrom, Inc. } \\
\text { SynChropak GPC } 300 \\
\text { 2-mm-i.d. x 250-mm-long }\end{array}$ \\
\hline Stationary phase & $\begin{array}{l}\text { Anion exchange resin } \\
(5-\mu \mathrm{m} \text { particles) }\end{array}$ & $\begin{array}{l}\text { Silica gel } \\
(5-\mu \mathrm{m} \text { particles, pore size }=300 \AA)\end{array}$ \\
\hline Mobile phase & $5 \mathrm{mM} \mathrm{NH}_{4} \mathrm{HCO}_{3} / 5 \mathrm{mM}\left(\mathrm{NH}_{4}\right)_{2} \mathrm{CO}_{3}$ & $0.1 \mathrm{M}$ Tris/HCl $(\mathrm{pH}=6.9)$ \\
\hline Sample flow rate & $100 \mu \mathrm{L} \min ^{-1}$ & $100 \mu \mathrm{L} \min ^{-1}$ \\
\hline Injection volume & $2 \mu \mathrm{L}$ & $2 \mu \mathrm{L}$ \\
\hline Isotopes monitored & $\mathrm{m} / \mathrm{z}={ }^{74} \mathrm{Se},{ }^{78} \mathrm{Se}$ & $\mathrm{m} / \mathrm{z}={ }^{23} \mathrm{Na},{ }^{63} \mathrm{Cu},{ }^{65} \mathrm{Cu},{ }^{54} \mathrm{Fe},{ }^{57} \mathrm{Fe}$, \\
\hline
\end{tabular}


Table II. Instrument Conditions and Operating Procedures

ICP torch

argon flow rates $\left(\mathrm{L} \mathrm{min}{ }^{-1}\right)$

outer

auxiliary

make-up

nebulizer gas

sample flow rate

forward power

sampling position

sampler

skimmer

detector voltage

ion lens setting

bessel

plate

barrel

photon stop

operating pressures

interface

quadrupole chamber
Modified Sciex short torch :

injector tube orifice diameter $=1 \mathrm{~mm}$;

6-mm-o.d. x 4-mm-i.d. quartz tee

attached at torch base

$12^{\circ}$

$1^{\circ}$

$0.30^{\circ}$ regulated by mass flow controller

$0.4^{\circ}$

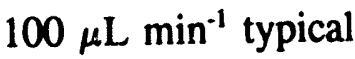

$1.4 \mathrm{~kW}^{*}$

$20 \mathrm{~mm}$ from load coil, on center

Copper, 1.0-mm-diameter orifice

Nickel, 0.9-mm-diameter orifice

$-4000 \mathrm{~V}$

$-19.80 \mathrm{~V}$

$-11.00 \mathrm{~V}$

$+5.42 \mathrm{~V}$

$-7.46 \mathrm{~V}^{\circ}$

1.5 torr

$3 \times 10^{-5}$ torr

- Typical values cited. These parameters were adjusted daily to maximize ion signal (see text) and differed slightly from day to day. 
Table III. Estimated molecular weight values and retention times for protein standards separated by SEC-DIN-ICP-MS using $0.1 \mathrm{M}$ Tris (pH 6.9) and elements associated with the individual protein standards.

\begin{tabular}{|c|c|c|c|c|}
\hline Protein standards & $\begin{array}{l}\text { Estimated molecular } \\
\text { weight (Da) }\end{array}$ & Isotope monitored & $\begin{array}{l}\text { Mean retention time } \\
(\mathrm{min})^{b}\end{array}$ & $\operatorname{RSD}(\%)^{b}$ \\
\hline Thyroglobulin & $6.7 \times 10^{5}$ & ${ }^{127} \mathrm{I}$ & 4.47 & 0.8 \\
\hline Ferritin & $4.4 \times 10^{5}$ & ${ }^{54} \mathrm{Fe},{ }^{63} \mathrm{Cu},{ }^{64} \mathrm{Zn}$ & 4.71 & 1.1 \\
\hline$\beta$-Amylase & $2.0 \times 10^{5}$ & ${ }^{63} \mathrm{Cu}$ & 4.94 & 1.5 \\
\hline Alcohol dehydrogenase & $1.5 \times 10^{5}$ & ${ }^{64} \mathrm{Zn},{ }^{114} \mathrm{Cd}$ & 5.15 & 1.3 \\
\hline Carbonic anhydrase & $2.9 \times 10^{4}$ & ${ }^{63} \mathrm{Cu},{ }^{64} \mathrm{Zn}$ & 5.88 & 1.4 \\
\hline
\end{tabular}

^Molecular weight values were provided by Sigma.

$b_{n}=3$ separate injections 
Table IV. Six metal-binding molecular weight fractions determined in human serum

Metal-binding molecular weight fractions
Trace metals associated with each molecular weight fraction
$650 \mathrm{k}$

$300 \mathrm{k}$

$130 \mathrm{k}$

$85 \mathrm{k}$

$50 \mathrm{k}$

$15 \mathrm{k}$
$\mathrm{Pb}, \mathrm{Cd}, \mathrm{Zn}, \mathrm{Cu}$

$\mathrm{Pb}, \mathrm{Zn}, \mathrm{Cu}$

$\mathrm{Pb}, \mathrm{Cd}, \mathrm{Zn}, \mathrm{Ba}, \mathrm{Cu}, \mathrm{Na}$

$\mathrm{Fe}$

$\mathrm{Zn}$

$\mathrm{Pb}, \mathrm{Zn}$ 
Table V. Estimated detection limits for metal ions in proteins

\begin{tabular}{|c|c|c|c|c|c|}
\hline \multirow[b]{2}{*}{ Metal } & \multirow[b]{2}{*}{$\mathrm{m} / \mathbf{z}$} & \multicolumn{4}{|c|}{ Detection limit } \\
\hline & & $\begin{array}{r}\text { Prese } \\
\text { Absolute (pg) }\end{array}$ & $\begin{array}{l}\text { work }^{2} \\
\text { Relative }\left(\mu \mathrm{g} \mathrm{L}^{-1}\right)\end{array}$ & $\begin{array}{l}\text { Liter } \\
\text { Absolute (pg) }\end{array}$ & $\begin{array}{l}\text { values } \\
\text { Relative }\left(\mu \mathrm{g} \mathrm{L}^{-1}\right)\end{array}$ \\
\hline $\mathrm{Fe}$ & 54 & 3 & 2 & $900^{b}$ & $9^{b}$ \\
\hline $\mathrm{Cu}$ & 63 & 0.7 & 0.4 & $6^{b}, 270^{c}, 10^{d}$ & $0.06^{b}, 2.7^{c}, 0.2^{d}$ \\
\hline $\mathrm{Zn}$ & 64 & 1 & 0.5 & $40^{b}, 63^{c}, 25^{d}$ & $0.4^{b}, 0.63^{c}, 0.5^{d}$ \\
\hline $\mathrm{Cd}$ & 114 & 0.5 & 0.3 & $12^{\mathrm{c}}, 25^{\mathrm{d}}, 100^{\mathrm{e}}$ & $0.12^{\mathrm{c}}, 0.5^{\mathrm{d}}, 1^{\mathrm{e}}$ \\
\hline $\mathrm{Pb}$ & 208 & 0.5 & 0.3 & $5-15^{b}$ & $0.05-0.15^{b}$ \\
\hline
\end{tabular}

- See text for calculation.

b Ref. 28

c Ref. 30

d Ref. 32

- Ref. 31 
Table VI. Analytical figures of merit for the separation of selenium species

\begin{tabular}{lcc}
\hline & $\mathrm{SeO}_{3}{ }^{2-}$ & $\mathrm{SeO}_{4}{ }^{2-}$ \\
\hline Retention time (min) & 3.4 & 9.0 \\
Sensitivity" (counts/pg of Se) & 15 & 14 \\
$\mathrm{RSD}^{\mathrm{b}}(\%)$ & 2.8 & 2.9 \\
$\begin{array}{l}\text { Detection limits: } \\
(\mathrm{pg} \text { of Se) } \\
\left(\mu \mathrm{g} \mathrm{L}^{-1}, \mathrm{ppb}\right)\end{array}$ & 14 & 15 \\
\hline
\end{tabular}

- Sensitivity was calculated based on net peak area and amount injected.

b Relative standard deviation of peak area for five replicate injections of $5 \mathrm{ng}$ (as Se) of each species. See Table I for LC conditions.

- Detection limit defined as amount of Se required to yield a net peak that was 3 times the standard deviation of background. Peak areas were used in these calculations. 
Table VII. Isotope ratio measurements on two selenium species

\begin{tabular}{lccc}
\hline $\begin{array}{l}\text { Selenium } \\
\text { Species }\end{array}$ & $\begin{array}{c}\text { Amount } \\
(\mathrm{ng})\end{array}$ & $\begin{array}{c}\text { Determined } \\
\text { Mean }\end{array}$ & $\begin{array}{c}{ }^{74} \mathrm{Se} /{ }^{78} \mathrm{Se} \\
\mathrm{RSD}(\%)^{*}\end{array}$ \\
\hline $\mathrm{SeO}_{3}{ }^{2-}$ & 5 & 0.035 & 1.3 \\
$\mathrm{SeO}_{4}{ }^{2-}$ & 5 & 0.033 & 1.7 \\
$\mathrm{SeO}_{3}{ }^{2-}$ & 25 & 0.036 & 0.3 \\
$\mathrm{SeO}_{4}{ }^{2-}$ & 25 & 0.036 & 0.5 \\
\hline
\end{tabular}

Accepted ratio: 0.038

" $n=5$ separate injections 


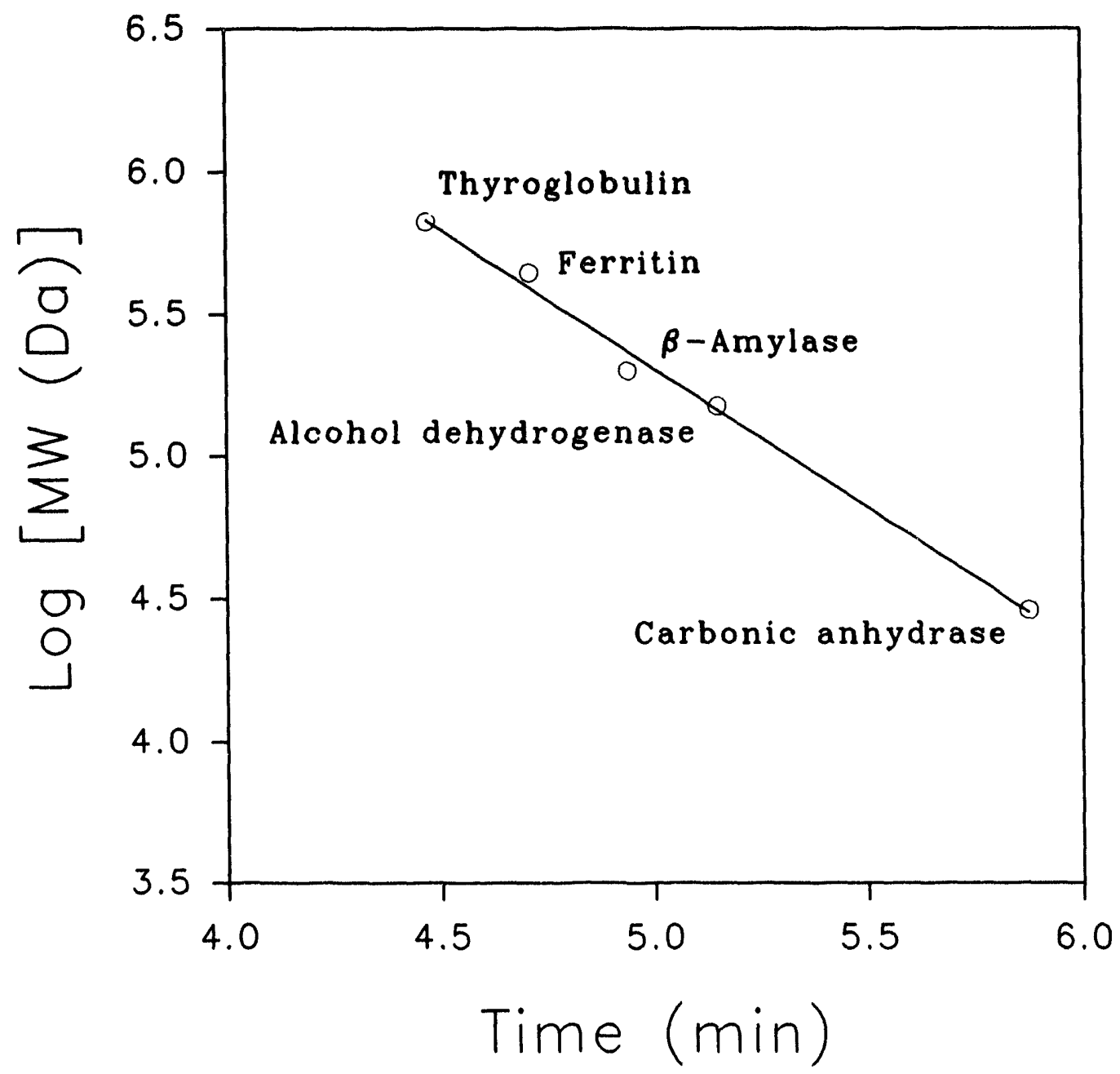

Figure 1. Calibration curve for the SEC column. See text for conditions. 

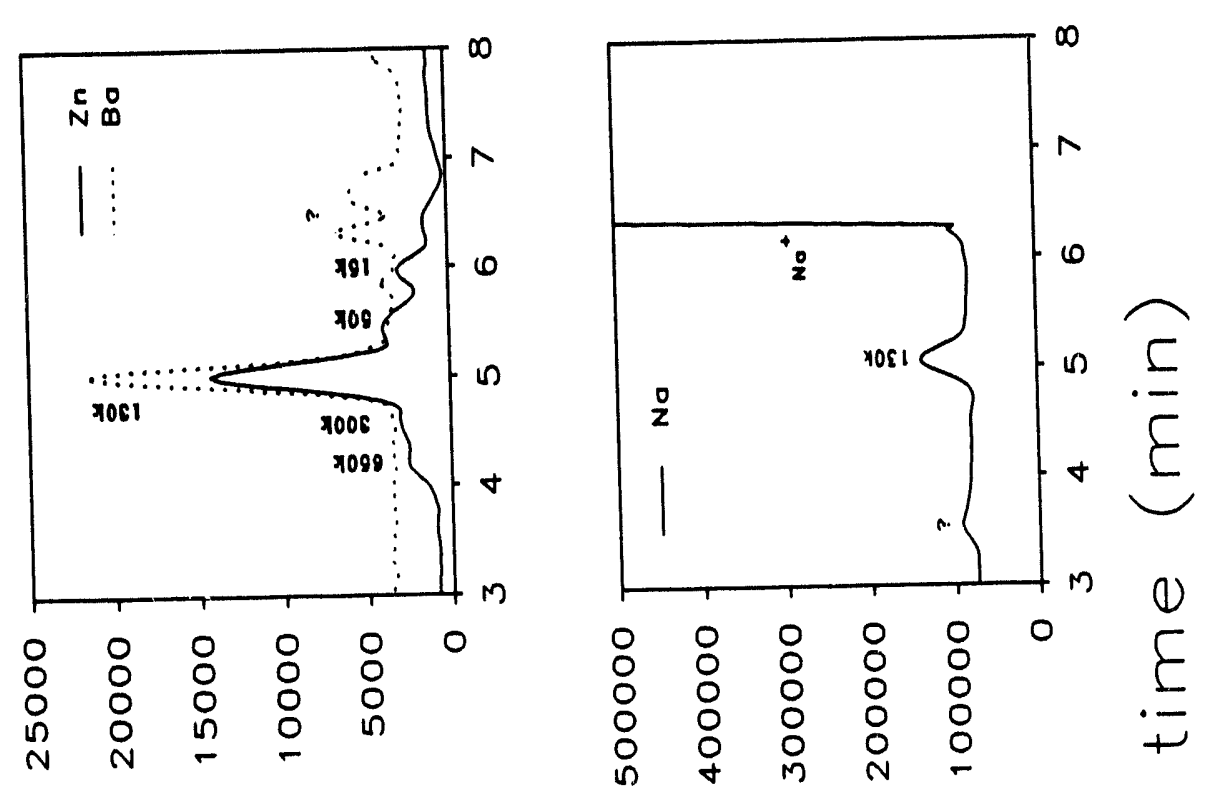

岕
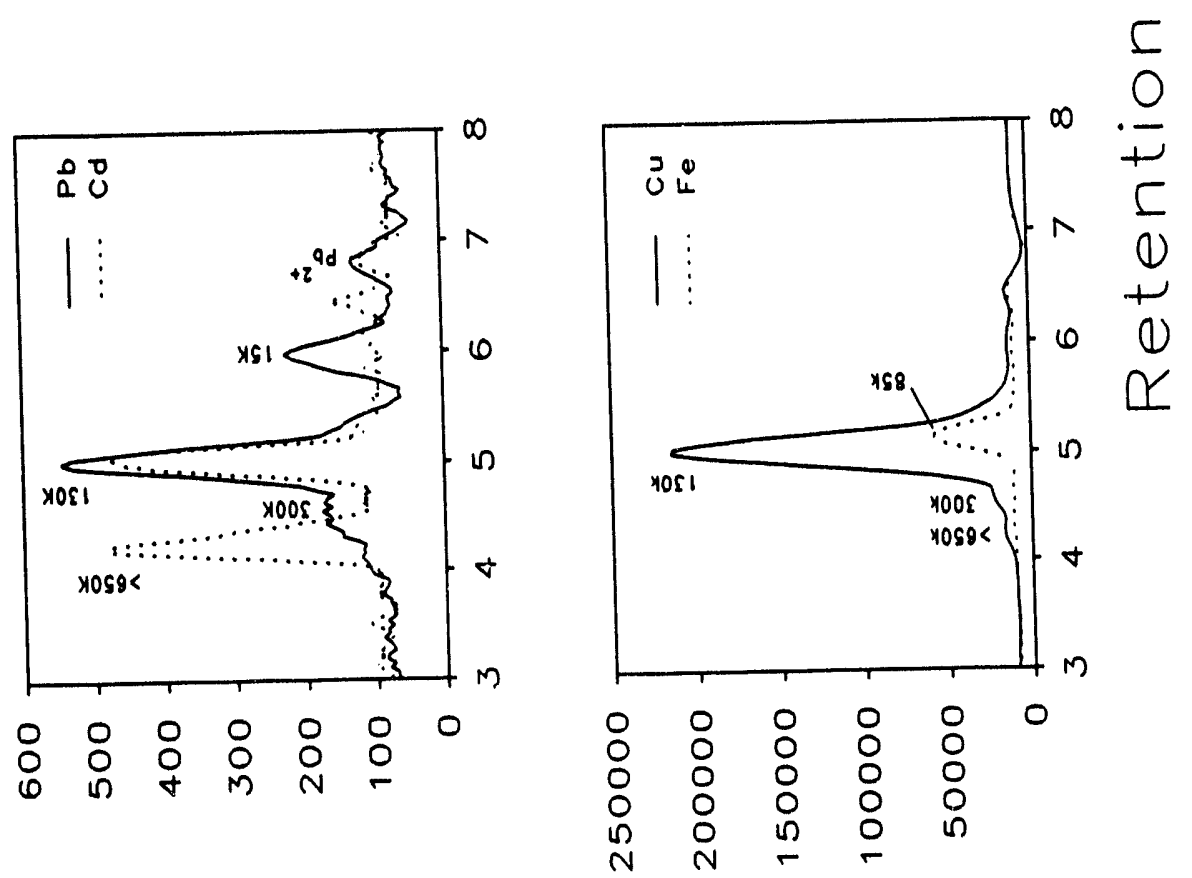

5 


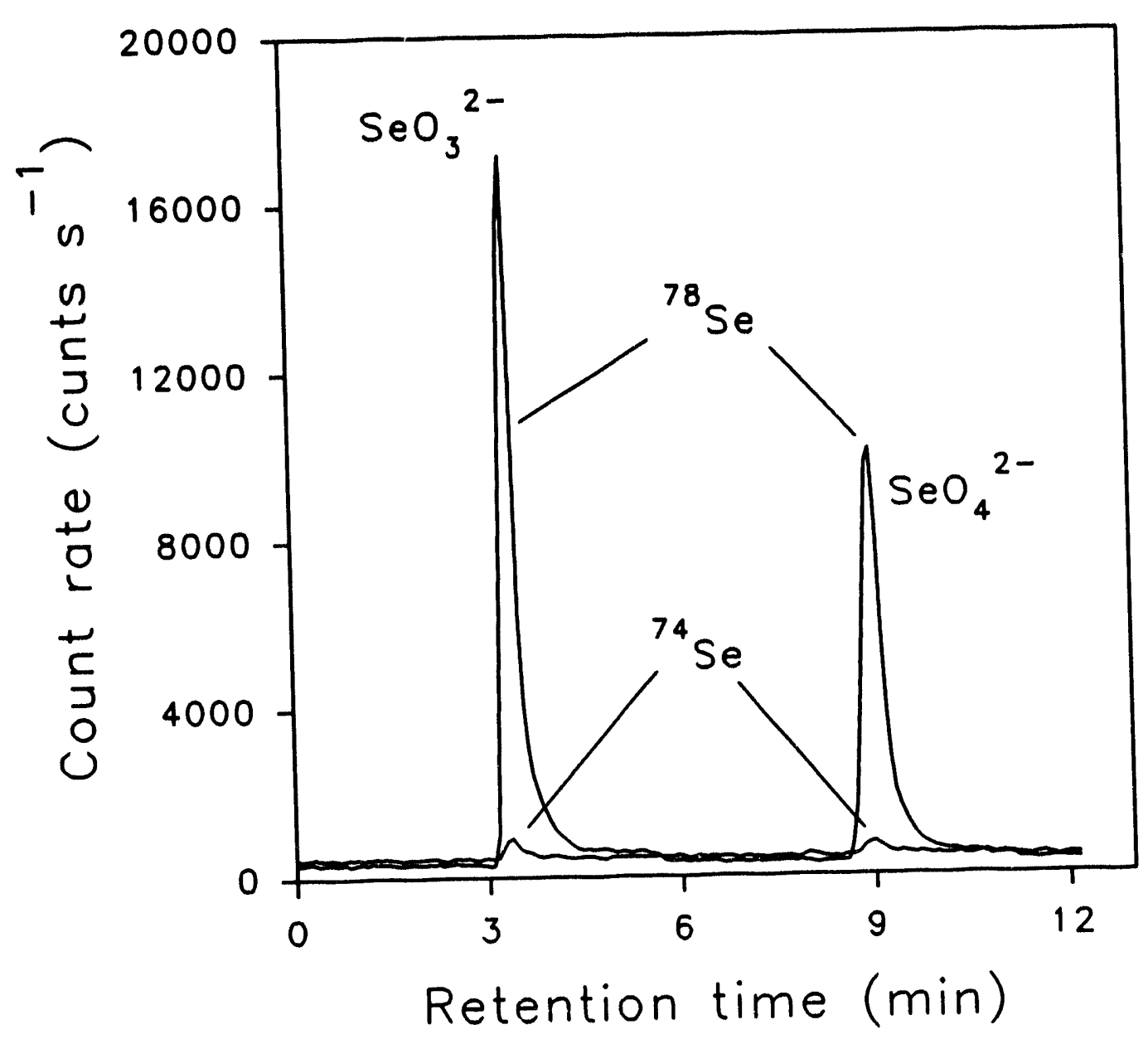

Figure 3. Separation of $\mathrm{SeO}_{3}{ }^{2-}$ and $\mathrm{SeO}_{4}{ }^{2-}$ by AC-DIN-ICP-MS. See text for conditions. 


\section{SUMMARY}

The primary goal of this work has been the development of the DIN for coupling LC with ICP-MS to provide elemental speciation information. In brief, the advantages of using LC-DIN-ICP-MS $(27,29,64)$ include little dead volume, low sample and solvent consumption, excellent plasma stability when nebulizing samples

containing concentrated organic solvent, excellent absolute detection limits, excellent precision, superior chromatographic resolution, and reduced memory effects from memory-prone elements (e.g., $\mathrm{Hg}, \mathrm{I}$, and B).

Table I summaries all the compounds, separation modes, and detection limits described in this dissertation. More than 20 compounds of $\mathrm{As}, \mathrm{Se}, \mathrm{Hg}, \mathrm{Pb}, \mathrm{Sn}$, and metalloproteins were separated and measured. Some of these compounds were present in biological and environmental samples, such as human urine and human serum, where no extraction or sample preparation was used that might disturb speciation. Various separation modes including RP-IP, IC, and SEC have been employed. Detection limits obtainable were $\approx 0.5-10 \mathrm{pg}$ depending on the element of interest. These detection limits are superior by at least 2 orciers of magnitude than those obtained previously by LC-ICP-MS with a conventional nebulizer.

We also demonstrated the ability to introduce solvents containing more than $20 \%$ of most organic modifiers into the plasma (27). In fact, a matrix containing about $20-30 \%$ methanol yields the best ion signal for many elements tested. 
Table I. A summary of various separations studied in this dissertation

Compounds" Separation Mode Detection Limits (pg)

As (As ${ }^{\text {III }}, \mathrm{As}^{\mathrm{v}}$,

MMAA, DMAA)

RP-IP

0.5

$\mathrm{Se}\left(\mathrm{Se}^{\mathrm{IV}}, \mathrm{Se}^{\mathrm{vl}}\right)$

IC

15

$\mathrm{Hg}\left(\mathrm{Hg}^{+2}, \mathrm{MeHg}^{+}\right.$

RP-IP

10

$\mathrm{EtHg}^{+}, \mathrm{PhHg}^{+}$)

$\mathrm{Pb}\left(\mathrm{Pb}^{+2},(\mathrm{Me})_{3} \mathrm{~Pb}^{+}\right.$

RP-IP

0.2

$\left.(\mathrm{Et})_{3} \mathrm{~Pb}^{+}\right)$

Metalloproteins

SEC

Sn (TMT, DMT,

RP-IP

8 DET, MMT)

${ }^{\mathrm{A}} \mathrm{As} \mathrm{s}^{\mathrm{III}}=$ arsenite, $\mathrm{As}{ }^{\mathrm{V}}=$ arsenate, $\mathrm{MMAA}=$ monomethylarsonic acid, DMAA $=$ dimethylarsinic acid, $\mathrm{Se}^{\mathrm{IV}}=$ selenite, $\mathrm{Se}^{\mathrm{vl}}=$ selenate, $\mathrm{Me}=$ methyl, $\mathrm{Et}=$ ethyl, $\mathrm{Ph}$ = phenyl, $\mathrm{TMT}=$ trimethyltin, $\mathrm{DMT}=$ dimethyltin, $\mathrm{DET}=$ diethyltin, and MMT

$=$ monomethyltin. 
Narrowing of the aerosol droplet size distribution with organic solvent composition probably caused this enhancement in ion signal (66). In addition, results from the spatially resolved measurements of size and velocity distributions of aerosol droplets from a DIN support the importance of generating aerosol with narrow distribution of droplet sizes in ICP-MS $(66,67)$.

Several possible areas for future research with the DIN are conceivable. First, there is still room for improvement in the design and construction of the DIN. The thickness and inner diameter (i.d.) of the inner capillary, as well as the width of the annular gap becween the inner capillary and the nebulizer tip, are important parameters for the production of fine aerosol droplets with the DIN. A systematic study on the effect of these parameters on the aerosol droplet size distribution warrants investigation. Furthermore, the possibility of measuring size distribution for aerosol particles inside the ICP by light scattering methods should be explored.

The possible benefits of a tapered DIN are being studied in our laboratory. Here, the tip of the fused silica capillary is carefully etched into a sharp point. Presumbably, this design will change the nebulizer gas flow pattern to enhance the interaction of the nebulizer gas with the sample liquid for the production of finer aerosol droplets.

So far, only deactivated fused silica capillaries have been used to construct the DIN. However, capillaries that are chemically modified with $C_{8}$ or $C_{18}$ are said to be more inert, which presumably will give even lower memory effects with memory- 
prone elements ( $\mathrm{Hg}, \mathrm{I}$, and $\mathrm{B})$ and metalloproteins. Thus, better chromatographic resolution should be obtainable for these elements.

Second, problems related to the solvent derived interferences in ICP-MS with the DIN need to be addressed (68-70). The DIN introduces more solvent than with other nebulizers; polyatomic ions such as $\mathrm{ArO}^{+}, \mathrm{ArOH}^{+}, \mathrm{ArC}^{+}, \mathrm{ArN}^{+}$, and $\mathrm{ArCl}^{+}$ are substantial. Several possible ways to reduce polyatomic ions are 1) the combination of the DIN with a small spray chamber with proper desolvation by cooling (71), 2) the addition of xenon to the make-up gas of the DIN (72), and 3) the combination of the DIN with a new ICP-MS device equipped with an offset ion lens $(73,74)$. These experiments are under way in our laboratory.

Finally, more speciation experiments can be investigated with the LC-DINICP-MS system. Some of these speciation experiments involve 1) chromium in organic samples $(75), 2)$ As in urine or sea-water $(32), 3)$ packed microcolumn $(0.2$ $<$ i.d. $<0.5 \mathrm{~mm})$, packed microcapillary column $(0.05<$ i.d. $<0.2 \mathrm{~mm})$, and open-tubular column $(0.01<$ i.d. $<0.06 \mathrm{~mm})(76), 4)$ solvent gradient to achieve faster and better chromatographic separation (27), and 5) on-line standard addition (77) or isotope dilution (78) for quantitation of chromatographic separated species. 


\section{ADDITIONAL LITERATURE CITED}

1. R.S. Houk, V.A. Fassel, G.D. Flesch, H.J. Svec, A.L. Gray and C.E. Taylor, Anal. Chem., 52 (1980) 2283.

2. D.W. Koppenaal, Anal. Chem., 64 (1992) 320R.

3. K.E. Jarvis, A.L. Gray and R.S. Houk, Handbook of Inductively Coupled Plasma Mass Spectrometry, Blackie, London, 1992.

4. H.E. Taylor and J.R. Garbarino, in A. Montaser and D.W. Golightly (Eds.), Inductively Coupled Plasma in Analytical Atomic Spectrometry, 2nd Edition, VCH, New York, 1992, Ch. 14.

5. G. Holland and A.N. Eaton (Eds.), Application of Plasma Source Mass Spectrometry, Royal Soc. Chem., Cambridge, 1991.

6. K.E. Jarvis, A.L. Gray, J.G. Williams and I. Jarvis (Eds.), Plasma Source Mass Spectrometry, Royal Soc. Chem., Cambridge, 1990.

7. H.P. Longerich, G.A. Jenner, B.J. Fryer and S.E. Jackson, Chem. Geol., 83 (1990) 105.

8. N. Imai, Anal. Sci., 6 (1990) 389.

9. A.L. Gray, Adv. Mass. Spectrom., 11B (1989) 1674.

10. D. Beauchemin, Mikrochim. Acta, 3 (1989) 273.

11. U. Siewers, Mikrochim. Acta, 3 (1989) 365.

12. D.C. Gregoire, Prog. Anal. Spectrosc., 12 (1989) 432. 
13. A.R. Date and A.L. Gray (Eds.), Applications of Inductively Coupled Plasma Mass Spectrometry, Blackie, London, 1989.

14. R.S. Houk, Anal. Chem. 58 (1986) 97A.

15. R.S. Houk and S.J. Jiang, in I.S. Krull (Ed.), Trace Metal Analysis and Speciation, Elsevier, Amsterdam, 1991, Ch. 5.

16. R.C. Elder, W.B. Jones and K. Tepperman, in P.C. Uden (Ed.), Element Speciñc Chromatographic Detection by Atomic Emission Spectroscope, ACS Symposium Series 479, Washington, DC, 1992, Ch. 18.

17. D.S. Braverman, J. Anal. At. Spectrom., 7 (1992) 43.

18. H. Suyani, D. Heitkemper, J. Creed and J. Caruso, Appl. Spectrosc. 43 (1989) 962.

19. D.S. Bushee, Analyst, 113 (1988) 1167.

20. D.S. Bushee, J.R. Moody and J.C. May, J. Anal. At. Spectrom., 4 (1989) 773.

21. J.J. Thompson and R.S. Houk, Anal. Chem., 58 (1986) 2541.

22. S.J. Jiang and R.S. Houk, Spectrochim. Acta, Part B, 43 (1988) 405.

23. D. Beauchemin, K.W.M. Siu, J.W. McLaren and S.S. Berman, J. Anal. At. Spectrom., 4 (1989) 285.

24. Y. Shibata and M. Morita, Anal. Chem., 61 (1989) 2116.

25. H. Suyani, J. Creed, T. Davidson amd J. Caruso, J. Chromatogr. Sci., 27 (1989) 139. 
26. A. Al-Rashdam, N.P. Vela, J.A. Caruso and D.T. Heitkemper, J. Anal. At. Spectrom., 7 (1992) 551.

27. S.C.K. Shum, R. Neddersen and R.S. Houk, Analyst, 117 (1992) 571.

28. Z. Zhao, W.B. Jones, K. Tepperman, J.G. Dorsey and R.C. Elder, J. Pharm. Biomed. Anal., 10 (1992) 279.

29. S.C.K. Shum, H.M. Pang and R.S. Houk, Anal. Chem., 64 (1992) 2444.

30. B.S. Sheppard, J.A. Caruso, D.T. Heitkemper and K.A. Wolnik, Analyst, 117 (1992) 971.

31. B.S. Sheppard, W.-L. Shen, J.A. Caruso, D.T. Heitkemper and F.L. Fricke, J. Anal. At. Spectrom., 5 (1990) 431.

32. D. Heitkemper, J. Creed, J. Caruso and F.L. Fricke, J. Anal. At. Spectrom., 4 (1989) 279.

33. S. Suzuki, H. Tsuchihashi, K. Nakajima, A. Matsushita and T. Nagao, J. Chromatogr., 437 (1988) 322.

34. K. Kawabata, Y. Kishi, O. Kawaguchi, Y. Watanabe and Y. Inoue, Anal. Chem., 63 (1991) 2137.

35. D.W. Boomer, M.J. Powell and J. Hipfner, Talanta, 37 (1990) 127.

36. K. Takatera and T. Watanabe, Anal. Sci., 8 (1992) 469.

37. L.M.W. Owen, H.M. Crews, R.C. Hutton and A. Walsh, Analyst, 117 (1992) 649.

38. B. Gercken and R.M. Barnes, Anal. Chem., 63 (1991) 283. 
39. K. Takatera and T. Watanabe, Anal. Sci., 7 (1991) 695.

40. A.Z. Mason, S.D. Storms and K.D. Jenkins, Anal. Biochem., 186 (1990) 187.

41. H.M. Crews, J.R. Dean, L. Ebdon and R.C. Massey, Analyst, 114 (1989) 895.

42. S.G. Matz, R.C. Elder and K. Tepperman, J. Anal. At. Spectrom., 4 (1989) 767.

43. J.R. Dean, S. Munro, L. Ebdon, H.M. Crews and R.C. Massey, J. Anal. At. Spectrom., 2 (1987) 607.

44. W.L. Shen, N.P. Vela, B.S. Sheppard and J.A. Caruso, Anal. Chem., 63 (1991) 1491.

45. J.C. Van Loon, L.R. Alcock, W.H. Pinchin and J.B. French, Spectrosc. Letters, $19(1986) 1125$.

46. N.S. Chong and R.S. Houk, Appl. Spectrosc., 41 (1987) 66.

47. R.J. Lewis and R.L. Tatken, Registry of Toxic Effects of Chemical Substances, Department of Health, Education and Welfare, Cincinnati, $\mathrm{OH}, 1978$.

48. S.A. Peoples, in E.A. Woolson (Ed.), Review of Arsenical Pesticides, ACS Symposium Series 7, American Chemical Society, Washington, DC, 1974, pp 112.

49. M. Vahter, E. Marafante and L. Dencker, Sci. Total Environ., 30 (1983) 197.

50. E. Marafante, M. Vahter and L. Dencker, Sci. Total Environ., 34 (1984) 223.

51. E.A. Crecelius, Environ. Health Perspect., 45 (1982) 165. 
52. V. Foa, A. Colombi, M. Maroni, M. Buratti and G. Calzaferri, Sci. Total Environ., 34 (1984) 241.

53. J.S. Edmonds, K.A. Francesconi, J.R. Cannon, C.L. Raston, B.W. Skelton and A.H. White, Tetrahedron Lett., 18 (1977) 1543.

54. J.R. Cannon, J.S. Edmonds, K.A. Francesconi, C.L. Raston, J.B. Saunders, B.W. Skelton and A.H. White, Aust. J. Chem., 34 (1981) 787.

55. J.F. Lawrence, P. Michalik, G. Tam and H.B.S. Conacher, J. Agric. Food Chem., 34 (1986) 315.

56. H. Norin and A. Christakopoulos, Chemosphere, 11 (1982) 287.

57. D.J. Douglas, in A. Montaser and D.W. Golightly (Eds.), Inductively Coupled Plasma in Analytical Atomic Spectrometry, 2nd Edition, VCH, New York, 1992, Ch. 13 .

58. T. Hasegawa, M. Umemoto, H.Haraguchi, C. Hsiech and A. Montaser, in A. Montaser and D.W. Golightly (Eds.), Inductively Coupled Plasma in Analytical Atomic Spectrometry, 2nd Edition, VCH, New York, 1992, Ch. 8.

59. J.S. Crain, F.G. Smith and R.S. Houk, Spectrochim. Acta, 45B (1990) 249.

60. P.E. Miller and M.B. Denton, J. Chem. Ed., 63 (1986) 617.

61. R.S. Houk, in K.A. Gschneidner and L. Eyring (Eds.), Handbook of Phys and Chem. of Rare Earths, Vol. 13, North-Holland Physics Publishing, Amsterdam, 1989.

62. G. Zhu and R.F. Browner, J. Anal. At. Spectrom., 3 (1988) 781. 
63. R.C. Hutton and A.N. Eaton, J. Anal. At. Spectrom., 2 (1987) 595.

64. R.S. Houk, S.C.K. Shum and D.R. Wiederin, Anal. Chim. Acta, 250 (1991) 61.

65. D.R. Wiederin, F.G. Smith and R.S. Houk, Anal. Chem., 63 (1991) 219.

66. S.C.K. Shum, H.M. Pang, S.K. Johnson and R.S. Houk, Appl. Spectrosc., 47 (1993) in press.

67. B. Etkin, J.B. French and R. Jong, Monodisperse Dried Microparticulate Injection, FACSS Conference, Philadelphia, PA, 1992, Paper No. 218.

68. S.H. Tan and G. Horlick, Appl. Spectrosc., 40 (1986) 445.

69. D. Beauchemin, J.W. McLaren and S.S. Berman, Spectrochim. Acta, 42B (1987) 467.

70. S.H. Tan and G. Horlick, J. Anal. At. Spectrom., 2 (1987) 745.

71. D.R. Wiederin, Ph.D. dissertation, Iowa State University, Ames, IA, 1991.

72. F.G. Smith, D.R. Wiederin and R.S. houk, Anal. Chem., 63 (1991) 1458.

73. K. Hu, S. Clemons and R.S. Houk, J. Am. Soc. Mass Spectrom., 4 (1993) 16.

74. K. Hu and R.S. Houk, J. Am. Soc. Mass Spectrom., 4 (1993) 28.

75. R. Roehl and M.M. Alforque, ICP Information Newsletter, 16 (1991) 455.

76. M. Novotny, Anal. Chem., 60 (1988) 500A.

77. D.R. Wiederin, R.E. Smyczek and R.S. Houk, Anal. Chem., 63 (1991) 1626.

78. M. Viczián, A. Lásztity, X. Wang and R.M. Barnes, J. Anal. At. Spectrom., 5 (1990) 125. 


\section{ACKNOWLEDGEMENTS}

First, I would like to express my most sincere gratitude to Professor R. S. Houk for guidance, not only in this research but in matters both personal and professional. His wide latitude, tolerance, confidence, and support are greatly appreciated. In addition, he taught me a great deal about scientific writing.

Also helpful were the many hours of discussion with Professor James S. Fritz, Dr. Ho-Ming Pang, Dr. Daniel Wiederin, Dr. Fred Smith, and Dr. Ke Hu for which I am privileged to express my gratitude.

I also like to acknowledge Luis Alves, Hongsen Niu, Rocky Warren, Scott Clemons, Xiaoshan Chen, Shen Luan, Tonya Bricker, Lloyd Allen, Steve Johnson, Bill Wheeler, and Robert Neddersen for their support, cooperation, and friendship.

The donation of time and talent by my wife, Swee Chin, for the preparation of the final draft is appreciated. Only inadequately can I express my gratitude for her patience and understanding throughout the period of this endeavor. I thank my children, Benjamin and Jennifer, for their supports and cheers when I was down.

I like to thank the members of the Ames Seventh-Day Adventist Church for providing us, in the last four and a half years, the opportunities to serve the Lord, the church body, and the Ames community. Special thanks go to Charles and Nancy Dye; Robb and Christine Long; Bruce, Linda, Andrew and Megan Wilkinson; David, Linda, Rob and Jessie Anderson; Craig, Amy and Sam Abel; Bill and Treva 
Martsching; Cody and Tracie Cameron; Nyla, Camden, Karen and Lance Hodges;

Dave and Jill Koch; Gertrude, Donald and Nancy Miller; Kevin Voss; Debbie Lien;

D'Joane McCorkle; Edward Osei; Buena Boyer; Dale, Maria, Daniel and Shanna Bivens for their prayers, supports, and friendship.

I also like to thank the Hong Kong gang, Che-Ting Chan, Stella Luk, Ho-Ming Pang, Kit-Sum Wong, Nai-Ho Cheung, Po-Lin Tang, Frankie Lam, Grace Ho, and Man-Kit Ho, for their friendship and all the wonderful parties and social getherings that my wife and I were privileged to join.

I wish to express my appreciation to Delavan Inc. for the use of the PDPA apparatus. Special thanks go to Dr. Chien-Pei Mao for his useful comments and efforts in arranging and conducting the experiments. I thank CETAC Technologies and Serasep, Inc. for suppling some of the columns used in this work.

The Phillips Petroleum Graduate Research Fellowship awarded to me is gratefully acknowledged. This work was performed at the Ames Laboratory under contract No. W-7405-ENG-82 with the U. S. Department of Energy. The United States government has assigned DOE report No. IS-T 1644 to this dissertation.

Lastly, thanks go to my parents, Tung-Sang Shum and Wai-Lan Wong, and my in-laws, Yew-Seng Wong and Mei-Chan Lok, for their countless support and encouragement in my education. Regrettably my mom did not live long enough to share the joy with us. 

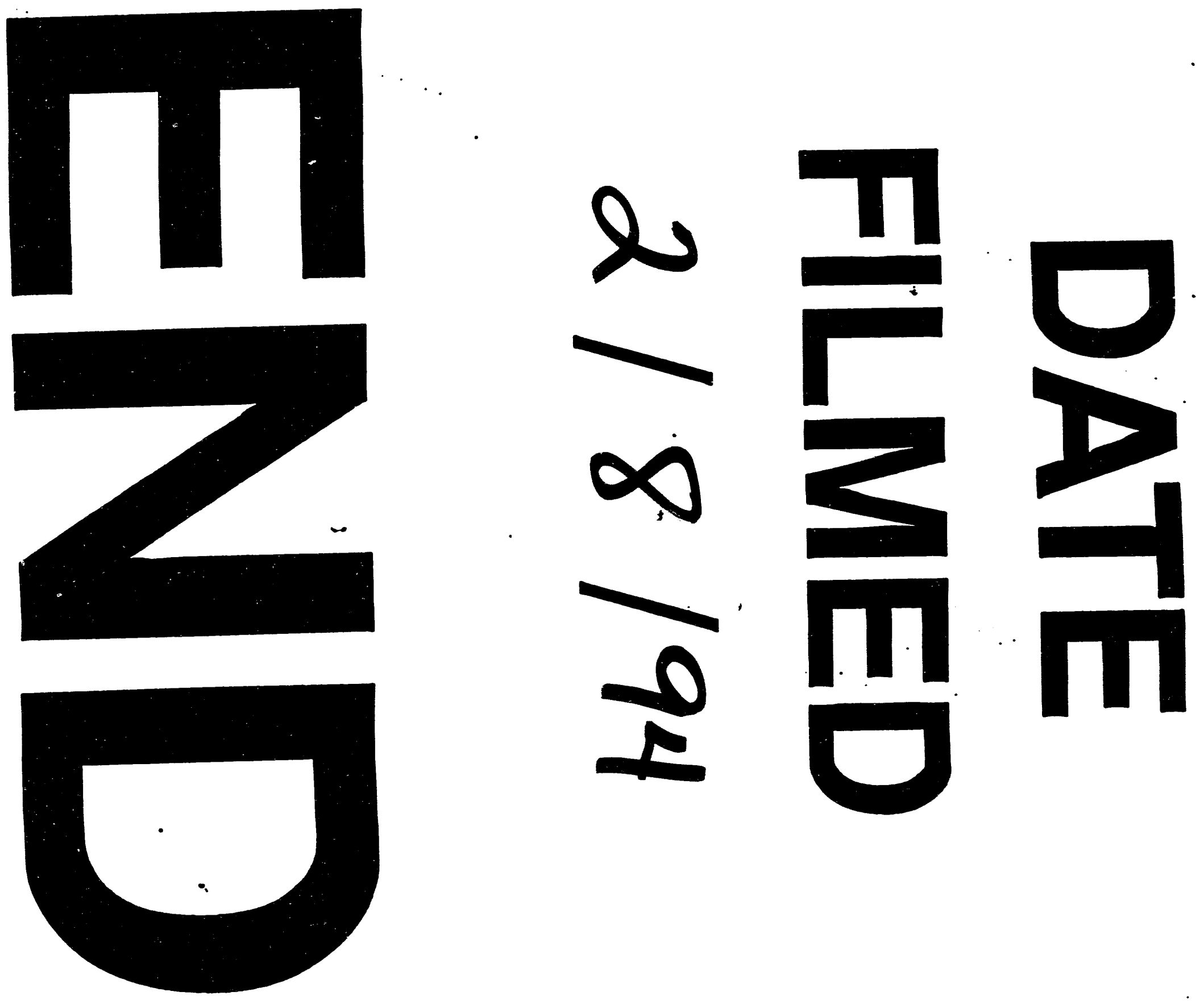


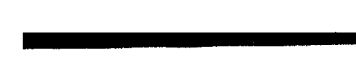

mang
} 